\title{
Cognitive-behavioural interventions for children who have been sexually abused (Review)
}

Macdonald G, Higgins JPT, Ramchandani P, Valentine JC, Bronger LP, Klein P, O'Daniel R, Pickering M, Rademaker B, Richardson G, Taylor M

Macdonald G, Higgins JPT, Ramchandani P, Valentine JC, Bronger LP, Klein P, O'Daniel R, Pickering M, Rademaker B, Richardson G, Taylor M.

Cognitive-behavioural interventions for children who have been sexually abused.

Cochrane Database of Systematic Reviews 2012, Issue 5. Art. No.: CD001930.

DOI: 10.1002/14651858.CD001930.pub3.

www.cochranelibrary.com 
TABLE OF CONTENTS

HEADER 1

ABSTRACT

PLAIN LANGUAGE SUMMARY

BACKGROUND

OBJECTIVES

METHODS

Figure 1.

RESULTS

Figure 2.

Figure 3.

DISCUSSION

AUTHORS' CONCLUSIONS

ACKNOWLEDGEMENTS

REFERENCES

CHARACTERISTICS OF STUDIES

DATA AND ANALYSES

Analysis 1.1. Comparison 1 CBT vs no CBT, Outcome 1 Child depression (CDI).

Analysis 1.2. Comparison 1 CBT vs no CBT, Outcome 2 Child post-traumatic stress disorder (various scales).

Analysis 1.3. Comparison 1 CBT vs no CBT, Outcome 3 Child anxiety.

Analysis 1.4. Comparison 1 CBT vs no CBT, Outcome 4 Child sexualised behaviour (CSBI).

Analysis 1.5. Comparison 1 CBT vs no CBT, Outcome 5 Child externalising behaviour (CBCL Externalising).

Analysis 1.6. Comparison 1 CBT vs no CBT, Outcome 6 Parent's belief of child (PRIDS and PSQ).

Analysis 1.7. Comparison $1 \mathrm{CBT}$ vs no CBT, Outcome 7 Parental attributions (PAS).

Analysis 1.8. Comparison 1 CBT vs no CBT, Outcome 8 Parenting skills (PPQ).

Analysis 1.9. Comparison 1 CBT vs no CBT, Outcome 9 Parents' emotional reaction (PERQ). ADDITIONAL TABLES

APPENDICES

WHAT'S NEW

HISTORY

CONTRIBUTIONS OF AUTHORS

DECLARATIONS OF INTEREST

SOURCES OF SUPPORT

DIFFERENCES BETWEEN PROTOCOL AND REVIEW

NOTES

INDEX TERMS 
[Intervention Review]

\section{Cognitive-behavioural interventions for children who have been sexually abused}

Geraldine Macdonald1, Julian PT Higgins², Paul Ramchandani³, Jeffrey C Valentine ${ }^{4}$, Latricia P Bronger 5 , Paul Klein ${ }^{5}$, Roland O'Daniel 6 , Mark Pickering 5 , Ben Rademaker 5 , George Richardson 7 , Matthew Taylor 5

1Director, Institute of Child Care Research, School of Sociology, Social Policy and Social Work, Queen's University Belfast, Belfast, UK. 2MRC Biostatistics Unit, Cambridge, UK. ${ }^{3}$ Department of Psychiatry, University of Oxford, Oxford, UK. ${ }^{4}$ Department of Educational and Counseling Psychology, University of Louisville, Louisville, Kentucky, USA. ${ }^{5}$ Department of Teaching and Learning, University of Louisville, Louisville, Kentucky, USA. ${ }^{6}$ Collaborative for Teaching and Learning, Louisville, Kentucky, USA. ${ }^{7}$ School of Human Services, University of Cincinnati, Cincinnati, Ohio, USA

Contact address: Geraldine Macdonald, Director, Institute of Child Care Research, School of Sociology, Social Policy and Social Work, Queen's University Belfast, 6 College Park, Belfast, Northern Ireland, BT7 1LP, UK. Geraldine.Macdonald@qub.ac.uk.

Editorial group: Cochrane Developmental, Psychosocial and Learning Problems Group

Publication status and date: New search for studies and content updated (no change to conclusions), published in Issue 5, 2012.

Citation: Macdonald G, Higgins JPT, Ramchandani P, Valentine JC, Bronger LP, Klein P, O'Daniel R, Pickering M, Rademaker B, Richardson G, Taylor M. Cognitive-behavioural interventions for children who have been sexually abused. Cochrane Database of Systematic Reviews 2012, Issue 5. Art. No.: CD001930. DOI: 10.1002/14651858.CD001930.pub3.

Copyright ( 2012 The Cochrane Collaboration. Published by John Wiley \& Sons, Ltd.

\section{A B S T R A C T}

\section{Background}

Despite differences in how it is defined, there is a general consensus amongst clinicians and researchers that the sexual abuse of children and adolescents ('child sexual abuse') is a substantial social problem worldwide. The effects of sexual abuse manifest in a wide range of symptoms, including fear, anxiety, post-traumatic stress disorder and various externalising and internalising behaviour problems, such as inappropriate sexual behaviours. Child sexual abuse is associated with increased risk of psychological problems in adulthood. Cognitivebehavioural approaches are used to help children and their non-offending or 'safe' parent to manage the sequelae of childhood sexual abuse. This review updates the first Cochrane review of cognitive-behavioural approaches interventions for children who have been sexually abused, which was first published in 2006.

\section{Objectives}

To assess the efficacy of cognitive-behavioural approaches (CBT) in addressing the immediate and longer-term sequelae of sexual abuse on children and young people up to 18 years of age.

\section{Search methods}

We searched the Cochrane Central Register of Controlled Trials (CENTRAL) (2011 Issue 4); MEDLINE (1950 to November Week 32011 ); EMBASE (1980 to Week 47 2011); CINAHL (1937 to 2 December 2011); PsycINFO (1887 to November Week 5 2011); LILACS (1982 to 2 December 2011) and OpenGrey, previously OpenSIGLE (1980 to 2 December 2011). For this update we also searched ClinicalTrials.gov and the International Clinical Trials Registry Platform (ICTRP).

\section{Selection criteria}

We included randomised or quasi-randomised controlled trials of CBT used with children and adolescents up to age 18 years who had experienced being sexually abused, compared with treatment as usual, with or without placebo control. 


\section{Data collection and analysis}

At least two review authors independently assessed the eligibility of titles and abstracts identified in the search. Two review authors independently extracted data from included studies and entered these into Review Manager 5 software. We synthesised and presented data in both written and graphical form (forest plots).

\section{Main results}

We included 10 trials, involving 847 participants. All studies examined CBT programmes provided to children or children and a nonoffending parent. Control groups included wait list controls $(n=1)$ or treatment as usual $(n=9)$. Treatment as usual was, for the most part, supportive, unstructured psychotherapy. Generally the reporting of studies was poor. Only four studies were judged 'low risk of bias' with regards to sequence generation and only one study was judged 'low risk of bias' in relation to allocation concealment. All studies were judged 'high risk of bias' in relation to the blinding of outcome assessors or personnel; most studies did not report on these, or other issues of bias. Most studies reported results for study completers rather than for those recruited.

Depression, post-traumatic stress disorder (PTSD), anxiety and child behaviour problems were the primary outcomes. Data suggest that CBT may have a positive impact on the sequelae of child sexual abuse, but most results were not statistically significant. Strongest evidence for positive effects of CBT appears to be in reducing PTSD and anxiety symptoms, but even in these areas effects tend to be 'moderate' at best. Meta-analysis of data from five studies suggested an average decrease of 1.9 points on the Child Depression Inventory immediately after intervention (95\% confidence interval $(\mathrm{Cl})$ decrease of 4.0 to increase of $0.4 ; \mathrm{I}^{2}=53 \%$; $\mathrm{P}$ value for heterogeneity $=0.08$ ), representing a small to moderate effect size. Data from six studies yielded an average decrease of 0.44 standard deviations on a variety of child posttraumatic stress disorder scales $\left(95 \% \mathrm{Cl} 0.16\right.$ to $0.73 ; \mathrm{I}^{2}=46 \%$; P value for heterogeneity $\left.=0.10\right)$. Combined data from five studies yielded an average decrease of 0.23 standard deviations on various child anxiety scales $(95 \% \mathrm{Cl} 0.3$ to $0.4 ; \mathrm{I}=0 \%$; $\mathrm{P}$ value for heterogeneity $=0.84$ ). No study reported adverse effects.

\section{Authors' conclusions}

The conclusions of this updated review remain the same as those when it was first published. The review confirms the potential of CBT to address the adverse consequences of child sexual abuse, but highlights the limitations of the evidence base and the need for more carefully conducted and better reported trials.

\section{PLAIN LANGUAGE SUMMARY}

\section{Cognitive behavioural interventions for children who have been sexually abused}

The sexual abuse of children is a substantial social problem that affects large numbers of children and young people worldwide. For many children, though not all, it can result in a range of psychological and behavioural problems, some of which can continue into adulthood. Knowing what is most likely to benefit children already traumatised by these events is important. This review aimed to find out if cognitivebehavioural approaches (CBT) help reduce the negative impact of sexual abuse on children. Ten studies, in which a total of 847 children participated, met the inclusion criteria for the review. The reporting of studies was poor, and there appear to be significant weaknesses in study quality. The evidence suggests that CBT may have a positive impact on the effects of child sexual abuse, including depression, posttraumatic stress and anxiety, but the results were generally modest. Implications for practice and further research are noted. 


\section{B A C K G R O U N D}

\section{Description of the condition}

Perceptions of what constitutes sexual abuse differ, as do the definitions used by researchers and others. Despite these differences, there is a general consensus amongst clinicians and researchers that this is a substantial social problem that affects large numbers of children, of both sexes, of all ages, across culture and social class (Finkelhor 1994; Prentky 1996). Methodological problems, including those of definition, mean that estimates of the incidence and prevalence of child sexual abuse vary considerably. Girls are more likely to be victims than boys, with estimates of prevalence rates ranging between $20 \%$ and $32 \%$ for females and between 4\% and 8\% for males (Finkelhor 1994; Andrews 2004; Pereda 2009).

Child sexual abuse refers not to a disease or medical condition but to an event, or series of events, in a child's life. Some children are victimised on a single occasion, but more often sexual abuse occurs over a period of time, sometimes years (Davis 2002). The duration of exposure to sexual abuse depends on a range of factors, including the perpetrator's ease of access to the child or young person and the steps taken to secure his or her silence, such as threats and coercion (Eilliot 1995; Kaufman 1998). Except in communities ('sects' or 'cults') where social relationships may be formulated in ways that undermine or break down normal relationships within families, sexual abuse is usually hidden.

Child sexual abuse can be perpetrated within the family (by a parent, step-parent, sibling or other relative); by those known to the child outside of the home (for example, friends, neighbours, teacher), or by strangers. It is estimated that around one third of sexual offences against children are committed by adolescents (Prentky 1996; Grubin 1998). Other subgroups of sexual offenders include those with a learning disability and those with mental health problems (see, for example, Beech 2009). The majority of sexual offences against children are committed by people known to them, although most are not members of their family. Around one third of perpetrators are family members, including fathers, brothers, cousins etc. Child sexual abuse perpetrated by natural parents appears relatively rare, with estimates ranging from between $1.5 \%$ to $16 \%$ of sexually abused children (Fergusson 1999). Whilst the rate of sexual offences committed by step-fathers is comparable to that of natural parents, the fact that stepfathers are a much smaller group means that they are more likely to commit child sexual abuse. When children experience sexual abuse by one parent within the family, the research literature often refers to the other parent as the 'non-offending parent'.

\section{Sequelae of sexual abuse}

The consequences of sexual abuse on the social and emotional well being of children, and on their development, are welldocumented. Many, but not all, children who have been sexually abused develop significant mental health difficulties related to this form of abuse. Cross-sectional studies have pointed to a number of factors that appear to influence the extent and severity of these effects, such as the age of the child, the frequency and duration of the abuse, the severity of the abuse and the relationship of the child to the perpetrator (see Friedrich 1986). A number of longitudinal studies shed some light on the likely developmental trajectory of problems over time and on those factors that limit adverse consequences and/or aid recovery (Oates 1994; Tebutt 1997; Puttnam 2003; Swanston 2003). Common symptoms include fear, anxiety and low mood, and these are often the focus of interventions (Andrews 2004; Gilbert 2009). It is helpful to use a developmental perspective when considering the effects of sexual abuse as different problems manifest depending on the age of the affected child. For example, preschool children are likely to experience anxiety, nightmares, externalising behaviour and inappropriate sexual behaviours (see Kendall-Tackett 1993; Trickett 1997). In school-aged children, difficulties may manifest as school problems, hyperactivity and nightmares, whereas adolescents are more likely to suffer from depression, generalised anxiety, suicidal or self-injurious behaviour, or substance misuse.

A significant percentage of children appear not to demonstrate any of these psychological sequelae immediately following their abuse. Some of these children may develop problems in their psychological or social functioning later (so-called 'sleeper effects'). Some may never present any problems.

Prolonged stress, particularly at critical times (such as infancy and adolescence), can bring about changes in the brain and brain functioning that may explain a number of the difficulties experienced by maltreated children in later life (for example, Teicher 2003; Andeson 2008). The body of research on the neurological impacts of abuse is relatively new, and whether different forms of abuse have differentiated consequences and how the long-term effects of maltreatment are influenced by the quality of subsequent caregiving or familial/genetic factors, amongst other questions, remain the subject of investigation (Jackowski 2009; Shenk 2010). Although the majority of sexually abused children do not go on to offend, there is some support for the hypothesis that the experience of sexual abuse in childhood is associated with an increased risk for sexual offending in adulthood (Jespersen 2009), and that child sexual abuse, like other forms of maltreatment, may increase the risk of delinquency and adult offending more generally (see Hubbard 2002; Currie 2006; Thornberry 2010).

\section{Impact on adult functioning and use of services}

In adults, a history of childhood sexual abuse is strongly associated with a wide range of psychiatric disorders. In an analysis of the UK Adult Psychiatric Morbidity Survey 2007, Jonas 2011 examined the association between sexual abuse in childhood (defined as younger than 16 years) and adulthood (16 or over) and six types of common mental disorder (depression, mixed anxiety/ depression, generalised anxiety disorder, panic, phobia and obsessive compulsive disorder), dependence disorders (alcohol and drug misuse) and disorders established from screening tools (post-traumatic stress disorder and eating disorders). The authors report that "all were strongly and highly significantly associated with childhood sexual abuse $(P=<0.0001)$, particularly if nonconsensual sexual intercourse was involved, for which odds ratios (ORs) ranged from 3.7 to 12.1. For some disorders, the relative odds were higher for females than males, but formal tests for moderation by gender were significant only for common mental disorders and then only in relation to non-consensual sexual intercourse" (p 712). In a study of 2759 children in Australia with a substantiated case of sexual abuse (in the period 1965 and 1995), Cutajar 2010 found a lifetime record of contact with public mental health services in $23.3 \%$ of cases of those who had been sexually abused in childhood, compared with just $7.7 \%$ of controls, with the rate of contact being 3.65 times higher $(95 \% \mathrm{Cl}, 3.09$ to $4.32, \mathrm{P}<0.0001)$. 
Childhood sexual abuse increased the risk for most disorders, including psychosis, affective disorder, anxiety, substance abuse and personality disorders (see also Fergusson 2008).

Not all victims of sexual abuse have consequent psychological problems throughout their life; however, there is an association between having suffered such a trauma in childhood and experiencing higher rates of a wide range of problems in psychological and social functioning in adult life (see Fergusson 2008). Many of these difficulties are similar to those reported by children who have been more recently abused, including: depression, anxiety, phobias (Molnar 2001), low self-esteem, and relationship and parenting difficulties (Green 1993). Young women who have been sexually abused have been reported to be at increased risk of engaging in high risk sexual behaviour (Farmer 1998) and experiencing higher rates of sexual re-victimisation (Nelson 2002). These consequences are reported by both men and women (Banyard 2004; Dube 2005). Finally, a small but important minority of abuse victims go on to abuse others sexually. It is not clear whether these outcomes are specific to the experience of being sexually abused, or related to the other difficulties that children in these situations often face. Some studies suggest that being brought up witnessing or experiencing intrafamilial violence may combine with the experience of sexual abuse to increase the risk of a young man subsequently abusing others (Skuse 1998). Longer-term prospective studies testing and examining these consequences are awaited.

The rationale for interventions for children who have been sexually abused is that successful intervention may not only reduce the psychological and social impact of sexual abuse for a victim and their family, but also modify the impact on future generations, through improved functioning as a parent, and (if there is an association) by reducing the risk of future abuse by its victims.

\section{Description of the intervention}

\section{Cognitive-behavioural approaches}

Cognitive-behavioural approaches derive philosophically, theoretically and empirically from four theories of learning: respondent conditioning (associative learning); operant conditioning (the effect of the environment on patterns of behaviour, particularly reinforcement and punishment); observational learning (learning by imitation), and cognitive learning (the impact of thought patterns on feelings and behaviour). They combine to provide an integrated approach to assessment and intervention that pays careful attention to the developmental and social contexts in which learning occurs. In the treatment of children who have been sexually abused, cognitivebehavioural approaches focus on the meaning of events for children and non-offending parents, endeavouring to identify and address maladaptive cognitions (for example, being permanently 'soiled'), misattributions (for example, feelings of blame and responsibility) and low self-esteem. In addition, interventions drawn from operant, respondent and observational learning paradigms are used to address more overtly behavioural problems such as externalising behaviours (aggression or 'acting out'), internalising behaviours (anxiety, self-blame or deprecation) or sexualised behaviour, usually mediated through the involvement of a parent not responsible for the abuse.
Cognitive-behavioural therapy (CBT) interventions for children who have been sexually abused are typically short-term structured interventions of around 12 sessions, though they can extend upwards to 40 sessions depending on need and case complexity (Deblinger 1996a). The intervention is tailored to the developmental age and symptomatology of individual children, so a fully prescribed programme does not exist.

In the 1990s, two research teams, Cohen and Mannarino (Cohen 1991; Cohen 1994) and Deblinger and Heflin (Deblinger 1996a), published manuals that described a cognitive-behavioural treatment model for children who had been sexually abused. Deblinger and Heflin's original model has three core components. The first is coping skills training, in which both children and parents learn skills for coping effectively with the emotional distress that often follows sexual abuse, for example cognitive coping, in which children and parents learn to identify and dispute dysfunctional thoughts and replace them with more accurate and effective coping responses. This helps to prepare children for the central component of the model, namely gradual exposure and cognitive and affective processing. Gradual exposure combines elements of systematic desensitisation and in vivo exposure to reminders of trauma. Children are gradually introduced to low-level anxiety-provoking stimuli, followed by increasingly anxiety-provoking ones. Gradual exposure "aims to disrupt the maladaptive associations between innocuous abuse-related cues and the more extreme negative emotions that develop as a result of respondent conditioning" (Deblinger 1996a, p.18). Cognitive and affective processing aims to help children make sense of their experiences, without which they may be vulnerable to developing distorted and maladaptive cognitions and feelings about sex, relationships and the world more generally. The third component is behavioural skills management, directed at helping parents manage the behavioural problems that can sometimes result from sexual abuse, including sexualised behaviours. Parents learn to model and reinforce effective coping and effectively to manage these problem behaviours. These therapeutic elements are accompanied by education regarding child sexual abuse, healthy sexuality and personal safety skills. Deblinger and Heflin describe their cognitive-behavioural intervention as "most appropriate for use with children who exhibit symptoms of PTSD and/or confusion or misconceptions about their sexual abuse experiences" and describe the intervention as designed to alleviate PTSD symptoms. In their model, Cohen and Mannarino integrate aspects of other theoretical frameworks of relevance to child sexual abuse, namely an emphasis on the meaning of the abuse (in terms of their relationship to the perpetrator and the non-offending parent, i.e. attachment theory and family systems); the extent of a child's interpersonal trust and self-efficacy (empowerment) and how their abuse experiences, and in many cases that of their mothers, were reflected in relationships with others (see Cohen 1991; Cohen 1994).

These two teams later collaborated in developing a broad-based cognitive-behavioural model, designed to address the breadth of behavioural, physical and/or emotional difficulties that can be the direct result of traumatic experiences, including sexual abuse. They refer to this as trauma-focused CBT, which they define as "a components-based hybrid approach that integrates trauma-sensitive interventions, cognitive-behavioural principles, as well as aspects of attachment, developmental neurobiology, family, empowerment, and humanistic theoretical models in order to optimally address the needs of traumatised children and 
families" (Cohen 2006, p.32). The approach to managing the symptomatology is fundamentally cognitive-behavioural and we use this term throughout the review.

\section{How the intervention might work}

Children who experience trauma, including child sexual abuse, may experience profound changes in how they see themselves, the world and others. Many of them may experience psychobiological changes that contribute to the development and maintenance of post-traumatic stress symptoms, which Cohen 2006 categorises as affective, behavioural, cognitive, complex PTSD and psychobiological trauma symptoms (Cohen 2006). To some extent these symptoms overlap and interact to reinforce one another. $\mathrm{CBT}$ is designed to address these symptoms using a range of specific techniques, examples of which are listed below.

Emotional distress: children are helped to cope effectively with their emotional distress by learning relaxation and a range of skills such as emotional expression and cognitive coping skills. Children (and parents) learn how to label the feelings associated with the abuse and to communicate them to others; they also learn to identifying maladaptive beliefs and attributions and replacing them with those that are more accurate and effective (Deblinger 1996a; FlannerySchreder 2005).

Anxiety: depending on age, children are taught to recognise the signs of anxiety, the triggers that precipitate it (both external and internal - maladaptive thoughts and cognitive errors) and gradually to replace their maladaptive responses with adaptive ones. Central to achieving this is helping the child to face (rather than avoid) the situations that promote anxiety, to experience and practice coping. Techniques might include relaxation, self-control, desensitisation and cognitive restructuring (for example, Muris 2009).

Behaviour problems: parents are taught how behaviour is triggered (antecedents) and shaped or maintained by consequences, and how to change these to improve behaviour. They are also taught about the effects of sexual abuse so as to better understand children's behaviour.

\section{Why it is important to do this review}

Generally speaking, cognitive-behavioural approaches have a record of experimental evidence of their effectiveness in dealing with a wide range of emotional and behavioural problems, many of which feature in the symptomatology of children who have been sexually abused, for example, anxiety (Kendall 1994), internalising and externalising behaviour (Harrington 1998; Kazdin 1989) and post-traumatic stress symptoms (Deblinger 1996). Conceptually they provide a broad, evidence-based framework for assessing the effects of sexual abuse on personal, interpersonal and familial relations, and planning interventions tailored to individual circumstances. As a focused, time-limited form of intervention, it may also be a cost-effective way of helping a larger number of children than currently receive help.

Earlier reviews within the field (Finkelhor 1995; Stevenson 1999) suggest that cognitive-behavioural interventions, as part of a broader psychosocial intervention, may be an effective form of treatment for sexually abused children. However, these reviews include studies of a wide range of methodological types, and did not select studies on the basis of methodological rigour. They also include a range of therapeutic interventions. Our review of CBT for sexually abused children was originally published in 2006. In keeping with good practice, this update was undertaken to ensure that the review continues to reflect current best evidence.

\section{OB JECTIVES}

To assess the efficacy of cognitive-behavioural approaches in treating the immediate and longer-term sequelae of child sexual abuse.

\section{METHODS}

\section{Criteria for considering studies for this review}

\section{Types of studies}

Studies were eligible for the review if the allocation of participants to experimental or control groups was by random allocation or quasi-random allocation (for example, by day of week, case number or alphabetical order).

Studies comparing CBT versus treatment as usual (referred to in the protocol as 'another intervention'), with or without placebo control, were eligible, as were studies comparing one intervention versus control.

\section{Types of participants}

Children and adolescents up to age 18 years who had experienced sexual abuse, as defined by trialists. The first protocol said the abuse should have occurred in the 12 months before referral. The review authors subsequently removed this restriction as lacking a sufficiently clear rationale.

\section{Types of interventions}

Interventions described by the authors as behavioural or cognitivebehavioural or that described the use of cognitive-behavioural interventions.

Interventions might or might not have included parents, but had to have included children as recipients of therapy.

\section{Types of outcome measures}

\section{Primary Outcomes}

\section{A. Psychological functioning of child}

i) Depression

ii) Post-traumatic stress disorder

iii) Anxiety

\section{B. Child behaviour problems}

i) Sexualised behaviour

ii) Externalising behaviour (for example, aggression, 'acting out')

\section{Secondary Outcomes}

\section{Future offending behaviour}

i) Of child when adolescent and/or adult, including delinquency, criminal offences or sexual offending

\section{Parental skills and knowledge}

i) Of child sexual abuse and its (possible) consequences

ii) Belief in their child's story 
iii) Accurate attributions for their child's behaviour or psychological problems

iv) Behaviour management skills

v) Parents' emotional reactions

\section{Rating scales}

A wide range of instruments are available to measure the behavioural and psychosocial problems associated with the consequences of child sexual abuse. These instruments vary in quality and validity. For this review the minimum standards for the inclusion of data from outcome instruments were i) that the psychometric properties of the instrument had been described in a peer-reviewed journal; ii) that the instrument was either (a) a selfreport, or (b) completed by an independent rater or relative.

\section{Search methods for identification of studies}

\section{Electronic searches}

The following databases were searched four times in the period between the date of search of the original review and this update (6 February 2009, 8 December 2009, 20 December 2010 and 2 December 2011). Searches were limited to records which had either been published between search dates or added to the database in the period between search dates. Appropriate randomised trials filters were added to each strategy where necessary, except in 2010 when, due to an oversight, RCT filters were not applied. The original search strategies can be found in Appendix 1 . Those used in December 2009, 2010 and 2011 can be found in Appendix 2.

Cochrane Central Register of Controlled Trials (CENTRAL) 2011 (4), searched 2 December 2011

MEDLINE (OVID) 1950 to November Week 3 2011, searched 2 December 2011

EMBASE (OVID) 1980 to 2011 Week 47, searched 2 December 2011 CINAHL (EbscoHOST) 1937 to current, last searched 2 December 2011
PsycINFO (EbscoHOST) 1887 to current, searched 20 December 2010

PsycINFO (OVID) 1806 to November Week 5 2011, searched 2 December 2011

LILACS 1982 to current, searched 2 December 2011

OpenGrey (previously openSIGLE), searched 2 December 2011

For this update we also searched the following.

CinicalTrials.gov, searched 2 December 2011

International Clinical Trials Registry Platform (ICTRP), searched 2 December 2011

\section{Searching other resources}

We also checked references in previous reviews and studies. We contacted authors and known experts to identify any additional or unpublished data. We made efforts to establish contacts in countries in which English is not the dominant language.

\section{Data collection and analysis}

\section{Selection of studies}

In the original review, two review authors (GM and $P R$ ) independently selected studies for inclusion in the review. No disagreements needed to be resolved.

For the searches run in December 2009, at least two authors (from $B R, R O ' D, M T, P K, M P, G R, B L$ and JV) independently selected studies for inclusion in the review. Disagreements were resolved in conference and a third author (always JV) was consulted as arbitrator where necessary.

For the searches run in December 2010 and December 2011 two authors (GM and JV) independently reviewed citations and selected studies.

See Figure 1 for the flow of studies through the identification and selection process for the literature searches. 
Figure 1. Study flow diagram.

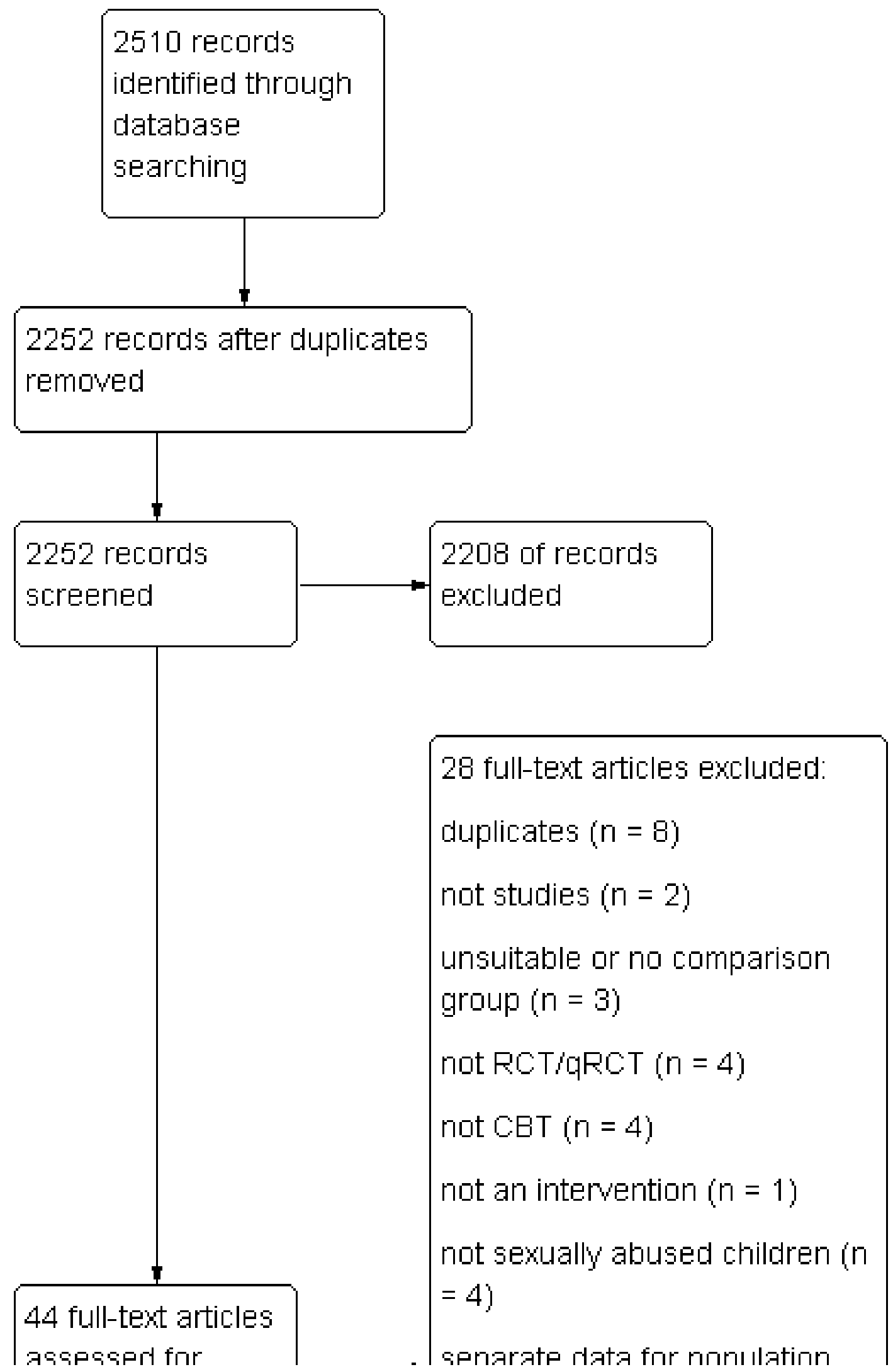


Figure 1. (Continued)

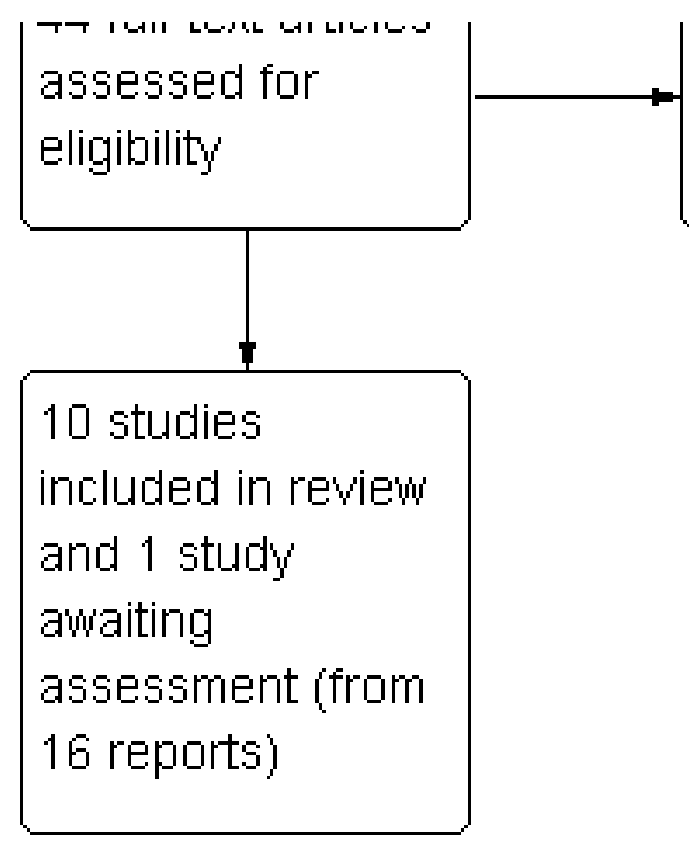

\section{Data extraction and management}

Two review authors independently extracted data. We resolved any disagreements or uncertainties by discussion. All decisions were documented and where necessary, we contacted authors of studies to assist in resolving problems.

In the original review, data were independently extracted by $G M$ and PR. At least two authors (from BR, RO'D, MT, PK, MP, GR, BL and JV) independently extracted data from papers identified in the December 2009 search. Disagreements or uncertainties were resolved by discussion, with JV arbitrating when consensus could not be reached. No data extraction was required following the 2010 and 2011 searches.

\section{Assessment of risk of bias in included studies}

We used the Cochrane Collaboration's tool for assessing the risk of bias of included studies (Higgins 2008). Two review authors independently assessed the risk of bias within each included study based on the following six domains, with review authors' judgements of low risk of bias, high risk of bias and unclear (uncertain) risk of bias.

Sequence generation: we describe the method used to generate the allocation sequence in detail so as to assess whether it should have produced comparable groups; review authors' judgement: risk of selection bias (biased allocation to interventions) due to inadequate generation of a randomised sequence.

Allocation concealment: we describe the method used to conceal allocation sequence in sufficient detail to assess whether intervention schedules could have been foreseen in advance of, or during, recruitment; review authors' judgement: risk of selection bias (biased allocation to interventions) due to inadequate concealment of allocations prior to assignment.

Blinding: we describe any measures used to blind outcome assessors so as to assess knowledge of any group as to which separate data for population

not available $(n=2)$ intervention a given participant might have received; review authors' judgement: risk of performance bias due to knowledge of the allocated interventions.

Incomplete outcome data: we report data on attrition and exclusions, as well the numbers involved (compared with total randomised), reasons for attrition/exclusion (where reported or obtained from investigators) and any re-inclusions in analyses performed by review authors; review authors' judgement: risk of attrition bias due to amount, nature or handling of incomplete outcome data.

Selective outcome reporting: we sought to assess the possibility of selective outcome reporting by investigators; review authors' judgement: risk of reporting bias due to selective outcome reporting.

Other sources of bias: we describe any important concerns about bias not addressed in the other domains in the tool.

Completed 'Risk of bias' tables can be found in the Characteristics of included studies tables.

\section{Measures of treatment effect}

For binary outcomes, for example, 'attempted suicide' or 'not attempted suicide', we calculated a standard estimation of the odds ratio $(\mathrm{OR})$ with the $95 \%$ confidence interval $(\mathrm{Cl})$. Numbers needed to treat were not calculated due to the small number of studies.

We analysed continuous data where (i) means and standard deviations were available or calculable and (ii) there was no clear evidence of skew in the distribution (mean less than one standard deviation from an upper or lower bound) if the study was small (fewer than 20 participants per group). Where standard deviations were not given directly, we calculated these using test statistics wherever possible. Where scales were measuring the same clinical outcomes in different ways, we used standardised mean differences in order to combine results across scales. 
Where an outcome was assessed using a measure with subscales, we used the total score, providing the full scale addressed the outcome of interest. Otherwise, we used the most relevant subscore. For example, when assessing the impact of CBT on anxiety, we used the total score for the Revised Children's Manifest Anxiety Scale (RCMAS) rather than the scores for any of its subscales, which are designed to assess the impact of intervention on particular aspects such as physiological anxiety or concentration anxiety. When assessing the impact of CBT on children's behaviour, we used the 'externalising' subscale of the Child Behavior Checklist ( $\mathrm{CBCL}$ ); when deciding between 'state anxiety' and 'trait anxiety', we used the former as this seemed best to capture the outcome of interest, i.e. present state anxiety; when selecting one of three data sets reported for K-SADS-E (with no total score), we selected 're-experiencing' rather than 'avoidance' or 'hypervigilance'.

When a choice needed to be made between two overlapping measures of the same outcome, we chose the measure that appeared most accurately to reflect the outcome of interest without reference to the results.

Some studies provided outcome assessments at multiple points in time. As per protocol, we grouped these into the categories of i) immediate, ii) up to six months ,and iii) at least one year. When a study collected outcomes at multiple time points within the three to six month category, we averaged these to arrive at a single composite estimate. For studies that measured outcomes at multiple time points at least one year after treatment (for example, 12 and 24 months), we used the most distal measure.

A summary of measures used by trialists and those used in this review can be found in Additional Table 1. See also Description of studies.

\section{Unit of analysis issues}

Two studies were randomised by group rather than by individual, but no information was available on group size or on intraclass correlation to allow us to perform an adjusted analysis to account for potential clustering. We assess that the greatest plausible effect this clustering could have would be an underestimate of standard error by about $30 \%$ (based on a group size of 10 , and an intraclass correlation coefficient (ICC) of 0.1 , giving a design effect (variance inflation factor) of 1.9).

\section{Dealing with missing data}

See Additional Table 2.

\section{Assessment of heterogeneity}

We assessed heterogeneity using a statistical test of heterogeneity $(\mathrm{Q})$, and also by the statistic $1^{2}$, which describes the percentage of variability in study effects that is due to real heterogeneity rather than chance.

\section{Data synthesis}

We based primary analyses on available data from all included studies relevant to the comparison and outcome of interest. We performed random effects meta-analyses, and illustrated these within the review using standard forest plots. In studies with more than one experimental group, we combined these arms to form a single group, and calculated appropriate summary statistics as if they had always been so (King 2000; Deblinger 2001). We corrected for small sample size bias by using Hedges' $\mathrm{g}$, which is the default in Revew Manager 5 (RevMan 5).

\section{Subgroup analysis and investigation of heterogeneity}

We did not undertake investigation of heterogeneity via subgroup analyses because the small number of included studies provided insufficient power reliably to identify correlated predictors. See also Additional Table 2 for information about future updates of the review.

\section{Sensitivity analysis}

For those analyses where there was a statistically significant finding, we performed sensitivity analyses for any statistically significant meta-analyses including cluster-randomised studies, using highly conservative assumptions i.e. a highly conservative ICC of 0.15 . No change in statistical significance of the meta-analysis was observed. We did not conduct other planned sensitivity analyses designed to examine the impact on results of the quality of data and approach to analysis due to the paucity of data. See Additional Table 2 for further information.

\section{RES U L T S}

\section{Description of studies}

\section{Results of the search}

The original search identified 794 records. The searches conducted for this update identified 1458 papers (745 records from 2009 searches, 579 from 2010 searches and 134 from 2011 searches).

Following assessment of the titles and abstracts in 2009, 22 full text papers were obtained. No new studies were found, but two of the 22 papers contained data relevant to included studies but not published at the time the review was first published (Cohen 2005; Deblinger 2006). These papers related to Cohen 1998 and Cohen 2004 respectively. (Deblinger and her colleagues had kindly made available some of the unpublished data prior to the publication of the original review).

Following assessment of the 2010 searches, two full text papers were obtained, of which one looks as if it may meet the inclusion criteria (Lewis 2010). We wrote to the study authors in December 2010 for additional information to determine eligibility and for the data that would be needed to include in any relevant meta-analysis. We did not receive a response. We did not identify any new studies in the 2011 searches.

This review therefore uses data from two additional papers published since the original publication of the review, but includes no new studies. One study is awaiting information from the authors (Lewis 2010).

\section{Included studies}

We have included 10 studies in this review: (Berliner 1996; Celano 1996; Cohen 1996; Deblinger 1996; Burke 1988; Cohen 1998; King 2000; Deblinger 2001; Dominguez 2001; Cohen 2004).

\section{Location of studies}

King 2000 was conducted in Australia. All other studies were conducted in the USA. 


\section{Participants}

Study authors typically reported data for study completers rather than for those recruited to the study (for example Cohen 1996).

Two studies focused solely on girls who had been sexually abused (Burke 1988; Celano 1996). The remaining studies included both boys and girls, with the percentage of boys ranging from $11 \%$ (Berliner 1996) to 42\% (Cohen 1996) (see Characteristics of included studies).

One study (Cohen 1996) was concerned with preschoolers (boys and girls aged 3 to 6 years). Four studies set similar inclusion criteria for age: 7 to 13 years (Deblinger 1996), 8 to 13 years (Burke 1988; Celano 1996), 8 to 14 years (Cohen 2004). Inclusion criteria for the other five studies ranged from children aged 2 to 8 years (Deblinger 2001) to children aged 4 to 13 years (Berliner 1996), 5 to 17 years (King 2000), 6 to 17 years (Dominguez 2001) and 7 to 15 years (Cohen 1998).

All trials made the independent substantiation of sexual abuse an inclusion criterion. Most set cut-off points on the time of last episode of abuse as an inclusion criteria, ranging from six months (Cohen 1996; Cohen 1998) to two or three years (Burke 1988; Celano 1996; King 2000). Whilst Deblinger 2001 did not set a time limit, the authors report that the mean age of the children was 5.45 years (SD $=1.47$ ) and the mean age of first experience of sexual abuse was 4.5 years $(S D=1.47)$, based on mothers' estimates. The report by Berliner 1996 did not specify inclusion or exclusion criteria, but all participants were said to have provided statements, substantiated by independent assessment, that they had been sexually abused.

All studies had inclusion criteria that specified contact sexual abuse. The range of abuse experienced by participants was broad, and differently reported, but the following picture of participants emerged. Most were abused by men known to them. The majority were family members. In four studies, approximately half the children and young people had experienced oral, vaginal or anal penetration (Berliner 1996; Celano 1996; Cohen 1998; Dominguez 2001). In the study dealing with the youngest participants, the percentage that had experienced vaginal or anal intercourse was $26 \%$ (Cohen 1996). In the study of children aged 2 to 8 years, the number reported to have experienced penile penetration was $16 \%$ (Deblinger 2001). Participants in all studies ranged from those who had experienced one incident of abuse to those who had experienced multiple incidents, sometimes over many years. Many participants also reported the use of force, or threat of force. Not all studies reported detailed abuse data (for example, Burke 1988; Deblinger 2001). See Table 3 for a profile of participants in each study.

Five studies reported the presence of particular symptomatology thresholds as an inclusion criterion. Burke 1988 required reports of behavioural difficulties in participants, as indicated in the records of the child's assigned caseworker, together with a pre-treatment score on the Child Depression Inventory of at least one standard deviation above the mean score obtained from a normative sample of girls aged 8 to 13 years. Cohen 1996 required a minimal level of symptomatology defined as a Weekly Behavior Report Total Behavior score of more than seven or any sexually inappropriate behaviour reported on the Child Sexual Behavior Inventory. Cohen 2004 stipulated that participants had to meet five criteria for sexual abuse-related DSM-IV-defined PTSD, including at least one in each of the three clusters (re-experiencing, avoidance or numbing, and hyperarousal). Deblinger 1996 required the presence of three posttraumatic stress (PTSD) symptoms, including at least one symptom of avoidance or re-experiencing the phenomenon. Investigators decided to take both children who met full DSM-III-R criteria for PTSD and those with partial PTSD symptoms because of the possibility of delayed onset of episodic course. King 2000 required that the children met diagnostic criteria for PTSD or provided evidence of high risk of developing the disorder.

\section{Interventions}

Details of each intervention can be found in Characteristics of included studies.

\section{Group treatments}

In two studies, therapy was provided only to children and on a group basis (Burke 1988; Berliner 1996). These studies compared the efficacy of CBT to a wait list control (Burke 1988) and 'conventional sexual abuse specific group therapy' (Berliner 1996) respectively.

One study provided group therapy to children and their mothers in separate groups (Deblinger 2001). This study compared CBT with supportive group therapy (parents) and an interactive CBT approach with a didactic, information-based approach for children. In addition, members of the CBT group met for an additional 15 minutes each week for a joint parent and child activity session.

\section{Individual treatments}

The remainder provided individual therapy. Celano 1996 compared the efficacy of CBT applied to children and their mothers with supportive, unstructured psychotherapy, also to children and their mothers. Three other studies compared CBT with nondirective supportive therapies (Cohen 1996; Cohen 1998; Dominguez 2001).

Two studies compared the efficacy of CBT provided for the child with CBT provided to the child and parent/family (Deblinger 1996; King 2000). Both studies also used a control group (community control and wait list respectively) and Deblinger 1996 had a fourth arm which examined the efficacy of teaching parents CBT strategies for helping their child.

\section{Number and content of sessions}

The group-based therapies were provided over six and 10 sessions respectively (Burke 1988; Berliner 1996). For the experimental group, Berliner augmented the conventional sexual abuse specific group therapy provided to the control group with sessions specifically explaining the nature of fear, the principles of Stress Inoculation Therapy and their application to disclosure impact and self-esteem. Burke's therapy was based primarily on classical conditioning (relaxation, imaginal exposure and behaviour rehearsal) and education, aimed at providing participants with strategies for managing negative affect.

The individual therapies were provided for between eight to 20 sessions (see Characteristics of included studies). Participants in Celano's study (Celano 1996) had eight sessions of one hour each, in which therapists deployed developmentally appropriate cognitive-behavioural and metaphoric techniques to address children's maladaptive beliefs, affect and behaviour. In all but two or three sessions, the therapist spent half the time with 
the mother and half with the child. The remaining sessions were conducted conjointly. Three studies provided around one and a half hours per week, divided between parents and child over eight and 12 weeks respectively (Cohen 1996; Cohen 1998; Cohen 2004). CBT programmes in these studies included the use of cognitive reframing, thought stopping, positive imagery, contingency reinforcement programmes, parent management training and problem solving, together with psychoeducational and supportive interventions. These interventions were also central to the studies by Deblinger and King, which had three arms: child, parent and child + parent. Deblinger 1996 provided therapy in $12 \times 45$ minute sessions to participants in the parent-only and child-only arms. In the parent and child arm, therapy also entailed 12 sessions, but this time of up to 90 minutes. In King 2000, all participants each received $20 \times 50$ minute sessions. This means that in the parent + child arm, $40 \times 50$ minute sessions were provided. No information is provided by Dominguez 2001.

\section{Outcome measures}

\section{Outcomes assessed using the same measure}

Where the impact of intervention on parenting practices was assessed, the measure used was the Parenting Practices Questionnaire (Strayhorn 1988).

In each study that examined child depression, child sexual behaviour and child behaviour, the same measures were used, namely the Child Depression Inventory (CDI) (Kovacs 1981), the Child Sexual Behavior Inventory (CSBI) (Friedrich 1992) and the Child Behavior Checklist (CBCL) (Achenbach 1991), respectively (see Table 1).

\section{Outcomes assessed using different measures}

\section{Post-traumatic stress disorder (PTSD)}

Six studies (Celano 1996; Deblinger 1996; Cohen 1998; King 2000; Deblinger 2001; Cohen 2004) assessed the impact of CBT on symptoms of post-traumatic stress using six different measures. Celano 1996 and King 2000 used both the PTSD subscale of the Child Behaviour Checklist (completed by the child's parent) (Achenbach 1991) and one other measure of PTSD. Celano 1996 used a child report measure (the CITES-R (Children's Impact of Traumatic Events Scales-Revised)) (Wolfe 1991) and King 2000 used a measure administered by a research assistant (the child version of the Anxiety Disorders Interview Schedule for DSM-IV (Silverman 1996). Two studies (Deblinger 1996; Deblinger 2001) used the Kiddie Schedule for Affective Disorders and Schizophrenia for School-Age Children - Epidemiologic Version administered to parents (K-SADSE) (Orvaschel 1982; Orvaschel 1994); one study (Cohen 2004) used the K-SADS-PL (Parent and Lifetime Version) (Kaufman 1997), and another (Cohen 1998) used the Trauma Symptom Checklist for Children (TSCC) (Briere 1996).

\section{Anxiety}

Of the studies using the STAIC, we used data on STAIC-STATE (as opposed to STAIC-TRAIT) as this measures present state anxiety (Deblinger 1996; Cohen 1998; Cohen 2004). Two measures were used to assess the impact of interventions on anxiety, namely the Revised Children's Manifest Anxiety Scale (RCMAS) (Reynolds 1978) and the Stait-Trait Anxiety Inventory for Children (STAIC) (Spielberger 1973). Of the three studies (Burke 1988; Berliner 1996;
King 2000) using the RCMAS, no data were available for inclusion from Burke 1988.

\section{Fear}

Three measures of fear were used in four of the included studies. Burke 1988 and Berliner 1996 both used the Fear Survey Schedule for Children-Revised (FSSR-R) (Ollendick 1983). Berliner 1996 also used the Sexual Abuse Fear Evaluation Scales (SAFE) (Wolfe 1986). King 2000 used the Fear Thermometer for Sexually Abused Children (FT-SAC) (Kleinknecht 1988).

\section{Other outcomes assessed within the studies}

Some studies examined outcomes not included in the protocol for this review. Some investigators also looked at children's coping ability. King 2000 used the Global Assessment Functioning scale (GAF) (APA 1987) and an instrument developed by the investigators themselves, the Coping Questionnaire for Sexually Abused Children (CQ-SAC) and Celano 1996 used the Children's Global Assessment Scale (CGAS) (Shaffer 1983). Dominguez 2001 measured children's subjective distress using the Impact of Events Rating (IES-R) (Horowitz 1979), whilst Cohen 2004 assessed children's attributions using the Children's Attribution and Perception Scale (CAPS) (Mannarino 1994).

The Parents' Emotional Reaction Questionnaire (PERQ) (Cohen 1996) was used in two studies to determine the impact of intervention on parental distress (Deblinger 2001; Cohen 2004). Researchers in the Celano 1996 study examined the impact of CBT on the attributions made by parents about responsibility for abuse using a scale they themselves developed, the Parental Attribution Scale (PAS).

One study examined mothers' reaction to disclosure of abuse using the Parents' Reaction to Incest Disclosure Scale (PRIDS) (Everson 1989), which looks at parental support for the child in three areas: emotional support, belief of the child and action towards the perpetrator (Celano 1996). Cohen 2004 looked at the parental level of support for the child and attributions about responsibility using the Parental Support Questionnaire (PAS) (Mannarino 1996).

Cohen 2004 reported on the impact of intervention on parental depression using the Beck Depression Inventory (BDI) (Beck 1996).

This review reports on those measures set out in the protocol. For a complete list of measures used by study authors and those included in this review see Table 1.

\section{Excluded studies}

We excluded three studies, two because they were not randomised or quasi-randomised (Verleur 1986; Downing 1988) and one because it compared cognitive-behavioural therapy with another experimental treatment (Jaberghaderi 2004).

\section{Risk of bias in included studies}

Five studies had small samples sizes ranging from 25 to 49 (Burke 1988; Celano 1996; King 2000; Deblinger 2001; Dominguez 2001). A multi-site trial by Cohen had a sample of 229 (Cohen 2004). The remainder ranged from 82 to 154 (Berliner 1996; Cohen 1996; Deblinger 1996; Cohen 1998). As a result, the meta-analyses we conducted did not have high power to detect small, but potentially important, effects. 
Quality aspects were generally not well reported. Full details of our assessments are available in the 'Risk of bias' tables, with a summary across the included studies in Figure 2 and Figure 3.

Figure 2. Risk of bias graph: review authors' judgements about each risk of bias item presented as percentages across all included studies.

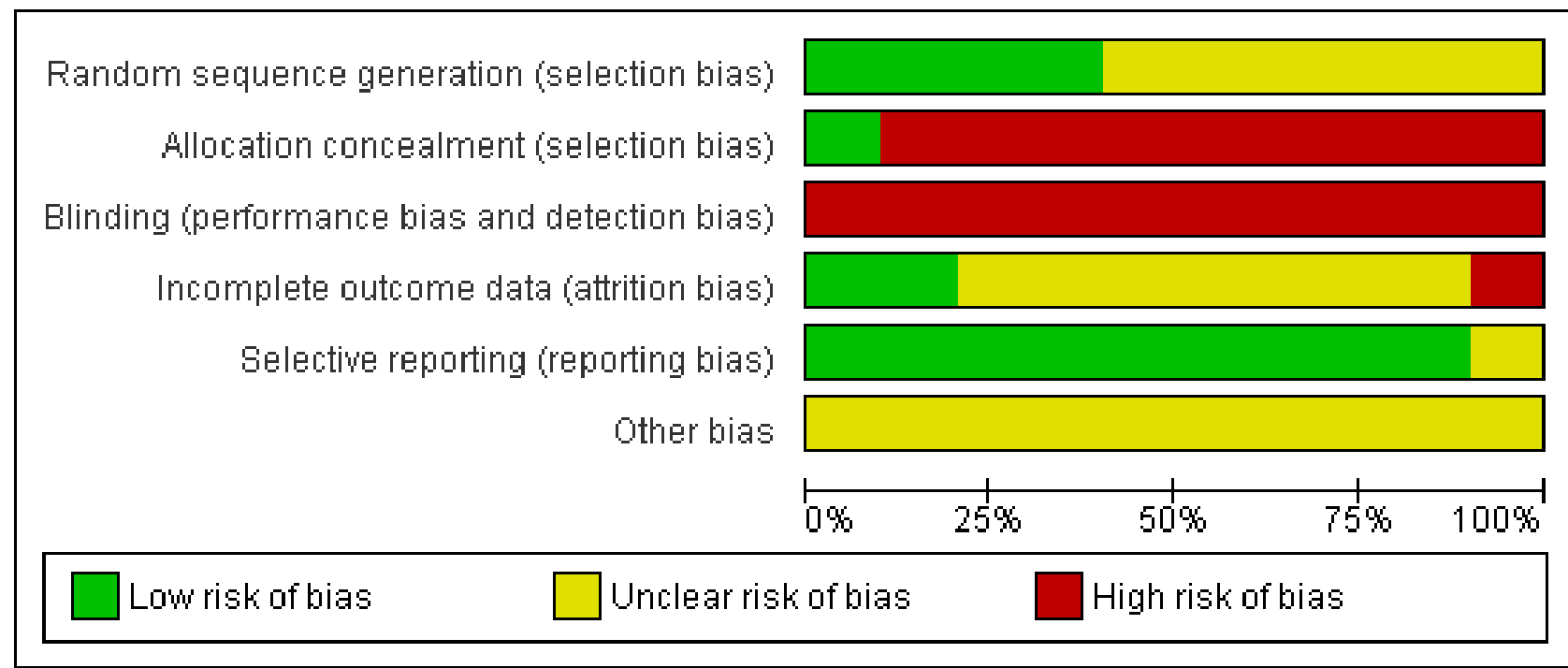


Figure 3. Risk of bias summary: review authors' judgements about each risk of bias item for each included study.

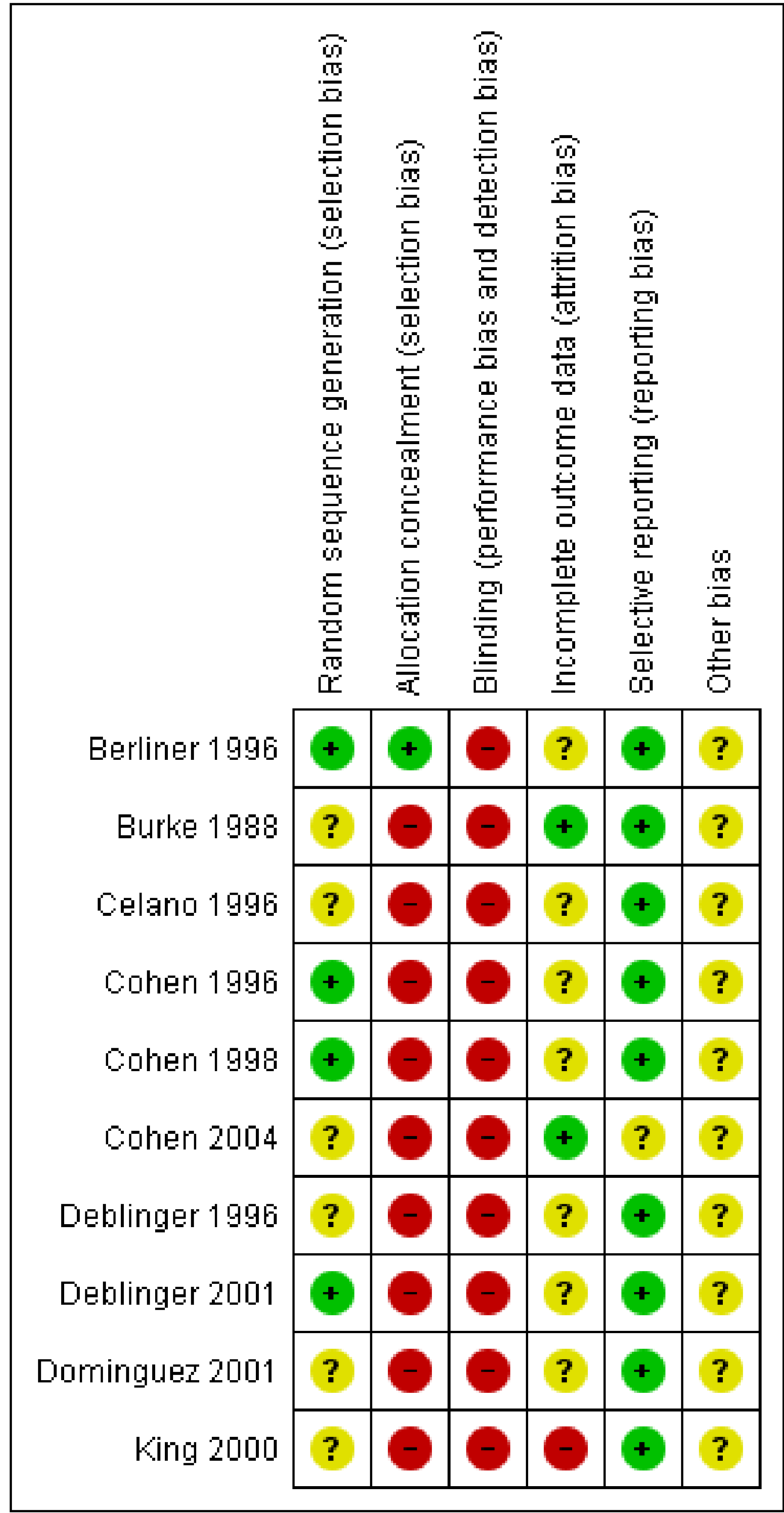

\section{Effects of interventions}

We were able to combine data from different studies for eight of our 11 outcomes, at up to three time points: immediately postintervention, three to six months later and at least one year later.
The results here only involve participants included by the study authors in their analyses, many of which excluded participants due to dropout, uncollected data or for reasons they do not report. Each result reported is the post-test score in the intervention group compared to the control group. 


\section{A. Psychological functioning of child}

\section{i) Depression}

Seven studies looked at the impact of intervention on depression in children using the Child Depression Inventory (CDI) (Kovacs 1981). Data from five studies were available in a form that could be combined in a meta-analysis. These five studies yielded an average decrease of 1.9 points on the CDI immediately after intervention (95\% confidence interval $(\mathrm{Cl})$ decrease of 4.0 to increase of 0.4 ; 12 inconsistency statistic $=53 \% ; \mathrm{P}$ value for heterogeneity $0.08 ; \tau^{2}$ = 3.55), and four of these studies (Berliner 1996; Deblinger 1996; Cohen 1998; Cohen 2004) sustained an average decrease of 1.3 points $\left(95 \% \mathrm{Cl}\right.$ decrease of 2.8 to increase of $0.2 ; \mathrm{I}^{2}=0 \% ; \mathrm{P}=0.98$; $\tau^{2}=0.0$ ) after at least one year (Analysis 1.1). A decrease of 1.9 on the $C D I$ represents a modest change in a scale that previous studies indicate has a standard deviation of approximately 7 (Smucker 1986; Twenge 2002). This represents a small to moderate effect size, broadly equivalent to that seen on the anxiety scales in metaanalyses in this review.

\section{ii) Post-traumatic stress disorder}

Six studies examined the impact of CBT on post-traumatic stress using a variety of scales (see above section on 'Outcome measures'). These studies yielded an average decrease of 0.44 standard deviations on various child post-traumatic stress disorder scales $\left(95 \% \mathrm{Cl} 0.16\right.$ to $0.73 ; \mathrm{I}^{2}=46 \%$; $\mathrm{P}$ value for heterogeneity $\left.0.10 ; \tau^{2}=0.05\right)$ immediately after treatment, and three of these (Deblinger 1996; Cohen 1998; Cohen 2004) sustained a decrease of 0.50 standard deviations ( $95 \% \mathrm{Cl} 0.09$ to 0.61$)$ after at least one year (Analysis 1.2).

\section{iii) Anxiety}

Six studies examined the impact of CBT on anxiety, but it was not possible to use the data provided by Burke 1988 in our metaanalysis. The other five studies, using two scales (Spielberger 1973; Reynolds 1978), yielded an average decrease of 0.23 standard deviations on various child anxiety scales $\left(95 \% \mathrm{Cl} 0.03\right.$ to $0.42 ; \mathrm{I}^{2}$ $=0 \%$; $\mathrm{P}$ value for heterogeneity $\left.0.84 ; \tau^{2}=0.0\right)$ immediately after treatment, and four of these (Berliner 1996; Deblinger 1996; Cohen 1998; Cohen 2004) reported a sustained decrease of 0.28 standard deviations $\left(95 \% \mathrm{Cl}\right.$ decrease of 0.52 to decrease of $0.04 ; \mathrm{I}^{2}=0 \%$; $\mathrm{P}$ value for heterogeneity $=0.62 ; \tau^{2}=0.0$ ) after at least one year (Analysis 1.3).

\section{B. Child behaviour problems}

\section{i) Sexualised behaviour}

Five studies provided conflicting evidence on the effectiveness of CBT in the domain of child behaviour problems assessed using the Child Sexual Behavior Inventory $(12=67 \%$, P value for heterogeneity 0.02; $\tau^{2}=6.81$ ) (Friedrich 1992). Two studies (Berliner 1996; Deblinger 2001) observed increases of 4.7 and 1.7 points and three (Cohen 1996; Cohen 1998; Cohen 2004) observed decreases, one of which was statistically significant (Cohen 1996). In a meta-analysis, there was no evidence of an effect on average (mean decrease of -0.65 points, $95 \% \mathrm{Cl}-3.53$ to +2.24 points). Four studies (Berliner 1996; Cohen 1996; Cohen 1998; Cohen 2004) provided longer-term data. The first of these observed a much smaller increase than the same study in the short term. Overall, the average effect found at the three- to six-month assessment point was similar to that immediately after treatment, but was not statistically significant ( -0.46 points, $95 \% \mathrm{Cl}-5.68$ to +4.76 points; Analysis 1.4$)$. Note that Cohen 2004 did not report data for this outcome because it was not statistically significant. We have not successfully retrieved these data, but their inclusion is highly unlikely to change the overall conclusion for this outcome.

\section{ii) Externalising behaviour (for example, aggression, 'acting out')}

Seven studies provided data on the Child Behaviour Checklist (CBCL) externalising behaviour scale (Achenbach 1991). A metaanalysis of standardised differences in means (due to different scoring systems being used for the scale) did not provide evidence of a beneficial effect on average (decrease of 0.12 standard deviations, $95 \% \mathrm{Cl}$ decrease of 0.40 to increase of 0.17 ). However, the results were inconsistent $\left(I^{2}=58 \%\right.$; $P$ value for heterogeneity $\left.0.03 ; \tau^{2}=0.08\right)$, with one study observing a statistically significant increase (Berliner 1996) and one a statistically significant decrease (Deblinger 1996).

Five studies provided longer-term data (Berliner 1996; Cohen 1996; Deblinger 1996; Cohen 1998; Cohen 2004). Again, the picture is of inconsistent findings that do not produce, on average, either a convincingly beneficial or harmful effect (Analysis 1.5).

\section{Future offending behaviour}

\section{i) Of child when adolescent and/or adult.}

No study set out to examine this as an outcome.

\section{Parental skills and knowledge}

\section{i) Of child sexual abuse and its (possible) consequences}

No data were available on parental understanding of child sexual abuse.

\section{ii) Belief in their child's story}

Two studies (Celano 1996; Cohen 2004) used the PRIDS (Everson 1989) and PSQ (Cohen 1996) scales respectively to measure parental belief of their children and support for them. A metaanalysis of standardised differences in means gave a statistically significant increase of 0.3 standard deviations $(95 \% \mathrm{Cl} 0.03$ to 0.57$)$ (Analysis 1.6).

\section{iii) Accurate attributions for their child's behaviour or psychological problems}

One study (Celano 1996) provided data on four aspects of parental attributions (PAS scale), observing small, but statistically non-significant decreases in self-blame, child-blame, perpetratorblame and negative impact (see forest plot) (Celano 1992) (Analysis 1.7).

\section{iv) Behaviour management skills}

Three studies provided data on Parenting Practices Questionnaire (Strayhorn 1988 ) scores in the short term (Deblinger 1996; Deblinger 2001; Cohen 2004), two of which looked also at longterm effects (Deblinger 1996; Cohen 2004). A statistically significant increase of 4.4 across the two studies was observed immediately after treatment $(95 \% \mathrm{Cl} 1.0$ to 7.7$)$. The long-term effects were not statistically significant, but pointed to improvement in the CBT group relative to control (Analysis 1.8). 


\section{v) Parents' emotional reactions}

We added this outcome as it is closely related to 'belief in their child's story' and 'accurate attributions'. The Parent Emotional Reaction Questionnaire (PERQ) is designed to assess stressful parental emotional reactions to the sexual abuse of their children. Parents are asked to endorse the frequency of specific reactions including fear, sadness, guilt, anger, embarrassment, shame and emotional preoccupation. No psychometric data are currently available. Two studies used the PERQ (Deblinger 2001; Cohen $2004)$ and across these a decrease of seven points (95\% $\mathrm{Cl} 3.8$ to 10.1) was observed (Analysis 1.9). Cohen 2004 measured outcomes longer term, and observed a smaller but still statistically significant decrease of 4.6 points.

\section{ISCUSSION}

\section{Summary of main results}

Ten randomised trials, involving 847 participants, were included in this review. All studies examined CBT programmes provided to children or children together with a 'non-offending' or 'safe' parent i.e. a parent not implicated in the abuse. One study compared CBT with a wait list control (Burke 1988); the remainder compared CBT with treatment as usual, which was typically supportive, unstructured psychotherapy. Only four studies were judged 'low risk of bias' with regards to sequence generation and only one study was judged 'low risk of bias' in relation to allocation concealment. All studies were judged 'high risk of bias' in relation to the blinding of outcome assessors or personnel. Most of the reports provided no information on these, or other domains of bias, and most reported results for study completers rather than those recruited.

Depression, post-traumatic stress disorder, anxiety and child behaviour problems (sexualised behaviour and externalising behaviour) were the primary outcomes in this review. The evidence from the trials suggest that CBT may have a positive impact on the sequelae of child sexual abuse, although most results were not statistically significant. Strongest evidence for positive effects of CBT appear to be a modest reduction in depression, PTSD and anxiety symptoms.

Depression: meta-analysis of data from five studies suggested an average decrease of 1.9 points on the Child Depression Inventory immediately after intervention $(95 \% \mathrm{Cl}$ decrease of 4.0 to increase of $0.4 ; 1^{2}=53 \% ; P$ value for heterogeneity $=0.08$ ). A decrease of 1.9 on the CDI represents a modest change on a scale that previous studies indicate has a standard deviation of approximately 7 (Smucker 1986; Twenge 2002) and represents a small to moderate effect size, broadly equivalent to that seen on the anxiety scales in meta-analyses in this review.

Post-traumatic stress: immediately post intervention, data from six studies yielded an average decrease of 0.44 standard deviations on a variety of child post-traumatic stress disorder scales $(95 \% \mathrm{Cl}$ 0.16 to $0.73 ; 1^{2}=46 \%$; $P$ value for heterogeneity $=0.10$ )

Anxiety: combined data from five studies yielded an average decrease of 0.23 standard deviations on various child anxiety scales $\left(95 \% \mathrm{Cl} 0.3\right.$ to $0.4 ; \mathrm{I}^{2}=0 \%$; P value for heterogeneity $\left.=0.84\right)$. No study reported adverse effects.

Child behaviour problems: a meta-analysis of data from five studies found no evidence of an effect on child behaviour problems (mean decrease of -0.65 points, $95 \% \mathrm{Cl}-3.53$ to +2.24 points). Combined data from five studies provided conflicting evidence on the effectiveness of CBT for sexualised behaviour, as measured by the Child Sexual Behavior Inventory $\left(I^{2}=67 \%\right.$, $P$ value for heterogeneity 0.02) (Friedrich 1992). Two studies (Berliner 1996; Deblinger 2001) observed increases of 4.7 and 1.7 points and three (Cohen 1996; Cohen 1998; Cohen 2004) observed decreases, one of which was statistically significant (Cohen 1996). Four studies (Berliner 1996; Cohen 1996; Cohen 1998; Cohen 2004) provided longer-term data. The first of these observed a much smaller increase than the same study in the short term. Overall, the average effect found at the three to six months assessment point was similar to that immediately after treatment, but was not statistically significant $(-0.46$ points, $95 \% \mathrm{Cl}-5.68$ to +4.76 points; Analysis 1.4$)$.

\section{Overall completeness and applicability of evidence}

There are few studies included in this review and they originate, with one exception, from the United States of America. Whilst this may limit the applicability of the evidence to some health and social care settings, the evidence itself has considerable crosscultural applicability, anchored as CBT is on an understanding of child sexual abuse and its consequences based on learning theory. Generally, the studies appear to be representative of the range of abuse experienced by children between the ages of three and 17 years.

One of the debates in the field is whether or not 'asymptomatic' children should be included in therapy. Five of the 10 studies included in this review appear to have included asymptomatic children. This may have limited the ability of these studies to reveal any effects of the intervention, as it is more difficult to demonstrate improvement in individuals who are functioning relatively well. The three studies that required evidence of posttraumatic stress symptoms as an inclusion criterion demonstrated a positive impact on this aspect of child health (Deblinger 1996; King 2000; Cohen 2004). Two of the studies that stipulated a minimal level of behavioural symptomatology as an inclusion criteria, including evidence of any sexually inappropriate behaviour (Cohen 1996; Cohen 2004), appeared to have some impact on externalising behaviour or sexualised behaviour, or both, but the evidence is only suggestive. The other study (Burke 1988) reported improvements, but did not provide data in a form that could be incorporated in the meta-analyses. Other studies that did not specifically target children with such behaviour, or with PTSD, had similar results. This may reflect similarities across study samples in symptomatology, irrespective of inclusion criteria, and the profile of abuse experienced by study participants supports this suggestion (see Table 3).

\section{Quality of the evidence}

The quality of current evidence about the efficacy of CBT in treating the emotional, psychological and behavioural consequences of children who have been sexually abused could be improved. Studies appear to have a range of methodological weaknesses which, exacerbated by poor reporting, make it difficult to draw firm conclusions. In line with other reviews, there is a suggestion that these approaches may be beneficial, compared to treatment as usual, but the strength of evidence contained within these randomised and quasi-randomised trials is considerably more muted than other reviews suggest (see below). 


\section{Potential biases in the review process}

We endeavoured to extract prespecified outcomes, but due to the absence of strong reporting norms there remains a risk that the scales reported are a biased representation of those collected by the study authors (selective reporting). It is also possible that the practice in some studies of reporting the results for only those children who completed all post-treatment assessments represents a further source of bias, though in what direction it is not possible to say. Only three studies stated that they undertook intention-to-treat analyses.

\section{Agreements and disagreements with other studies or reviews}

The findings of this updated review do not differ from those of the original review, published first in 2006 and republished in a new format in 2009. The general direction of findings presented is in keeping with those of other reviews (see, for example, Corcoran 2008; de Medeiros Passarela 2010; Harvey 2010; Trask 2011). However, this review emphasises the inherent methodological weaknesses of the available studies. This should augur more caution in the interpretation of results than is espoused by other reviewers (for example, Cohen 2000). Studies may have been well designed (Cohen 2004) but there are potentially serious weaknesses in their implementation, analyses and reporting.

\section{AUTHORS' CONCLUSIONS}

\section{Implications for practice}

There is nothing in this review to detract from the general consensus that cognitive-behavioural approaches merit consideration as a treatment of choice for sexually abused children who are experiencing adverse consequences of that abuse (see Trask 2011). There is relatively consistent evidence that cognitivebehavioural approaches may lead to reductions in depressive, anxiety and post-traumatic stress symptoms in children. The results of this review do, however, suggest that the evidence is weaker than other reviews would suggest. Most of the studies in this review describe the CBT intervention used as 'trauma-focused', meaning simply that the adverse consequences of child sexual abuse are conceptualised as the consequences of trauma, which is reflected in the structure and the content of treatment.

Trauma-focused cognitive-behavioural approaches are already recommended by some as part of a flexible, staged response to this problem in a number of jurisdictions (Jones 1999; Puttnam 2003; Cohen 2005b; Hahn 2008). In practice, however, they are not often widely available.

\section{Implications for research}

The single most important implication for research in this area is for researchers to better document and report study design and execution. Researchers should pay particular attention to reporting the history and reasons for dropouts and exclusions throughout the course of the study and the methods of randomisation. Further studies should consider focusing solely on sexually abused children who are experiencing identifiable symptoms of post-traumatic stress or other adverse consequences of sexual abuse. Studies should endeavour, wherever possible, to follow up participants for at least one year, and preferably two, rather than the very short term (or no) follow-up periods that characterise some current studies.

More, carefully conducted trials that consider which subgroups benefit (or not) from particular styles of treatment delivery would be helpful to clinicians (for example, group versus individual and parent-child versus child only), as would studies that considered treatment harms more carefully. Five of the 10 studies in this review come from essentially a single team of researchers (Cohen and colleagues) and it would be helpful to engage more teams of researchers to study what is a promising intervention for an important problem.

Finally, this is an area where observational studies of follow-up in real world settings would provide important information about how symptoms develop and/or attenuate, and critically, on the mechanisms leading to participant attrition.

\section{ACK N OWLEDGEMEN TS}

Thanks to Dr Jane Dennis, Laura MacDonald, Jo Abbott and Margaret Anderson for their patience and support during the long gestation period of the original review and this update. Thanks also to editorial and external peer reviewers whose comments helped strengthen both the protocol and the final review. The update was realised by a timely offer of help from Dr Jeff Valentine and a group of his students (listed below).

Especial thanks are due to Dr Liz McWhirter, Department of Health and Social Services and Public Safety, Northern Ireland, whose vision is not only responsible for this review, but also for the growing portfolio of reviews that this particular Group nurtures to publication. 


\section{RE F E R E N C E S}

\section{References to studies included in this review}

Berliner 1996 \{published data only\}

Berliner L, Saunders BE. Treating fear and anxiety in sexually abused children: results of a controlled 2-year follow-up study. Child Maltreatment 1996;1(4):294-309.

\section{Burke 1988 \{unpublished data only\}}

Burke MM. Short-term Group Therapy for Sexually Abused Girls: A Learning Theory Based Treatment for Negative Affect [Phd dissertation]. Athens, Georgia: University of Georgia, 1988.

\section{Celano 1996 \{published data only\}}

Celano M, Hazzard A, Webb C, McCall C. Treatment of traumagenic beliefs among sexually abused girls and their mothers: an evaluation study. Journal of Abnormal Child Psychology 1996;24(1):1-17.

\section{Cohen 1996 \{published data only\}}

* Cohen JA, Mannarino AP. A treatment outcome study for sexually abused preschool children: initial findings. Journal of the American Academy of Child and Adolescent Psychiatry 1996;35(1):42-50.

Cohen JA, Mannarino AP. A treatment study for sexually abused preschool children: outcome during a one-year follow-up. Journal of the American Academy of Child and Adolescent Psychiatry 1997;36(9):1228-35.

Cohen, JA, Mannarino. AP. Factors that mediate treatment outcome in sexually abused preschool children. Journal of the American Academy of Child and Adolescent Psychiatry. 1996;35(10):1402-10.

\section{Cohen 1998 \{published data only\}}

* Cohen JA, Mannarino AP. Interventions for sexually abused children: initial treatment outcome findings. Child Maltreatment 1998;3(1):17-26.

Cohen JA, Mannarino AP, Knudsen K. Treating sexually abused children: 1 year follow-up of a randomized controlled trial. Child Abuse \& Neglect 2005;29(2):135-45.

Cohen 2004 \{published data only\}

* Cohen JA, Deblinger E, Mannarino AP, Steer RA. A multisite, randomized controlled trial for children with sexual abuserelated PTSD symptoms. Journal of the American Academy of Child and Adolescent Psychiatry 2004;43(4):393-402.

Deblinger E, Mannarino AP, Cohen JA, Steer RA. A followup study of a multisite, randomized controlled trial for children with sexual abuse-related PTSD symptoms. Journal of the American Academy of Child and Adolescent Psychiatry 2006;45(12):1474-84.

\section{Deblinger 1996 \{published data only\}}

Deblinger E, Lippman J, Steer R. Sexually abused children suffering post traumatic stress symptoms. Child Maltreatment 1996;1(4):310-21.
* Deblinger E, Steer R, Lippman J. Two-year follow-up study of cognitive behavioral therapy for sexually abused children suffering post-traumatic stress symptoms. Child Abuse and Neglect 1999;23(12):1371-8.

\section{Deblinger 2001 \{published data only\}}

Deblinger E, Stauffer LA, Steer RA. Comparative efficacies of supportive and cognitive behavioral group therapies for young children who have been sexually abused and their nonoffending mothers. Child Maltreatment 2001;6(4):332-43.

Dominguez 2001 \{unpublished data only\}

* Dominguez RZ. Evaluation of Cognitive-Behavioral and Supportive Treatments for Sexually Abused Children: Analyzing the Process of Change Using Individual Growth Curve Analyses [Phd dissertation]. Houston TX: University of Houston, 2001.

\section{King 2000 \{published data only\}}

King NJ, Tonge BJ, Mullen P, Myerson N, Heyne D, Rollings S, et al. Treating sexually abused children with posttraumatic stress symptoms: a randomized clinical trial. Journal of the American Academy of Child and Adolescent Psychiatry 2000;39(11):1347-55.

\section{References to studies excluded from this review}

Downing 1988 \{published data only\}

Downing J, Jenkins SJ, Fisher GL. A comparison of psychodynamic and reinforcement treatment with sexually abused children. Elementary School Guidance and Counseling 1988;22(4):291-8

\section{Jaberghaderi 2004 \{published data only\}}

Jaberghaderi N, Greenwald R, Rubin A, Zand SO, Dolatabadi S. A comparison of CBT and EMDR for sexually abused Iranian girls. Clinical Psychology and Psychotherapy 2004;11:358-68.

\section{Verleur 1986 \{published data only\}}

Verleur D, Hughes RE, Dobkin de Rios M. Enhancement of selfesteem among female adolescents incest victims: a controlled comparison. Adolescence 1986;21(84):843-54.

\section{References to studies awaiting assessment}

Lewis 2010 \{published data only\}

Lewis CC, Simons AD, Nguyen LJ, Murakami JL, Reid MW, Silva SG, et al. Impact of childhood trauma on treatment outcome in the treatment for adolescents with depression study (TADS). Journal of the American Academy of Child and Adolescent Psychiatry 2010;49(2):132-40.

\section{Additional references}

\section{Achenbach 1991}

Achenbach TM. Manual for the Child Behavior Checklist/4-18 and 1991 Profile. Burlington VT: University of Vermont Department of Psychiatry, 1991. 


\section{Andeson 2008}

Anderson SL, Tomada A, Vincow ES, Valente E, Polcari A, Teicher $\mathrm{MH}$. Preliminary evidence for sensitive periods in the effect of childhood sexual abuse on regional brain development. Journal of Neuropsychiatry and Clinical Neurosciences 2008;20:292-301.

\section{Andrews 2004}

Andrews G, Corry J, Slade T, Issakidis C, Swanston H. Child sexual abuse. Comparative Quantification of Health Risks: Global and Regional Burden of Disease Attributable to Selected Major Risk Factors. Vol. 2, Geneva, Switzerland: WHO, 2004.

\section{APA 1987}

American Psychiatric Association. Diagnostic and Statistical Manual of Mental Disorders, 3rd Edition-revised (DSM III-R). Washington DC: APA, 1987.

\section{Banyard 2004}

Banyard VL, Williams LM, Siegal JA. Childhood sexual abuse: A gender perspective on context and consequences. Child Maltreatment 2004;9(3):223-38.

\section{Beck 1996}

Beck AT, Steer RA, Brown GK. Manual for the Beck Depression Inventory II. San Antonio, TX: Psychological Corporation, 1996.

\section{Beech 2009}

Beech AR, Craig LA, Browne KD (eds). Assessment and Treatment of Sex Offenders. Chichester: John Wiley, 2009.

\section{Briere 1996}

Briere J. Trauma Symptom Checklist for Children. Odessa, FL: Psychological Assessment Resources, 1996.

\section{Celano 1992}

Celano M, Webb C, Hazzard A. Parental attributions of responsibility for child sexual abuse. Paper presented at the National Symposium on Child Victimization. Washington, DC: NSCV, 1992 (May).

\section{Cohen 1991}

Cohen J, Mannarino AP. Trauma-focused CBT for sexually abused preschoolers.. Trauma-focused CBT for sexually abused preschool children. University of Pittsburgh, School of Medicine: Pittsburgh, PA: Unpublished Manuscript, 1991.

\section{Cohen 1994}

Cohen J, Mannarion AP. Trauma-focused CBT treatment manual for children and adolescents. Pittsburgh, PA: MCP-Hahnemann University, School of Medicine, 1994.

\section{Cohen 2000}

Cohen JA, Berliner L, Mannarno P. Treating traumatized children: a research review and synthesis. Trauma, Violence, and Abuse 2000;1(1):29-46.

\section{Cohen 2005}

Cohen JA, Mannarino AP, Knudsen K. Treating sexually abused children: 1 year follow-up of a randomized controlled trial. Child Abuse \& Neglect 2005;29(2):135-45.

\section{Cohen 2005b}

Cohen JA. Treating traumatized children: current status and future directions. Journal of Trauma Dissociation 2005;6(2):109-21.

\section{Cohen 2006}

Cohen JA, Mannarino AP, Deblinger E. Treating Trauma and Traumatic Grief in Children and Adolescents. New York: The Guilford Press, 2006.

\section{Corcoran 2008}

Corcoran J, Pillai V. A meta-analysis of parent-involved treatment for child sexual abuse. Research on Social Work Practice 2008;18(5):453-64.

\section{Currie 2006}

Currie J, Tekin E. Does Child Abuse Cause Crime?. Working Paper 06-31, Andrew Young School of Policy Studies April 2006.

\section{Cutajar 2010}

Cutajar MC, Mullen PE, Ogloff JRP, Thomas SD, Wells DL, Spataro J. Psychopathology in a large cohort of sexually abused children followed up to 43 years. Child Abuse and Neglect 2010;34:813-22.

\section{Davis 2002}

Davis JL, Combs-Lane AM, Jackson TL. Risky behaviors associated With interpersonal victimization. Comparisons Based on type, number, and characteristics of assault incidents. Jounral of Interpersonal Violence 2002;17(6):611-29.

\section{de Medeiros Passarela 2010}

de Medeiros Passarela C, Mendes DD, de Jesus Mari J. A systematic review to study the efficacy of cognitive behavioral therapy for sexually abused children and adolescents with posttraumatic stress disorder. Revista de Psiquiatria Clínica 2010;37(2):60-5.

\section{Deblinger 1996a}

Deblinger E, Hope Heflin A. Treating Sexually Abused Children and their Nonoffending Parents: A Cognitive Behavioral Approach. Thousand Oaks, California: Sage, 1996.

\section{Deblinger 2006}

Deblinger E, Mannarino AP, Cohen JA, Steer RA. A followup study of a multisite, randomized controlled trial for children with sexual abuse-related PTSD symptoms. Journal of the American Academy of Child and Adolescent Psychiatry 2006;45(12):1274-84.

\section{Dube 2005}

Dube SR, Anda RF, WHitfield CL, Brown DW, Felitti VJ, Dong M, et al. Long-term consequences of childhood sexual abuse by gender of victim. American Journal of Preventive Medicine 2005;28(5):430-8.

\section{Eilliot 1995}

Eilliot M, Browne K, Kilcoyne J. Child sexual abuse prevention: What offenders tell us. Child Abuse and Neglect 1995;19:579-94. 


\section{Everson 1989}

Everson MD, Hunter WM, Runyon DK, Edelsohn GA, Coulter ML. Maternal support following disclosure of incest. American Journal of Orthopsychiatry 1989;59(2):197-207.

\section{Farmer 1998}

Farmer E, Pollock S. Sexually Abused and Abusing Children in Substitute Care. Chichester: Wiley, 1998.

\section{Fergusson 1999}

Fergusson DM, Mullen PE. Childhood Sexual Abuse: An Evidence Based Perspective. Thousand Oaks: Sage, 1999.

\section{Fergusson 2008}

Fergusson DM, Boden JM, Horwood LJ. Exposure to childhood sexual and physical abuse and adjustment in early adulthood. Child Abuse and Neglect 2008;32:607-19.

\section{Finkelhor 1994}

Finkelhor D. The international epidemiology of child sexual abuse: an update. Child Abuse and Neglect 1994;18(5):409-17.

\section{Finkelhor 1995}

Finkelhor D, Berliner L. Research on the treatment of sexually abused children: a review and recommendations. Journal of the American Academy of Child and Adolescent Psychiatry 1995;34(11):1408-23.

\section{Flannery-Schreder 2005}

Flannery-Schroeder E, Choudhury MS, Kendall PC. Group and individual cognitive-behavioral treatments for youth with anxiety disorders: 1-year follow-up. Cognitive Therapy and Research 2005;29(2):253-9.

\section{Friedrich 1986}

Friedrich WN, Urquiza AJ, Beilke RL. Behaviour problems in sexually abused young children. Journal of Pediatric Psychology 1986;11(1):47-57.

\section{Friedrich 1992}

Friedrich WN, Grambsch P, Damon L, et al. Child Sexual Behavior Inventory: normative and clinical comparisons. Psychological Assessment 1992;4(3):303-11.

\section{Gilbert 2009}

Gilbert R, Spatz-Widom C, Browne K, Fergusson D, Webb E, Janson S. Burden and consequences of child maltreatment in high-income countries. Lancet 2009;373(9657):68-81.

\section{Green 1993}

Green AH. Child sexual abuse: immediate and long term effects and intervention. Journal of the American Academy of Child and Adolescent Psychiatry 1993;32(5):890-902.

\section{Grubin 1998}

Grubin D. Sex offending against children: Understanding the risk. London: Home Office, 1998.

\section{Hahn 2008}

Hahn RA. Recommendation to reduce psychological harm from traumatic events among children and adolescents. American Journal of Preventive Medicine 2008;35(3):314-6.

\section{Harrington 1998}

Harrington R, Wood A, Verduyn C. Clinically depressed adolescents. In: Graham P editor(s). Cognitive-Behaviour Therapy for Children and Families. Cambridge: Cambridge University, 1998.

\section{Harvey 2010}

Harvey ST, Taylor JE. A meta-analysis of the effects of psychotherapy with sexually abused children and adolescents. Clinical Psychology Review 2010;30:517-535.

\section{Higgins 2008}

Higgins JPT, Green S (editors). Cochrane Handbook for Systematic Reviews of Interventions. Chichester: WileyBlackwell, 2008.

\section{Horowitz 1979}

Horowitz M, Wilner N, Alvarez W. Impact of Events Scale: a measure of subjective stress. Psychometric Medicine 1979;41(3):209-18

\section{Hubbard 2002}

Hubbard DJ, Pratt TC. A meta-analysis of the predictors of delinquency among girls. Journal of Offender Rehabilitation 2002;34(3):1-13.

\section{Jackowski 2009}

Jackowski AP, de Araujo CM, de Lacerda ALT, de Jesus Mari, J, Kaufman J. Neurostructural imaging findings in children with post-traumatic stress disorder: Brief review. Psychiatry and Clinical Neurosciences 2009;63:1-8.

\section{Jespersen 2009}

Jesperson AF, Lalumiere MF, Seto MC. Sexual abuse history among adult sex offenders and non-sex offenders: A metaanalysis. Child Abuse and Neglect 2009;33:179-92.

\section{Jonas 2011}

Jonas S, Bebbington P, McManus S, Meltzer JH, Jenkins R, Kuipers E, et al. Sexual abuse and psychiatric disorder in England: results from the 2007 Adult Psychiatric Morbidity Survey. Psychological Medicine 2011;41(4):709-19.

\section{Jones 1999}

Jones DPH, Ramchandani P. Child sexual Abuse: Informing Practice from Research. Abingdon: Radcliffe Medical Press, 1999.

\section{Kaufman 1997}

Kaufman J, Birmaher B, Brent D, Rao U, Flynn C, Moreci P, et al. Schedule for affective disorders and schizophrenia for schoolage children - present and lifetime version (K-SADS-PL). Journal of the American Academy of Child and Adolescent Psychiatry 1997;36(7):980-8. 


\section{Kaufman 1998}

Kaufman KL, Holmberg DR, Orts KA, McCrady FE, Rotzien AL, Daleiden EL, et al. Factors influencing sexual offenders' modus operandi: An examination of victim-offender relatedness and age. Child Maltreatment 1998;3(4):349-61.

\section{Kazdin 1989}

Kazdin AE. Cognitive-behavioural therapy and relationship therapy in the treatment of children referred for antisocial behavior. Journal of Consulting and Clinical Psychology 1989;57(4):522-35.

\section{Kendall 1994}

Kendall PC. Treating anxiety disorders in children: results of a randomized clinical trial. Journal of Consulting and Clinical Psychology 1994;62(1):100-10.

\section{Kendall-Tackett 1993}

Kendall-Tackett KA, Meyer-Williams L, Finkelhor D. Impact of sexual abuse on children: a review and synthesis of recent empirical studies. Psychological Bulletin 1993;113(1):164-80.

\section{Kleinknecht 1988}

Kleinknecht RA, Bernstein DA. Fear thermometer. In: Hersen $\mathrm{M}$, Bellach A editor(s). Dictionary of Behavioral Assessment Techniques. New York: Pergamon, 1988:220-1.

\section{Kovacs 1981}

Kovacs M. Rating scales to assess depression in school-age children. Acta Paedopsychiatrica 1981;46(5-6):305-15.

\section{Mannarino 1994}

Mannarino AP, Cohen JA, Berman SR. The children's attributions and perceptions scale: A new measure of sexual abuse-related factors. Journal of Clinical Child Psychology 1994;23(2):204-11.

\section{Mannarino 1996}

Mannarino AP, Cohen JA. Family related variables and psychological system formation in sexually abused girls. Journal of Child Sexual Abuse 1996;5:105-19.

\section{Molnar 2001}

Molnar BE, Buka SL, Kessler RC. Child sexual abuse and subsequent psychopathology: results from the National Comorbidity Survey. American Journal of Public Health 2001;91(5):753-60.

\section{Muris 2009}

Muris P, Mayer B, den Adel M, Roos T, Van Wamelen J. Predictors of change following cognitive-behavioral treatment of children with anxiety problems: A preliminary investigation on negative automatic thoughts and anxiety control. Child Psychiatry and Human Development 2008;40:139-51.

\section{Nelson 2002}

Nelson EC, Heath AC, Madden PA, Cooper ML, Dinwiddie SH, Bucholz KK, et al. Association between self-reported childhood sexual abuse and adverse psychosocial outcomes: results from a twin study. Archives of General Psychiatry 2002;59(2):139-45.

\section{Oates 1994}

Oates RK, O'Toole BI, Lunch D, Stern A, Cooney G. Stability and change in outcomes for sexually abused children. Journal of the American Academy of Child and Adolescent Psychiatry 1994;33(7):945-53.

\section{Ollendick 1983}

Ollendick TH. Reliability and validity of the revised fear survey schedule for children. Behavior Research and Therapy 1983;21(6):685-92.

\section{Orvaschel 1982}

Orvaschel H, Puig-Antich J, Chambers W, Tabrizi MA, Johnson R. Retrospective assessment of child psychopathology with the Kiddie-SADS-E. Journal of the American Academy of Child Psychiatry 1982;21(4):392-7.

\section{Orvaschel 1994}

Orvaschel H. Schedule for Affective Disorders and Schizophrenia for School-Aged Children - Epidemiologic Version 5 (K-SADS-E) [unpublished instrument]. Fort Lauderdale, FL: Nova Southeastern University, 1994.

\section{Pereda 2009}

Pereda N, Guilera G, Forns M, Gómez-Benito J. The international epidemiology of child sexual abuse: A continuation of Finkelhor (1949). Child Abuse \& Neglect 2009;33(6):331-42.

\section{Prentky 1996}

Prentky RA. A rationale for the treatment of sex offenders: Pro Bono Publico. In: J McGuire editor(s). What works: Reducing Reoffending. Guidelines from Research and Practice. Chichester: John Wiley \& Sons, 1996.

\section{Puttnam 2003}

Puttnam FW. Ten-year research update review: child sexual abuse. Journal of the American Academy of Child and Adolescent Psychiatry 2003;42(3):269-78.

\section{RevMan 5 [Computer program]}

The Nordic Cochrane Centre, The Cochrane Collaboration. Review Manager (RevMan). Version 5.1. Copenhagen: The Nordic Cochrane Centre, The Cochrane Collaboration, 2011.

\section{Reynolds 1978}

Reynolds CR, Richmond CO. What I think and feel: a revised measure of children's manifest anxiety. Journal of Abnormal Child Psychology 1978;6(2):271-80.

\section{Shaffer 1983}

Shaffer D, Gould MS, Ambrosini P, Fisher P, Bird H, Aluwahila S. A children's global assessment scale (CGAS). Archives of General Psychiatry 1983;40(11):1228-31.

\section{Shenk 2010}

Shenk CE, Noll JG, Putnam FW, Trickett PK. A prospective examination of the role of childhood sexual abuse and physiological asymmetry in the development of psychopathology. Child Abuse and Neglect 2010;34(10):752-61. 


\section{Silverman 1996}

Silverman WK, Albano AM. Anxiety Disorders Interview Schedule for DSM-IV, Child and Parent Versions. San Antonio, TX: Psychological Corporation, 1996.

\section{Skuse 1998}

Skuse D, Bentovim A, Hodges J, Stevenson J, Andreou C, Lanyado M, et al. Risk factors for the development of sexually abusive behaviour in sexually victimised adolescent males: cross sectional study. BMJ 1998;317(7152):175-9.

\section{Smucker 1986}

Smucker MN, Craighead WE, Craighead LW, Green BJ. Normative and reliability data for the Children's Depression Inventory. Journal of Abnormal Child Psychology 1986;14(1):25-39.

\section{Spielberger 1973}

Spielberger CD. Manual for the State-Trait Anxiety Inventory for Children. Palo Alto, CA: Consulting Psychologists Press, 1973.

\section{Stevenson 1999}

Stevenson J. The treatment of long-term sequelae of child abuse. Journal of Child Psychology and Psychiatry 1999;40(1):89-111.

\section{Strayhorn 1988}

Strayhorn JM, Weidman CS. A parent practices scale and its relation to parent and child mental health. Journal of the American Academy of Child and Adolescent Psychiatry 1988;27(5):613-8.

\section{Swanston 2003}

Swanston HY, Plunkett AM, O'Toole BI, Shrimpton S, Parkinson PN, Oates RK. Nine years after child sexual abuse. Child Abuse \& Neglect 2003;27(8):967-84.

\section{Tebutt 1997}

Tebutt J, Swanston H. Five years after child sexual abuse: persisting dysfunction and problems of prediction. Journal of the American Academy of Child and Adolescent Psychiatry 1997;36(3):330-9.

\section{Teicher 2003}

Teicher MH, Andersen SL, Polcari A, Anderson CM, Navalta CP, Kim DM. The neurobiological consequences of early stress and childhood maltreatment. Neuroscience and Biobehavioral Reviews 2003;27(1-2):33-44.

\section{CHARACTERISTICS OF STUDIES}

Characteristics of included studies [ordered by study ID]

\section{Thornberry 2010}

Thornberry TP, Henry KL, Ireland TO, Smith CA. The causal impact of childhood-limited maltreatment and adolescent maltreatment on early adult adjustment. Journal of Adolescent Health 2010;46:359-65.

\section{Trask 2011}

Trask EV, Walsh K, DiLillo D. Treatment effects for common outcomes of child sexual abuse: A current meta-analysis. Aggression and Violent Behavior 2011;16:6-19.

\section{Trickett 1997}

Trickett PK. Sexual and physical abuse and the development of social competence. In: Luthar SS, Burack JA, Cicchetti D, Weisz JR editor(s). Developmental Psychopathology: Perspectives on Adjustment, Risk and Danger. New York: Cambridge University Press, 1997.

\section{Twenge 2002}

Twenge JM, Nolen-Hoeksema S. Age, gender, race, socioeconomic status, and birth cohort differences on the Children's Depression Inventory: a meta-analysis. Journal of Abnormal Psychology 2002;111:578-88.

\section{Wolfe 1986}

Wolfe VV, Wolfe DA. The Sexual Abuse Fear Evaluation (SAFE): a subscale for the Fear Survey Schedule for Children - Revised. Unpublished questionnaire. London, Ontario: University of Western Ontario, 1986.

\section{Wolfe 1991}

Wolfe VV, Gentile C, Michienzi T, Sas L, Wolfe DA. Children's Impact of Traumatic Events Scale: a measure of postsexual abuse PTSD symptoms. Behavioural Assessment 1991;13(4):359-83.

\section{References to other published versions of this review \\ Macdonald 2006}

Macdonald G, Higgins JPT, Ramchandani P. Cognitivebehavioural interventions for children who have been sexually abused. Cochrane Database of Systematic Reviews 2006, Issue 4. [DOI: 10.1002/14651858.CD001930.pub2]

* Indicates the major publication for the study

Berliner 1996

\begin{tabular}{ll}
\hline Methods & RCT \\
\hline Participants & 154 sexually abused children aged 4-13. \\
& 103 completed the post-treatment assessments. \\
87 completed the 1-year follow-up.
\end{tabular}


Berliner 1996 (Continued)

80 completed the 2 -year follow-up assessment. 87 ( $84.5 \%$ of treatment completers) completed the 1year follow-up.

Interventions

Control group ( $\mathrm{n}$ randomised unclear): Ten sessions covering: getting acquainted and establishing ground rules; feelings; family and friends ( 2 sessions); disclosure impact, self-esteem and sexual abuse; body awareness and sexuality ( 2 sessions), and prevention and termination.

Experimental group ( $\mathrm{n}$ randomised unclear): as for the Control group with:

i) a specific focus on explaining fear in the feelings session; (ii) the replacement of one of the family and friends sessions with one on Stress Inoculation Therapy (SIT),

(iii) two sessions devoted to gradual exposure, and (iv) the application of SIT principles to sessions on disclosure impact and self-esteem.

Outcomes Assessed at post-treatment; 1-year follow-up and 2-year follow-up.

Fear: the Fear Survey Schedule for Children-Revised (FSSC-Revised); the Sexual Abuse Fear Evaluation Scales (SAFE) and the Revised Children's Manifest Anxiety Scale (RCMAS).

Behaviour: externalising (Child Behaviour Checklist-CBCL); internalising (CBCL); Social Competence $(\mathrm{CBCL})$; Total Behavior Problem (CBCL). Depression: Children's Depression Inventory (CDI). Sexual Behaviour: Children's Sexual Behavior Inventory (CSBI).

Depression (Children's Depression Inventory - CDI).

Sexual behaviour (Child Sexual Behavior Inventory (CSBI).

Other data were collected via a Parent Information and Therapist Information form.

Notes Random numbers table generated at the beginning of the project.

Overall loss of 74 children from recruitment to final assessment period. There appears to be differential attrition between groups and across outcome measures.

One assumes more loss in the comparison group (which ended up with 32) than in the intervention group (final sample 48) but this is supposition.

\section{Risk of bias}

\begin{tabular}{|c|c|c|}
\hline Bias & Authors' judgement & Support for judgement \\
\hline $\begin{array}{l}\text { Random sequence genera- } \\
\text { tion (selection bias) }\end{array}$ & Low risk & Used a random numbers table generated at the beginning of the project. \\
\hline $\begin{array}{l}\text { Allocation concealment } \\
\text { (selection bias) }\end{array}$ & Low risk & $\begin{array}{l}\text { "Assigned therapists and other staff were blind to the random assignment } \\
\text { schedule" (p. 299). }\end{array}$ \\
\hline $\begin{array}{l}\text { Blinding (performance } \\
\text { bias and detection bias) } \\
\text { All outcomes }\end{array}$ & High risk & All measures were either self- or parent-reported. \\
\hline $\begin{array}{l}\text { Incomplete outcome data } \\
\text { (attrition bias) } \\
\text { All outcomes }\end{array}$ & Unclear risk & $\begin{array}{l}\text { Data are reported only on } 80 \text { (of } 154 \text { total) children who completed at least } \\
\text { eight sessions and also completed at least one outcome measure at both of } \\
\text { the follow-up assessment points. The authors conducted statistical tests com- } \\
\text { paring baseline characteristics of treatment completers and non-completers, } \\
\text { and did not find statistically significant differences. However, these analyses } \\
\text { were likely not conducted with high statistical power to detect meaningful dif- } \\
\text { ferences, and the authors did not report data that would allow for computa- } \\
\text { tion of effect sizes comparing participants who had dropped out and those } \\
\text { who did not. The authors also conducted statistical tests examining the base- } \\
\text { line characteristics of completers lost to follow-up and those contributing da- } \\
\text { ta to the study. In these analyses, completers contributing data to the study } \\
\text { had statistically significantly higher scores on the CBCL (total score), but no } \\
\text { other statistically significant differences emerged. Again however these analy- } \\
\text { ses were likely not conducted with high statistical power to detect meaningful } \\
\text { differences, and the authors did not report data that would allow for compu- } \\
\text { tation of effect sizes comparing participants who had dropped out and those }\end{array}$ \\
\hline
\end{tabular}


Berliner 1996 (Continued)

who did not. Finally, the authors compared baseline characteristics of the 80 treatment and control participants contributing data to the study, and found no statistically significant differences. Here, the authors did provide data that would allow for the computation of effect sizes illustrating the magnitude of differences between the two groups. In general, differences are small and favour the comparison group (i.e., the completers in the comparison group were slightly better off at baseline), with SMDs ranging from -..42 to +.39 (mean $=+.03$ ). This suggests that, on balance, the treatment and comparison groups were comparable on measured baseline characteristics, although their comparability on unmeasured characteristics is unclear (this is especially worrisome given the magnitude of attrition).

\begin{tabular}{lll}
\hline $\begin{array}{l}\text { Selective reporting (re- } \\
\text { porting bias) }\end{array}$ & Low risk & All measured outcomes appear to have been reported. \\
\hline Other bias & Unclear risk & $\begin{array}{l}\text { The protocol identified no additional potentially biasing factors for coding and } \\
\text { analysis. }\end{array}$
\end{tabular}

Burke 1988

\begin{tabular}{ll}
\hline Methods & RCT \\
\hline Participants & 25 sexually abused girls aged 8-13 \\
\hline Interventions & $\begin{array}{l}\text { Experimental group ( } \mathrm{n} \text { randomised }=12) \text { : Six group sessions comprising: Good and bad touching; relax- } \\
\text { ation and education about anxiety; review of relaxation homework; imaginal exposure and identifying } \\
\text { times or situations when participants felt depressed, identifying pleasurable events and 'making one- } \\
\text { self' engage in them; and developing strategies for actively dealing with anxiety provoking interactions } \\
\text { with anyone who might attempt 'bad touching'. } \\
\text { Control group ( } \mathrm{n} \text { randomised }=13 \text { ): wait list control. }\end{array}$ \\
\hline
\end{tabular}

Outcomes Assessed at post-treatment and 6 weeks follow-up.

Depression: Children's Depression Inventory (CDI). Anxiety: Revised Manifest Anxiety Scale (RCMAS). Fear: Fear Survey Schedule for Children-Revised (FSSC-Revised). Behaviour: Internalising (Child Behavior Checklist - CBCL).

Anxiety (Revised Children's Manifest Anxiety Scale - RCMAS).

Fear (Revised Fear Survey Schedule - FSSC-R).

Internalising behaviour (Child Behaviour Checklist - $\mathrm{CBCL}$ ).

Notes Not clear how participants were randomised.

Study report says participants were randomly assigned within the matching constraints of age, type of abuse and amount of force used.

\section{Risk of bias}

\begin{tabular}{lll}
\hline Bias & Authors' judgement & Support for judgement \\
\hline $\begin{array}{ll}\text { Random sequence genera- } \\
\text { tion (selection bias) }\end{array}$ & Unclear risk & "Assignment to groups was random" (p. 31). No specifics given. Report states \\
& additionally that a constraint was imposed on randomisation requiring "that \\
& treatment subjects were matched with waiting list subjects" on age, type of \\
& abuse, and type of force used during abuse. Unclear if this means that a strati- \\
& fied random assignment scheme was used (possibly suggested on p. 35), or if it \\
& means something else.
\end{tabular}

$\begin{aligned} & \text { Allocation concealment } \\ & \text { (selection bias) }\end{aligned}$ High risk Not described, and unlikely to have been used.


Burke 1988 (Continued)

Blinding (performance High risk Not described. Most measures were self-report, and blinding was not disbias and detection bias) cussed for the CBP.

All outcomes

\begin{tabular}{lll}
$\begin{array}{l}\text { Incomplete outcome data } \\
\text { (attrition bias) } \\
\text { All outcomes }\end{array}$ & Low risk & $\begin{array}{l}\text { Study does not report that attrition occurred. Randomisation of 25 persons } \\
\text { was reported, and analyses were conducted with a sample size of } 25 .\end{array}$ \\
\hline $\begin{array}{l}\text { Selective reporting (re- } \\
\text { porting bias) }\end{array}$ & Low risk & All measured outcomes seem to be fully reported. \\
\hline Other bias & Unclear risk & $\begin{array}{l}\text { The protocol identified no additional potentially biasing factors for coding and } \\
\text { analysis. }\end{array}$ \\
\hline
\end{tabular}

\section{Celano 1996}

\begin{tabular}{ll}
\hline Methods & RCT \\
\hline Participants & $\begin{array}{l}49 \text { sexually abused girls aged 8-13 and their (non-offending) female caretakers. } \\
32 \text { completed post-treatment assessments. }\end{array}$
\end{tabular}

Interventions Assessed at post-treatment only.

Experimental group ( $\mathrm{n}$ randomised $=25$ ): Recovering from Abuse Program (RAP) - eight group sessions focused on children's maladaptive beliefs, affects and behaviour along four dimensions - self-blame/ stigmatisation; betrayal; traumatic sexualisation and powerlessness.

Control group $(n=24)$. Treatment as Usual (TAU) defined as supportive, unstructured psychotherapy that sexually abused children and their mothers would normally receive at the clinic.

Outcomes

CHILDREN: Behaviour: Internalising (Child Behavior Checklist - CBCL); Externalising (CBCL). PTSD: Children's Impact of Traumatic Events Scales-Revised (CITES-R); PTSD Subscale of the CBCL. Overall psychosocial functioning: Children's Global Assessment Scale (CGAS).

Behaviour (Child Behavior Checklist - CBCL); Children's Impact of Traumatic Events Scales - Revised (CITES-R); Children's Global Assessment Scale (CGAS).

PARENTS: Parents Reaction to Incest Disclosure Scale (PRIDS); Parental Attribution Score (PAS).

Notes

\section{Risk of bias}

\begin{tabular}{lll}
\hline Bias & Authors' judgement & Support for judgement \\
\hline $\begin{array}{l}\text { Random sequence genera- } \\
\text { tion (selection bias) }\end{array}$ & Unclear risk & $\begin{array}{l}\text { "Subjects were randomly assigned to either the experimental program or the } \\
\text { treatment-as-usual condition." No other specifics given. }\end{array}$ \\
\hline $\begin{array}{l}\text { Allocation concealment } \\
\text { (selection bias) }\end{array}$ & High risk & Not described, and unlikely to have been done. \\
\hline $\begin{array}{l}\text { Blinding (performance } \\
\text { bias and detection bias) }\end{array}$ & High risk & $\begin{array}{l}\text { The CGAS was completed by a psychiatrist blinded to condition. No other out- } \\
\text { comes were blinded. }\end{array}$ \\
\hline $\begin{array}{l}\text { Incomplete outcome data } \\
\text { (attrition bias) } \\
\text { All outcomes }\end{array}$ & Unclear risk & $\begin{array}{l}\text { Although not entirely clear, it seems that two eligible families dropped out of } \\
\text { the study before treatment began, and another 15 dropped out after assign- } \\
\text { ment to conditions occurred. The authors state that "t-tests and chi-square } \\
\text { analyses comparing subjects who dropped out and subjects who completed }\end{array}$ \\
\hline
\end{tabular}


treatment did not reveal significant differences", but these analyses were likely not conducted with high statistical power to detect meaningful differences, and the authors did not report data that would allow for computation of effect sizes comparing participants who had dropped out and those who did not. In addition, some outcomes were not completed by all participants (completion rates ranged from $81 \%$ to $100 \%)$.

\begin{tabular}{lll}
\hline $\begin{array}{l}\text { Selective reporting (re- } \\
\text { porting bias) }\end{array}$ & Low risk & All measured outcomes seem to be fully reported. \\
\hline Other bias & Unclear risk & $\begin{array}{l}\text { The protocol identified no additional potentially biasing factors for coding and } \\
\text { analysis. }\end{array}$
\end{tabular}

\section{Cohen 1996}

Methods $\quad$ RCT with therapist cross-over design, to control for the possibility that a particularly effective therapist
in one type of treatment might unduly influence the results.

Participants
86 sexually abused children aged 3-6 and their (non-offending) parent.
63 children completed post-treatment assessments.
43 completed all follow-up assessments.

Interventions Experimental group ( $\mathrm{n}$ randomised is unclear): Cognitive-behavioural therapy for sexually abused children (CBT-SAP).

Control ( $\mathrm{n}$ randomised is unclear): Non-directive supportive therapy (NST).

Outcomes
Assessed at post-treatment, 6 months and 1 year follow-up.
Child behaviour: externalising (Child Behaviour Checklist-CBCL); internalising (CBCL); Social Com-
petence (CBCL); Weekly Behavior Record (WBR). Sexual Behaviour: Child Sexual Behavior Inventory
(CSBI).

Notes Used the 4-11 CBCL although some children were 3 at first measurement.

\section{Risk of bias}

\begin{tabular}{lll}
\hline Bias & Authors' judgement & Support for judgement \\
\hline $\begin{array}{l}\text { Random sequence genera- } \\
\text { tion (selection bias) }\end{array}$ & Low risk & "randomized with the use of Efron's biased coin toss" (p. 45). \\
\hline $\begin{array}{l}\text { Allocation concealment } \\
\text { (selection bias) }\end{array}$ & High risk & Not described, and probably not done. \\
\hline $\begin{array}{l}\text { Blinding (performance } \\
\text { bias and detection bias) }\end{array}$ & High risk & No measures were assessed by blinded assessors. \\
\hline $\begin{array}{l}\text { All outcomes } \\
\text { (attrition bias) } \\
\text { All outcomes }\end{array}$ & $\begin{array}{l}\text { Unclear risk } \\
\text { This study experienced attrition. Of 86 participants recruited for the study, six } \\
\text { dropped out after completing one or two sessions, seven dropped out after } \\
\text { completing three to eight sessions, and six participants were removed due to } \\
\text { inappropriate behaviour during sessions. The authors conducted statistical } \\
\text { tests comparing characteristics of treatment completers relative to non-com- } \\
\text { pleters. There were no statistically significant differences, except that com- } \\
\text { pleters tended to be from families of lower socioeconomic status. These analy- } \\
\text { ses however were likely not conducted with high statistical power to detect }\end{array}$
\end{tabular}


Cohen 1996 (Continued)

meaningful differences, and the authors did not report data that would allow for computation of effect sizes comparing completers to non-completers.

\begin{tabular}{|c|c|c|}
\hline $\begin{array}{l}\text { Selective reporting (re- } \\
\text { porting bias) }\end{array}$ & Low risk & $\begin{array}{l}\text { Some measures were collected but not reported. According to the authors } \\
\text { "The second category of instruments, which measured possible mediating fac- } \\
\text { tors in symptom persistence and treatment response, was not included be- } \\
\text { cause of space constraints" (p. 44). It is unlikely that this reporting choice af- } \\
\text { fected the outcomes that are relevant to this review, however, as all relevant } \\
\text { measured outcomes seem to have been reported. }\end{array}$ \\
\hline Other bias & Unclear risk & $\begin{array}{l}\text { The protocol identified no additional potentially biasing factors for coding and } \\
\text { analysis. }\end{array}$ \\
\hline
\end{tabular}

\begin{tabular}{|c|c|}
\hline Methods & $\mathrm{RCT}$ \\
\hline Participants & $\begin{array}{l}82 \text { sexually abused children aged } 7-15 \text {. } \\
49 \text { children competed post-treatment assessments. }\end{array}$ \\
\hline Interventions & $\begin{array}{l}\text { Experimental group ( } \mathrm{n} \text { randomised }=41 \text { ): Sexual Abuse Specific Cognitive behavioural therapy. For the } \\
\text { child the focus was on depression, anxiety and associated behavioural difficulties. For the parent it fo- } \\
\text { cused on parental emotional distress and enhancing emotional support and behaviour management. } \\
\text { Control Group ( } \mathrm{n} \text { randomised }=41 \text { ): non-specific therapy (NST) which did not provide suggestions or } \\
\text { directive advice, but encouraged exploration of alternative attributions, behaviours and feelings via } \\
\text { nondirective interventions. } \\
12 \times \text { weekly sessions, } 45 \text { minutes with the child and } 45 \text { minutes with the parent. }\end{array}$ \\
\hline
\end{tabular}

\begin{tabular}{ll}
\hline Outcomes & Assessed at post-treatment, 6 months and 1 year follow-up. \\
& Child behaviour: internalising (Child Behaviour Checklist-CBCL); Externalising (CBCL); Social Compe- \\
& tence (CBCL). Anxiety: State/Trait Anxiety Inventory for Children (STAIC). Depression: Children's Depres- \\
& sion Inventory (CDI). Sexual Behaviour: Children's Sexual Behaviour Inventory (CSBI). PTSD: Truama \\
& Symptom Checklist for Children (TSCC). Parents: Parent Satisfaction (Parental Satisfaction Question- \\
& niare).
\end{tabular}

\begin{tabular}{ll}
\hline Notes & High attrition rates throughout the study, and not clear from what groups participants dropped out at \\
what stage.
\end{tabular}

\section{Risk of bias}

\begin{tabular}{|c|c|c|}
\hline Bias & Authors' judgement & Support for judgement \\
\hline $\begin{array}{l}\text { Random sequence genera- } \\
\text { tion (selection bias) }\end{array}$ & Low risk & $\begin{array}{l}\text { "Efron's biased coin toss was used to ensure that the two groups were bal- } \\
\text { anced with respect to (a) CBCL Total Behavior Problems, (b) gender, and (c) } \\
\text { age" (p. 22). }\end{array}$ \\
\hline $\begin{array}{l}\text { Allocation concealment } \\
\text { (selection bias) }\end{array}$ & High risk & Not mentioned, and likely not done. \\
\hline $\begin{array}{l}\text { Blinding (performance } \\
\text { bias and detection bias) } \\
\text { All outcomes }\end{array}$ & High risk & No measures were assessed by blinded assessors. \\
\hline $\begin{array}{l}\text { Incomplete outcome data } \\
\text { (attrition bias) } \\
\text { All outcomes }\end{array}$ & Unclear risk & $\begin{array}{l}\text { Four participants dropped out before the start of the study. It is unclear if } \\
\text { these participants were ever assigned to a condition. An additional } 10 \text { dropped } \\
\text { out after completing three or fewer sessions, } 10 \text { dropped out after completing }\end{array}$ \\
\hline
\end{tabular}


4-8 sessions, and 9 participants were removed due to inappropriate behaviour during sessions. The authors conducted statistical tests comparing characteristics of treatment completers relative to non-completers. There were no statistically significant differences. These analyses however were likely not conducted with high statistical power to detect meaningful differences, and the authors did not report data that would allow for computation of effect sizes comparing completers to non-completers.

\begin{tabular}{lll}
\hline $\begin{array}{l}\text { Selective reporting (re- } \\
\text { porting bias) }\end{array}$ & Low risk & All measured outcomes appear to have been reported. \\
\hline Other bias & Unclear risk & $\begin{array}{l}\text { The protocol identified no additional potentially biasing factors for coding and } \\
\text { analysis. }\end{array}$ \\
\hline
\end{tabular}

\section{Cohen 2004}

\begin{tabular}{ll}
\hline Methods & $\begin{array}{l}\text { RCT } \\
\text { Multisite trial }\end{array}$ \\
\hline Participants & 229 sexually abused children aged $8-14$ and their parents/caretakers $(n=189)$. \\
\hline Interventions & $\begin{array}{l}\text { Experimental group }(n=114 \text { randomised). } \\
\text { Control group ( } n=115 \text { randomised). } \\
\text { Each group received } 12 \text { weekly individual sessions of } 45 \text { minutes each for both parent and child. Partici- } \\
\text { pants in the trauma-focused CBT also received } 3 x \text { joint sessions of } 30 \text { minutes. For these sessions, indi- } \\
\text { vidual chid and parent sessions were reduced to } 30 \text { minutes. }\end{array}$ \\
\hline
\end{tabular}

Outcomes Assessed at post-treatment only.

CHILDREN: Behaviour: Internalising (Child Behavior Checklist-CBCL); Externalising (CBCL); Social Competence $(\mathrm{CBCL})$. Depression: Child Depression Inventory (CDI). Sexual Behaviour: Children's Sexual Behavior Inventory (CSBI).

Psychiatric disorders (K-SADS--PL, using PTSD, Psychosis and Substance Use Disorders sections). Perceptions and attributions: Children's Attributions and Perceptions Scale (CAPS). PARENTS: Depression: Beck Depression Inventory (BDI); Emotional Reactions: Parents' Emotional Reactions Questionaire (PERQ). Parenting: Parenting Practices Questionaire (PPQ); Parental Support: Parental Support Questionnaire (revised PSQ).

Notes $\quad$ Although not included as an outcome in this review, comparison group participants were about 1.5 times more likely than treatment group participants to have a post-traumatic stress disorder diagnosis at post-test $(\mathrm{OR}=3.15)$, as rated by blinded, independent assessors. However, this outcome was somewhat reported differently in the 2006 follow-up study (total number of PTSD symptoms instead of meeting diagnostic criteria), and was apparently not assessed by blinded, independent assessors.

\section{Risk of bias}

\begin{tabular}{lll}
\hline Bias & Authors' judgement & Support for judgement \\
\hline $\begin{array}{l}\text { Random sequence genera- } \\
\text { tion (selection bias) }\end{array}$ & Unclear risk & Study simply states that "subjects were randomly assigned" (p. 397). \\
\hline $\begin{array}{l}\text { Allocation concealment } \\
\text { (selection bias) }\end{array}$ & High risk & Not mentioned, and unlikely to have been done. \\
\hline $\begin{array}{l}\text { Blinding (performance } \\
\text { bias and detection bias) }\end{array}$ & High risk & Outcomes used in this review were all based on parent- or self-reports. \\
\end{tabular}


Cohen 2004 (Continued)

All outcomes

Incomplete outcome data Low risk Used a multiple imputation procedure for dropouts.
(attrition bias)

(attrition bias)

All outcomes

Selective reporting (re- Unclear risk
porting bias)

\begin{abstract}
Data for three outcomes measured at 6 and 12 months were censored because their results were not statistically significant. One of these (the Child Sexual Behavior Inventory) was an outcome included in this review. Data for this outcome have been requested from the study authors. However, it is highly unlikely that inclusion of data from this study would change the overall conclusion reached in this review regarding the effects of CBT interventions on child sexual behaviour.
\end{abstract}

$\begin{array}{ll}\text { Other bias Unclear risk } & \begin{array}{l}\text { The protocol identified no additional potentially biasing factors for coding and } \\ \text { analysis. }\end{array}\end{array}$

\section{Deblinger 1996}

\begin{tabular}{|c|c|}
\hline Methods & $\mathrm{RCT}$ \\
\hline Participants & $\begin{array}{l}100 \text { sexually abused children aged } 7-13 \text { suffering post-traumatic stress disorder. } \\
90 \text { children completed post-treatment assessments. } \\
\text { No information on numbers of children completing follow-up assessments. }\end{array}$ \\
\hline Interventions & $\begin{array}{l}\text { Experimental Group } 1 \text { ( } \mathrm{n} \text { randomised }=25 \text { ) - Child Intervention comprising a range of cognitive behav- } \\
\text { ioural methods, including gradual exposure, modelling, education, coping and body safety training. Ex- } \\
\text { perimental Group } 2 \text { ( } \mathrm{n} \text { randomised }=25 \text { ) - Parent Intervention providing mothers with cognitive-behav- } \\
\text { ioural skills to use in responding to their children's fears and avoidance behaviours. } \\
\text { Experimental Group } 3 \text { ( } \mathrm{n} \text { randomised }=25 \text { ) - Combined Parent and Child intervention comprising indi- } \\
\text { vidual sessions with parent and child, and combined sessions designed to facilitate parent-child com- } \\
\text { munication designed, in part, to help continue therapeutic work at home. } \\
\text { Control Group ( } \mathrm{n} \text { randomised }=25 \text { ) - Community control. Participants received information about chil- } \\
\text { dren's symptom patterns and were strongly encouraged to seek therapeutic help. }\end{array}$ \\
\hline
\end{tabular}

Outcomes Assessed at post-treatment, three and six months, and 1 and 2 years follow-up.

CHILDREN Behaviour: Internalising (Child Behavior Checklist-CBCL); Externalising (CBCL). PTSD: PTSD section of the K-SADS-E. Depression: Child Depression Inventory (CDI). Anxiety: Stait-Trait Anxiety Inventory for Children (STAIC).

Notes Participants in the combined group received considerable more therapeutic exposure time than the
other two experimental groups.

\section{Risk of bias}

\begin{tabular}{lll}
\hline Bias & Authors' judgement & Support for judgement \\
\hline $\begin{array}{l}\text { Random sequence genera- } \\
\text { tion (selection bias) }\end{array}$ & Unclear risk & Study simply states that subjects "were randomly assigned" (p. 313). \\
\hline $\begin{array}{l}\text { Allocation concealment } \\
\text { (selection bias) }\end{array}$ & High risk & Not mentioned, and unlikely to have been done. \\
\hline $\begin{array}{l}\text { Blinding (performance } \\
\text { bias and detection bias) }\end{array}$ & High risk & All outcomes were based on parent- or self-reports. \\
\hline
\end{tabular}


Deblinger 1996 (Continued)

All outcomes

Incomplete outcome data Unclear risk (attrition bias)

All outcomes
Drop-out rate was relatively low (10\%) for the initial post-test assessment. The authors conducted statistical tests comparing characteristics of treatment completers relative to non-completers. Non-completers had experienced fewer instances of sexual abuse than completers, but otherwise there were no statistically significant differences. These analyses however were likely not conducted with high statistical power to detect meaningful differences, and the authors did not report data that would allow for computation of effect sizes comparing completers to non-completers.

Some additional attrition occurred in the follow-up sample (68 of the 90 participants who completed treatment were available). The authors conducted statistical tests of the outcomes by imputing the last available score, and state that these analyses were comparable to analyses using only participants who had complete data reported, although the standards employed in this judgement are unclear. Because results were comparable the authors based results only on participants with complete data.

\begin{tabular}{lll}
\hline $\begin{array}{l}\text { Selective reporting (re- } \\
\text { porting bias) }\end{array}$ & Low risk & $\begin{array}{l}\text { One measure was assessed for the immediate post-test but not mentioned } \\
\text { in the published follow-up study. Data were obtained from study authors. As } \\
\text { such, data from all measured outcomes appear to be available. }\end{array}$ \\
\hline Other bias & Unclear risk & $\begin{array}{l}\text { The protocol identified no additional potentially biasing factors for coding and } \\
\text { analysis. }\end{array}$ \\
\hline
\end{tabular}

Deblinger 2001

\begin{tabular}{|c|c|}
\hline Methods & RCT Cluster randomised. \\
\hline Participants & 54 sexually abused children aged 2 to 8 and their non-offending mothers. \\
\hline Interventions & $\begin{array}{l}\text { Experimental group (n randomised unknown) PARENTS - } 11 \text { sessions of cognitive-behavioural therapy } \\
\text { designed to i) help parents cope with their own emotional reaction in order to help them support their } \\
\text { children, ii) educate them as to how to initiate and maintain open parent-child communication regard- } \\
\text { ing their children's sexually abusive experiences, and iii) provide them with behaviour management } \\
\text { skills in order to help them manage their children's behavioural difficulties. CHILDREN - } 11 \text { sessions } \\
\text { that aimed to help children i) communicate about and cope with their feelings, ii) to identify 'okay' and } \\
\text { 'not okay' touches and iii) to learn abuse response skills, using an interactive behavioural format. } \\
\text { Control group (n randomised unknown) PARENTS- } 11 \text { sessions of supportive group therapy based on } \\
\text { the available clinical and empirical literature regarding self-help groups. Therapists acted as support- } \\
\text { ive and empathic facilitators and the aim was to empower parents. Therapists did not provide specif- } \\
\text { ic information about cognitive coping, gradual exposure or behaviour management. CHILDREN - As } \\
\text { above but in the control group the therapists used a didactic format, presenting age appropriate in- } \\
\text { formation and personal safely using pictures, stories and activity age exercises. Both approaches were } \\
\text { manualised and all sessions lasted } 1 \text {. hr } 45 \text { minutes. }\end{array}$ \\
\hline
\end{tabular}

Outcomes Assessed at around 11 weeks into therapy, then at 3 months post-treatment.

CHILDREN Behaviour: Child Behavior Checklist (CBCL). PTSD: PTSD section of the K-SADS-E. Sexual Behaviour: Child Sexual Behavior Inventory (CSBI-3). Ability to respond appropriately: What If Situations Test (WIST). PARENTS Behaviour (Coping) Style: Miller Behavior Style Scale (not used in the analyses). PTSD Symptoms: Posttraumatic Symptom Scale (SCL-90-R). Subjective Distress: Impact of Events Scale (IES). Parenting: Parenting Practices Questionnaire (PPQ). Emotional Reactions: Parent Emotional Reaction Questionnaire (PERQ). Social Support: Social Support Questionnaire (SSQ). Satisfaction: Therapist Satisfaction Questionnaire (TSQ).

Overall functioning: Glocal Assessment Functioning Scale (GAF). 
Deblinger 2001 (Continued)

Notes

\section{Risk of bias}

\begin{tabular}{lll}
\hline Bias & Authors' judgement & Support for judgement \\
\hline $\begin{array}{l}\text { Random sequence genera- } \\
\text { tion (selection bias) }\end{array}$ & Low risk & "assignment was randomly determined by computer program" (p. 335). \\
\hline $\begin{array}{l}\text { Allocation concealment } \\
\text { (selection bias) }\end{array}$ & High risk & Not mentioned, and likely not done. \\
\hline $\begin{array}{l}\text { Blinding (performance } \\
\text { bias and detection bias) }\end{array}$ & High risk & All measures were self- or parent-reports \\
\hline $\begin{array}{l}\text { Incomplete outcome data } \\
\text { (attrition bias) }\end{array}$ & Unclear risk & $\begin{array}{l}\text { Four of } 67 \text { families that were eligible were never assigned to a condition. An- } \\
\text { otl outcomes } \\
\text { treatment but did not provide both immediate post-test and follow-up data. } \\
\text { The authors conducted statistical tests comparing characteristics of partic- } \\
\text { ipants who completed all three assessments relative to those who did not. } \\
\text { There were no statistically significant differences. These analyses however } \\
\text { were likely not conducted with high statistical power to detect meaningful dif- } \\
\text { ferences (in addition, the a Type I error rate of } \alpha=.002 \text { was used as the criteri- } \\
\text { on for statistical significance), and the authors did not report data that would } \\
\text { allow for computation of effect sizes comparing completers to dropouts. }\end{array}$
\end{tabular}

\begin{tabular}{lll}
$\begin{array}{l}\text { Selective reporting (re- } \\
\text { porting bias) }\end{array}$ & Low risk & All measured outcomes appear to have been reported. \\
\hline Other bias & Unclear risk & $\begin{array}{l}\text { The protocol identified no additional potentially biasing factors for coding and } \\
\text { analysis. }\end{array}$
\end{tabular}

Dominguez 2001

\begin{tabular}{ll}
\hline Methods & RCT \\
\hline Participants & $\begin{array}{l}32 \text { sexually abused children and adolescents aged } 6-17 . \\
25 \text { children completed post-treatment assessments. }\end{array}$ \\
\hline Interventions & $\begin{array}{l}\text { Experimental Group ( } \mathrm{n} \text { randomised }=22) \text { : Cognitive behavioural therapy, the primary goal of which was } \\
\text { to teach participants new skills to manage their affective, cognitive, and behavioural responses to the } \\
\text { traumatic events. } \\
\text { Control Group ( } \mathrm{n} \text { randomised }=10) \text { - Supportive treatment, designed to facilitate change via a combina- } \\
\text { tion of consciousness raising and corrective emotional experiences that occur in the context of a gen- } \\
\text { uine, empathic relationship characterised by unconditional positive regard. }\end{array}$ \\
\hline
\end{tabular}

Outcomes Assessed at post-treatment only.

CHILDREN Intrusive thoughts and avoidance behaviour: Impact of Events Scale Revised (IES-R). Depression: Child Depression Inventory (CDI).

At pre-treatment they also used the Youth Self Report; the Diagnostic Interview for Children and Adolescents-III-Revised and the parent completed the Child Behavior Checklist (CBCL). tween recruitment and the first therapy session. 
Dominguez 2001 (Continued)

Risk of bias

\begin{tabular}{lll}
\hline Bias & Authors' judgement & Support for judgement \\
\hline $\begin{array}{l}\text { Random sequence genera- } \\
\text { tion (selection bias) }\end{array}$ & Unclear risk & $\begin{array}{l}\text { Study simply states that participants were "randomly assigned" (p. 35); no oth- } \\
\text { er details provided. }\end{array}$
\end{tabular}

Allocation concealment High risk Not mentioned, and unlikely to have been done.

(selection bias)

Blinding (performance High risk All measures were self-reports.

bias and detection bias)

All outcomes

Incomplete outcome data Unclear risk

(attrition bias)

Seven of 32 participants dropped out of the study. African-American children

All outcomes were over-represented in the drop-out sample, while Hispanic children were over-represented in the sample of children who remained in the study. In addition, youth who dropped out had marginally lower higher scores on the CDI $(\mathrm{SMD}=.62, \mathrm{p}=.09)$ and on the intrusive thoughts subscale of the Impact of Events Scale - Revised (SMD $=.54, p=.15)$, as well as statistically significantly higher self-esteem $(S M D=1.00, P=.008)$. SMDs for the other measures ranged from -.29 to +.20 , and seem to be relatively balanced between illustrating better functioning for the dropouts and the participants who remained in the study.

Dominguez also examined differences between completers in the treatment sample and completers in the comparison sample at baseline. In this case no differences were statistically significant, but statistical power for these tests was quite low. Generally speaking, participants in the CBT group had fewer problems at baseline than their comparison group counterparts. Treatment youth reported better baseline functioning on eight of ten reported outcomes (SMDs ranged from -.42 to +.91 ), with a mean effect size of +.29 .

\begin{tabular}{lll}
\hline $\begin{array}{l}\text { Selective reporting (re- } \\
\text { porting bias) }\end{array}$ & Low risk & All measured outcomes seem to have been reported. \\
\hline Other bias & Unclear risk & $\begin{array}{l}\text { The protocol identified no additional potentially biasing factors for coding and } \\
\text { analysis. }\end{array}$
\end{tabular}

King 2000

\begin{tabular}{|c|c|}
\hline Methods & $\mathrm{RCT}$ \\
\hline Participants & $\begin{array}{l}36 \text { sexually abused children aged 5-17 with symptoms that met diagnostic criteria for PTSD or who } \\
\text { were at high risk of this. } \\
28 \text { children completed post-treatment and follow-up assessments }\end{array}$ \\
\hline Interventions & $\begin{array}{l}\text { Experimental group } 1 \text { ( } \mathrm{n} \text { randomised }=12 \text { ): Child Cognitive-Behavioural Therapy }[\mathrm{CCBT}] \text { comprising } 20 \mathrm{x} \\
50 \text { minute sessions aimed at helping the child overcome his or her post-abuse distress and PTSD symp- } \\
\text { toms. } \\
\text { Experimental Group } 2 \text { ( } \mathrm{n} \text { randomised }=12 \text { ): Family Cognitive-Behavioural Therapy comprising CCBT } \\
\text { plus } 20 \times 50 \text { minutes sessions for parents who were trained in child behaviour management skills and } \\
\text { parent-child communication skills. } \\
\text { Control Group ( } \mathrm{n} \text { randomised }=12 \text { ) wait-list control. Participants were not contacted during the } 24- \\
\text { week waiting period. }\end{array}$ \\
\hline
\end{tabular}


CHILDREN Behaviour: Internalising: (Child Behavior Checklist-CBCL); Externalising (CBCL). PTSD: PTSD section of the Anxiety Disorders Interview Schedule (ADIS, Child Version) and PTSD Subscale of the Child Behavior Checklist (CBCL) . Depression: Children's Depression Inventory (DPI). Fear: Fear Thermometer for Sexually Abused Children (FT-SAC). Anxiety: Revised Children's Manifest Anxiety Scale (RCMAS).

Children's perceived ability to cope with abuse-related symptoms and specific anxiety-provoking situations: Coping Questionnaire for Sexually Abused Children (CQ-SAC).

Overall functioning (Clinician using the Glocal Assessment Functioning Scale - GAF).

\section{Notes}

10 children were 'lost' during screening and consent. A further 8 dropped out during treatment, 2 from the control group, and 3 from each experimental group.

\section{Risk of bias}

\begin{tabular}{|c|c|c|}
\hline Bias & Authors' judgement & Support for judgement \\
\hline $\begin{array}{l}\text { Random sequence genera- } \\
\text { tion (selection bias) }\end{array}$ & Unclear risk & $\begin{array}{l}\text { Study simply reports that children were randomly assigned (p. 1347); no other } \\
\text { information provided. }\end{array}$ \\
\hline $\begin{array}{l}\text { Allocation concealment } \\
\text { (selection bias) }\end{array}$ & High risk & Not mentioned, and unlikely to have been done. \\
\hline $\begin{array}{l}\text { Blinding (performance } \\
\text { bias and detection bias) } \\
\text { All outcomes }\end{array}$ & High risk & $\begin{array}{l}\text { Most outcomes were parent or self-reports. Overall functioning was assessed } \\
\text { by a clinician, but the report does not state that the clinician was blinded to } \\
\text { condition. }\end{array}$ \\
\hline $\begin{array}{l}\text { Incomplete outcome data } \\
\text { (attrition bias) } \\
\text { All outcomes }\end{array}$ & High risk & $\begin{array}{l}10 \text { families were lost in the screening process. The report does not specifical- } \\
\text { ly mention or give an indication that there was attrition at posttest (all of the } \\
\text { statistical tests use the same -- clearly incorrect -- value for the error degrees } \\
\text { of freedom). For the follow-up assessment, some attrition occurred (ranging } \\
\text { from zero to } 7 \text { participants, out of 36). }\end{array}$ \\
\hline $\begin{array}{l}\text { Selective reporting (re- } \\
\text { porting bias) }\end{array}$ & Low risk & All measured outcomes seem to have been reported \\
\hline Other bias & Unclear risk & $\begin{array}{l}\text { The protocol identified no additional potentially biasing factors for coding and } \\
\text { analysis. }\end{array}$ \\
\hline
\end{tabular}

RCT: randomised controlled trial; SMD: standardised mean difference

Characteristics of excluded studies [ordered by study ID]

\begin{tabular}{ll}
\hline Study & Reason for exclusion \\
\hline Downing 1988 & Not a randomised or quasi-randomised trial. \\
\hline Jaberghaderi 2004 & Other treatment control. \\
\hline Verleur 1986 & Not a randomised or quasi-randomised trial. Matched comparison groups. \\
\hline
\end{tabular}

\section{Characteristics of studies awaiting assessment [ordered by study ID]}


Lewis 2010

Methods

The authors took data from a larger study and broke out results for children with a history of sexual abuse (including some with a history of both physical and sexual abuse) and randomly assigned them to one of four conditions. One of these was a CBT group, and the other was a placebo group (other conditions were a drug group, and a drug + CBT group).

\section{Participants}

Interventions

\section{Outcomes}

Notes

We have written to the authors to ask for confirmation of the study design to determine its eligibility, and also for unadjusted data to incorporate into the meta-analyses.

CBT: cognitive behavioural therapy

DATA AND ANALYSES

Comparison 1. CBT vs no CBT

\begin{tabular}{|c|c|c|c|c|}
\hline Outcome or subgroup title & $\begin{array}{l}\text { No. of } \\
\text { studies }\end{array}$ & $\begin{array}{l}\text { No. of } \\
\text { partici- } \\
\text { pants }\end{array}$ & Statistical method & Effect size \\
\hline 1 Child depression (CDI) & 5 & & Mean Difference (IV, Random, 95\% CI) & Subtotals only \\
\hline $\begin{array}{l}1.1 \text { Short term (immediately after } \\
\text { treatment) }\end{array}$ & 5 & 421 & Mean Difference (IV, Random, 95\% CI) & $-1.92[-4.24,0.40]$ \\
\hline $\begin{array}{l}1.2 \text { Intermediate term ( } 3-6 \text { months af- } \\
\text { ter treatment) }\end{array}$ & 4 & 286 & Mean Difference (IV, Random, 95\% CI) & $-1.84[-3.41,-0.27]$ \\
\hline 1.3 Long term (at least one year) & 4 & 301 & Mean Difference (IV, Random, 95\% CI) & $-1.19[-2.70,0.32]$ \\
\hline $\begin{array}{l}2 \text { Child post-traumatic stress disorder } \\
\text { (various scales) }\end{array}$ & 6 & & $\begin{array}{l}\text { Std. Mean Difference (IV, Random, } \\
95 \% \mathrm{CI})\end{array}$ & Subtotals only \\
\hline $\begin{array}{l}2.1 \text { Short term (immediately after } \\
\text { treatment) }\end{array}$ & 6 & 442 & $\begin{array}{l}\text { Std. Mean Difference (IV, Random, } \\
95 \% \mathrm{CI})\end{array}$ & $-0.44[-0.73,-0.16]$ \\
\hline $\begin{array}{l}2.2 \text { Intermediate term ( } 3-6 \text { months af- } \\
\text { ter treatment) }\end{array}$ & 5 & 327 & $\begin{array}{l}\text { Std. Mean Difference (IV, Random, } \\
95 \% \mathrm{CI})\end{array}$ & $-0.39[-0.74,-0.04]$ \\
\hline 2.3 Long term (at least one year) & 3 & 246 & $\begin{array}{l}\text { Std. Mean Difference (IV, Random, } \\
95 \% \mathrm{Cl})\end{array}$ & $-0.38[-0.65,-0.11]$ \\
\hline 3 Child anxiety & 5 & & $\begin{array}{l}\text { Std. Mean Difference (IV, Fixed, 95\% } \\
\mathrm{Cl} \text { ) }\end{array}$ & Subtotals only \\
\hline $\begin{array}{l}3.1 \text { Short term (immediately after } \\
\text { treatment) }\end{array}$ & 5 & 434 & $\begin{array}{l}\text { Std. Mean Difference (IV, Fixed, 95\% } \\
\mathrm{CI} \text { ) }\end{array}$ & $-0.23[-0.42,-0.03]$ \\
\hline $\begin{array}{l}3.2 \text { Intermediate term ( } 3-6 \text { months af- } \\
\text { ter treatment) }\end{array}$ & 4 & 296 & $\begin{array}{l}\text { Std. Mean Difference (IV, Fixed, 95\% } \\
\text { CI) }\end{array}$ & $-0.38[-0.61,-0.14]$ \\
\hline
\end{tabular}




\begin{tabular}{|c|c|c|c|c|}
\hline Outcome or subgroup title & $\begin{array}{l}\text { No. of } \\
\text { studies }\end{array}$ & $\begin{array}{l}\text { No. of } \\
\text { partici- } \\
\text { pants }\end{array}$ & Statistical method & Effect size \\
\hline 3.3 Long term (at least one year) & 4 & 278 & $\begin{array}{l}\text { Std. Mean Difference (IV, Fixed, 95\% } \\
\mathrm{Cl} \text { ) }\end{array}$ & $-0.28[-0.52,-0.04]$ \\
\hline 4 Child sexualised behaviour (CSBI) & 5 & & Mean Difference (IV, Random, 95\% CI) & Subtotals only \\
\hline $\begin{array}{l}4.1 \text { Short term (immediately after } \\
\text { treatment) }\end{array}$ & 5 & 451 & Mean Difference (IV, Random, 95\% Cl) & $-0.65[-3.53,2.24]$ \\
\hline $\begin{array}{l}4.2 \text { Intermediate term ( } 3-6 \text { months af- } \\
\text { ter treatment) }\end{array}$ & 3 & 133 & Mean Difference (IV, Random, 95\% CI) & $-0.46[-5.68,4.76]$ \\
\hline 4.3 Long term (at least one year) & 3 & 161 & Mean Difference (IV, Random, 95\% CI) & $-1.61[-5.72,2.49]$ \\
\hline $\begin{array}{l}5 \text { Child externalising behaviour (CBCL } \\
\text { Externalising) }\end{array}$ & 7 & & $\begin{array}{l}\text { Std. Mean Difference (IV, Random, } \\
95 \% \mathrm{CI} \text { ) }\end{array}$ & Subtotals only \\
\hline $\begin{array}{l}5.1 \text { Short term (immediately after } \\
\text { treatment) }\end{array}$ & 7 & 537 & $\begin{array}{l}\text { Std. Mean Difference (IV, Random, } \\
95 \% \mathrm{Cl} \text { ) }\end{array}$ & $-0.12[-0.40,0.17]$ \\
\hline $\begin{array}{l}5.2 \text { Intermediate term ( } 3-6 \text { months af- } \\
\text { ter treatment) }\end{array}$ & 4 & 175 & $\begin{array}{l}\text { Std. Mean Difference (IV, Random, } \\
95 \% \mathrm{Cl} \text { ) }\end{array}$ & $-0.11[-0.42,0.21]$ \\
\hline 5.3 Long term (at least one year) & 5 & 355 & $\begin{array}{l}\text { Std. Mean Difference (IV, Random, } \\
95 \% \mathrm{CI} \text { ) }\end{array}$ & $0.05[-0.16,0.27]$ \\
\hline $\begin{array}{l}6 \text { Parent's belief of child (PRIDS and } \\
\text { PSQ) }\end{array}$ & 2 & & $\begin{array}{l}\text { Std. Mean Difference (IV, Random, } \\
95 \% \mathrm{CI} \text { ) }\end{array}$ & Subtotals only \\
\hline $\begin{array}{l}6.1 \text { Short term (immediately after } \\
\text { treatment) }\end{array}$ & 2 & 211 & $\begin{array}{l}\text { Std. Mean Difference (IV, Random, } \\
95 \% \mathrm{CI} \text { ) }\end{array}$ & $0.30[0.03,0.57]$ \\
\hline $\begin{array}{l}6.2 \text { Intermediate term ( } 3-6 \text { months af- } \\
\text { ter treatment) }\end{array}$ & 1 & 143 & $\begin{array}{l}\text { Std. Mean Difference (IV, Random, } \\
95 \% \mathrm{CI} \text { ) }\end{array}$ & $-0.32[-0.65,0.01]$ \\
\hline 6.3 Long term (at least one year) & 1 & 146 & $\begin{array}{l}\text { Std. Mean Difference (IV, Random, } \\
95 \% \mathrm{CI} \text { ) }\end{array}$ & $-0.10[-0.43,0.23]$ \\
\hline 7 Parental attributions (PAS) & 1 & & Mean Difference (IV, Random, 95\% CI) & Subtotals only \\
\hline 7.1 Self blame & 1 & 30 & Mean Difference (IV, Random, 95\% CI) & $-0.80[-4.03,2.43]$ \\
\hline 7.2 Child blame & 1 & 30 & Mean Difference (IV, Random, 95\% CI) & $-1.20[-4.47,2.07]$ \\
\hline 7.3 Perpetrator blame & 1 & 30 & Mean Difference (IV, Random, 95\% CI) & $-0.60[-2.62,1.42]$ \\
\hline 7.4 Negative impact & 1 & 30 & Mean Difference (IV, Random, 95\% CI) & $-1.90[-4.67,0.87]$ \\
\hline 8 Parenting skills (PPQ) & 3 & & Mean Difference (IV, Random, 95\% CI) & Subtotals only \\
\hline $\begin{array}{l}8.1 \text { Short term (immediately after } \\
\text { treatment) }\end{array}$ & 3 & 278 & Mean Difference (IV, Random, 95\% CI) & $3.86[0.47,7.26]$ \\
\hline $\begin{array}{l}8.2 \text { Intermediate term ( } 3-6 \text { months af- } \\
\text { ter treatment) }\end{array}$ & 3 & 231 & Mean Difference (IV, Random, 95\% CI) & $2.36[-1.55,6.28]$ \\
\hline
\end{tabular}




\begin{tabular}{llllll}
\hline Outcome or subgroup title & $\begin{array}{l}\text { No. of } \\
\text { studies }\end{array}$ & $\begin{array}{l}\text { No. of } \\
\text { partici- } \\
\text { pants }\end{array}$ & Statistical method & Effect size \\
\hline 8.3 Long term (at least one year) & 2 & 193 & Mean Difference (IV, Random, 95\% Cl) & $-0.89[-4.89,3.11]$ \\
\hline 9 Parents' emotional reaction (PERQ) & 2 & 558 & Mean Difference (IV, Fixed, 95\% Cl) & $-5.17[-7.17,-3.17]$ \\
\hline $\begin{array}{l}9.1 \text { Short term (Immediately after } \\
\text { treatment) }\end{array}$ & 2 & 223 & Mean Difference (IV, Fixed, 95\% Cl) & $-6.95[-10.11,-3.80]$ \\
\hline $\begin{array}{l}9.2 \text { Intermediate term (3-6 months af- } \\
\text { ter treatment) }\end{array}$ & 2 & 187 & Mean Difference (IV, Fixed, 95\% Cl) & $-3.46[-6.98,0.06]$ \\
\hline \begin{tabular}{l}
9.3 Long term (at least one year) \\
\hline
\end{tabular} & 1 & 148 & Mean Difference (IV, Fixed, 95\% Cl) & $-4.56[-8.37,-0.75]$ \\
\hline
\end{tabular}

Analysis 1.1. Comparison 1 CBT vs no CBT, Outcome 1 Child depression (CDI).

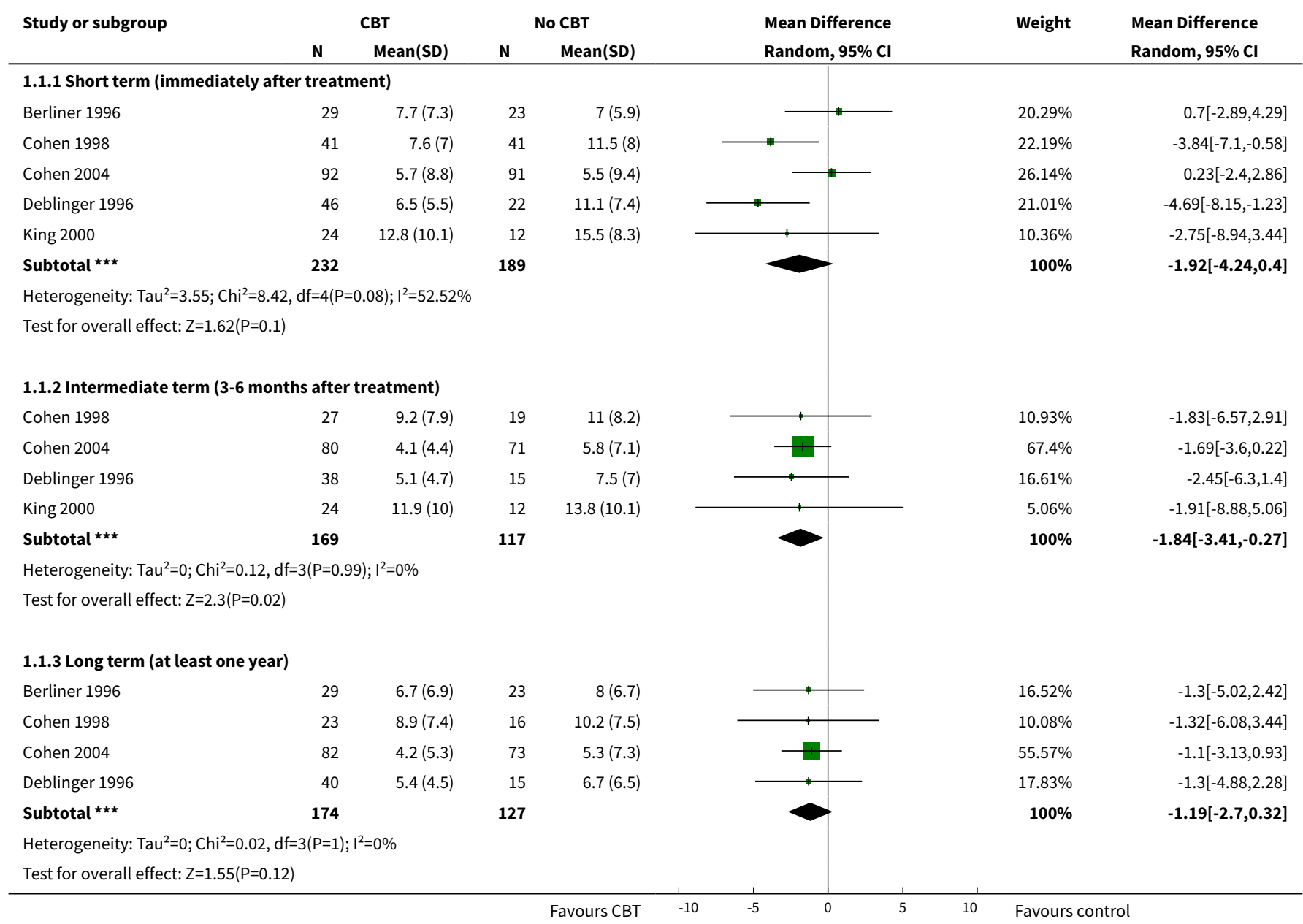


Analysis 1.2. Comparison 1 CBT vs no CBT, Outcome 2 Child post-traumatic stress disorder (various scales).

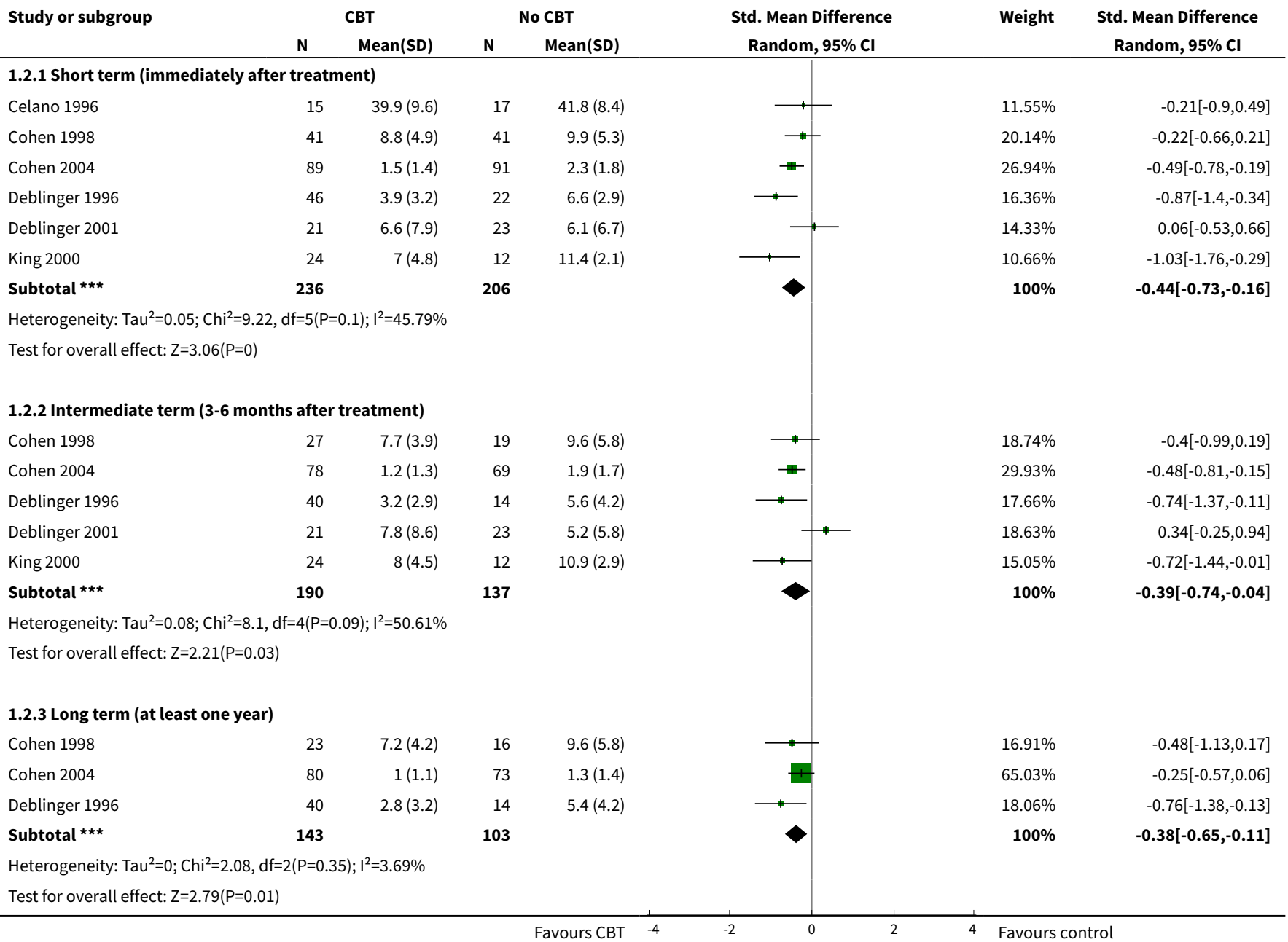

Analysis 1.3. Comparison 1 CBT vs no CBT, Outcome 3 Child anxiety.

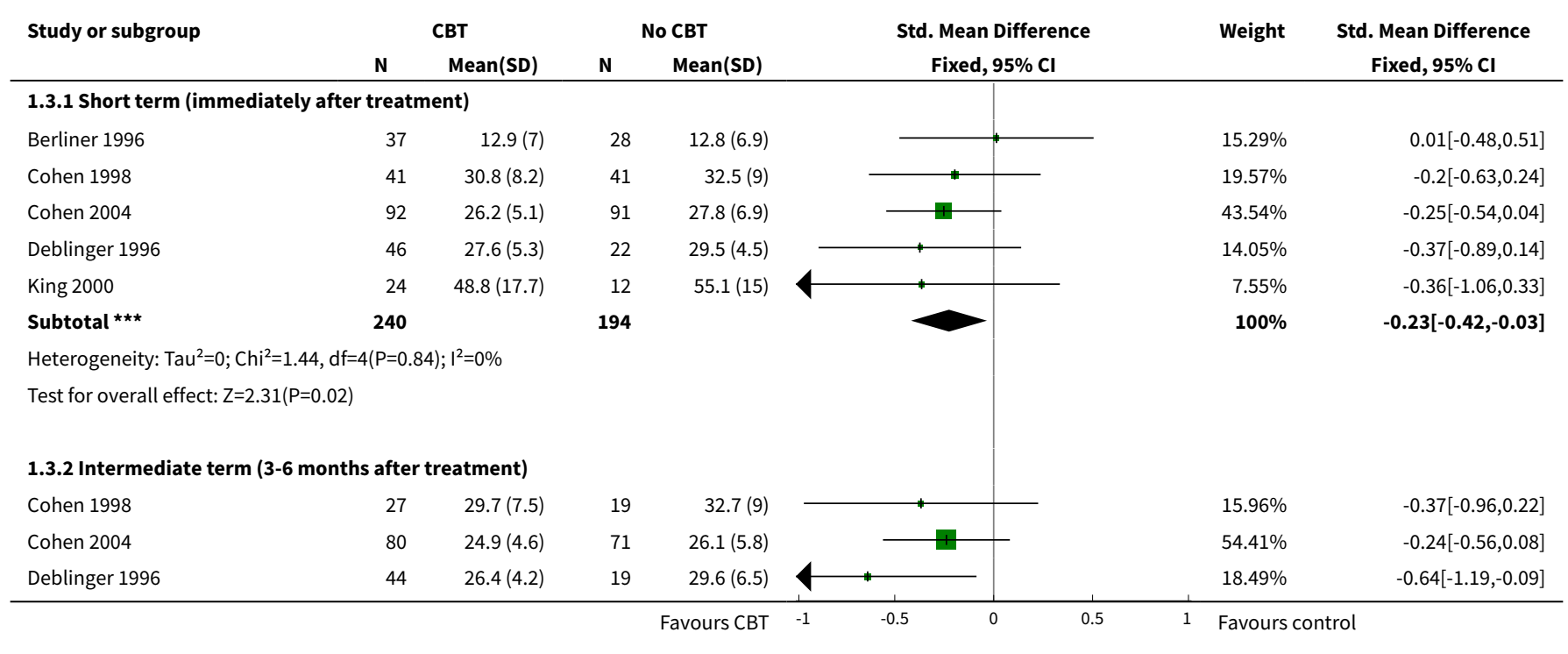




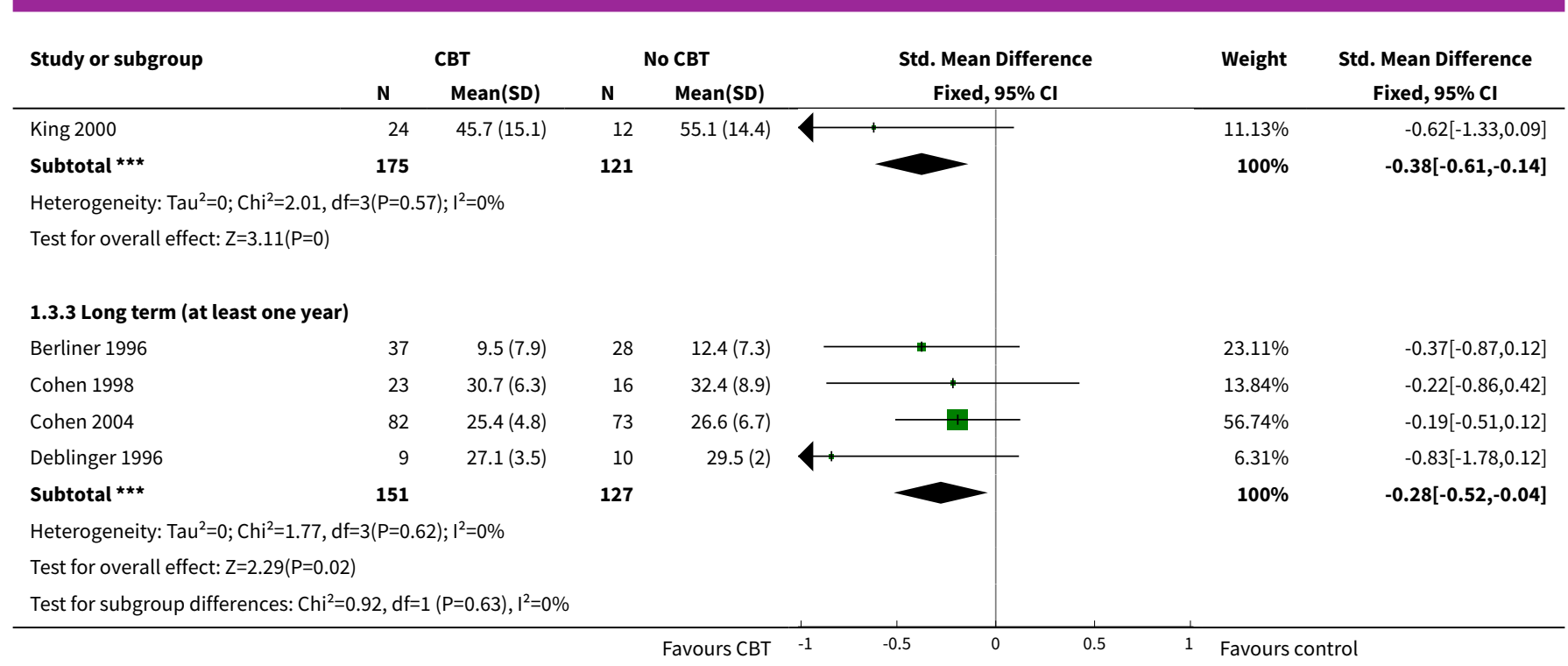

Analysis 1.4. Comparison 1 CBT vs no CBT, Outcome 4 Child sexualised behaviour (CSBI).

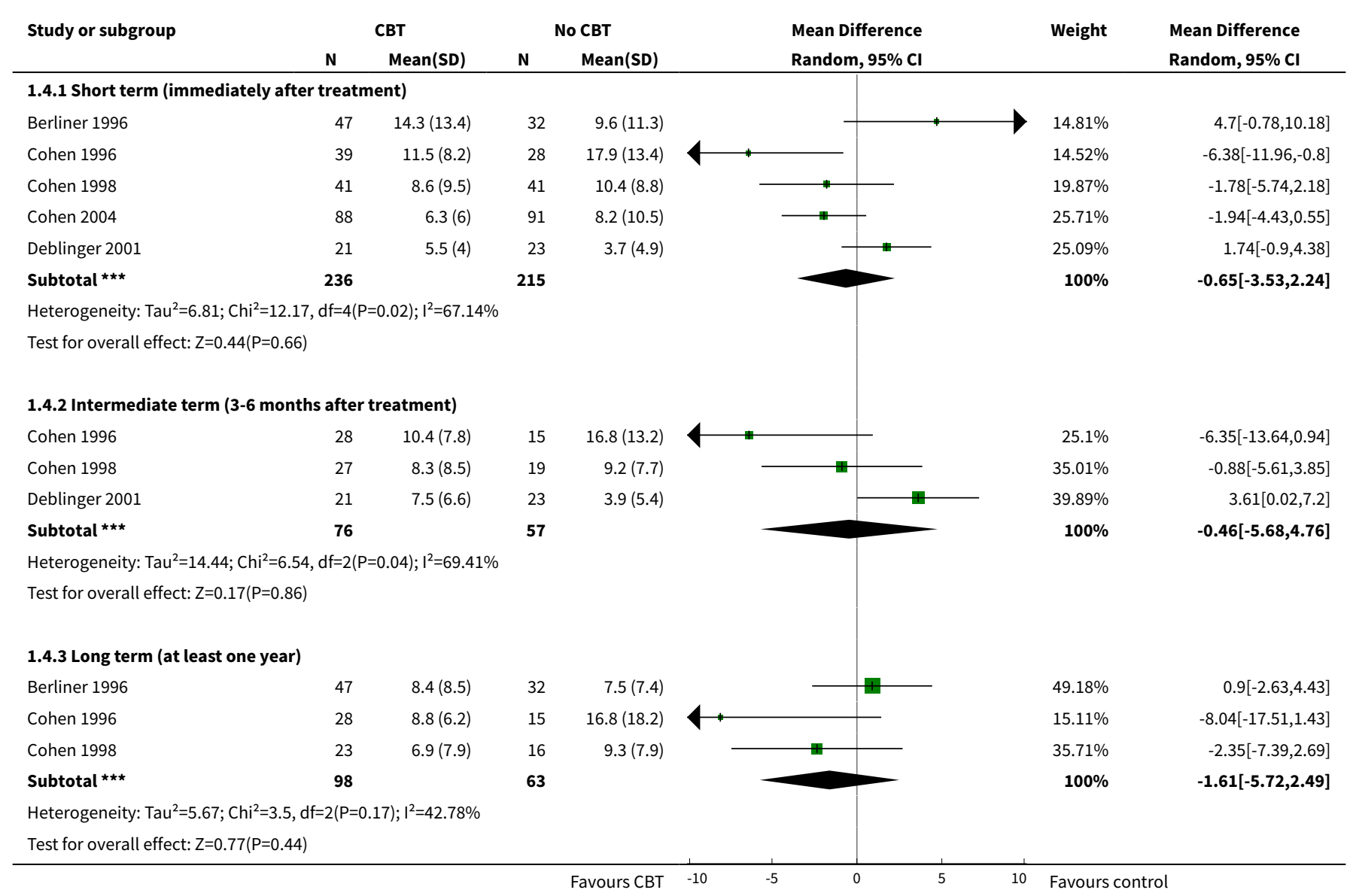


Analysis 1.5. Comparison 1 CBT vs no CBT, Outcome 5 Child externalising behaviour (CBCL Externalising).

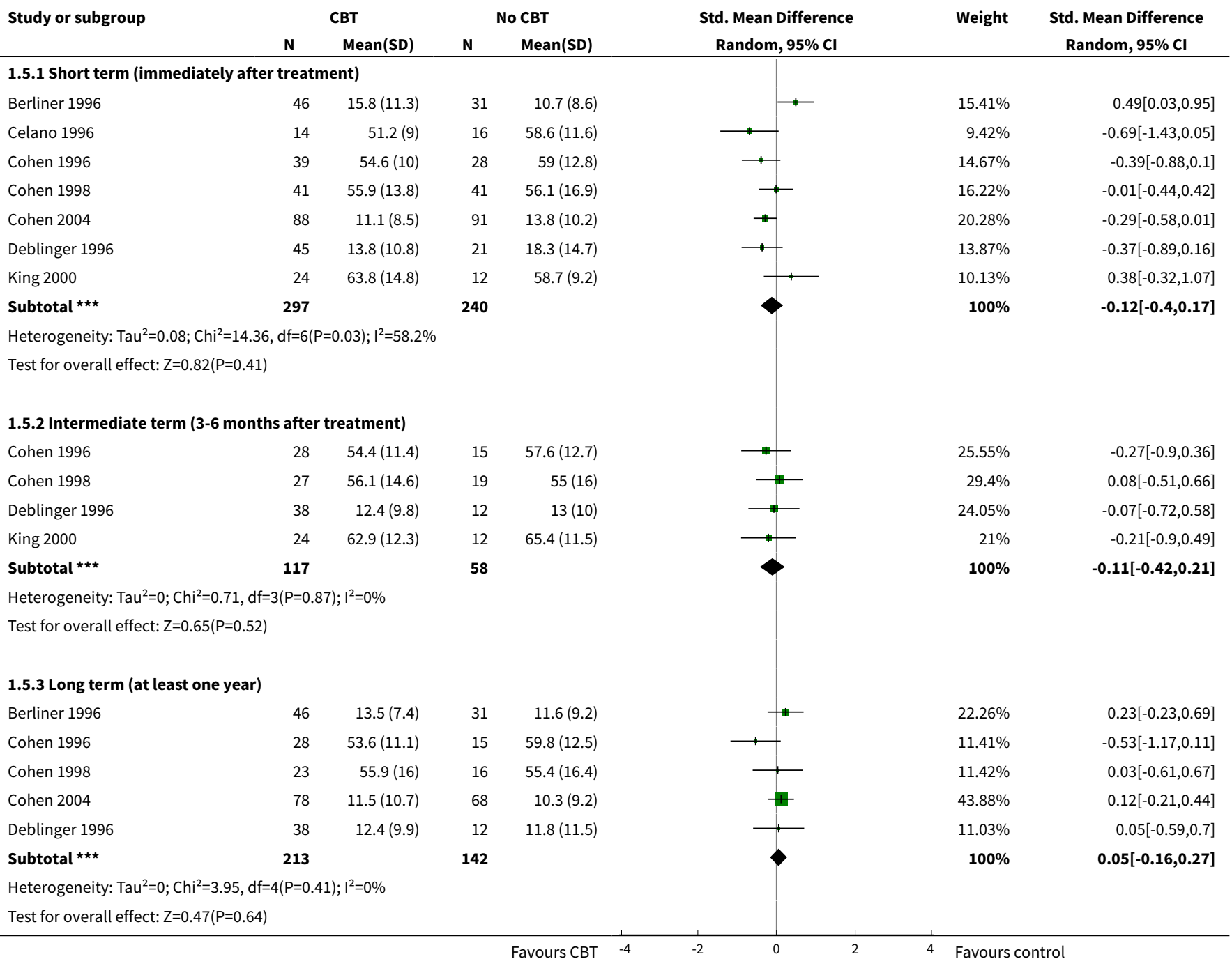

\section{Analysis 1.6. Comparison 1 CBT vs no CBT, Outcome 6 Parent's belief of child (PRIDS and PSQ).}

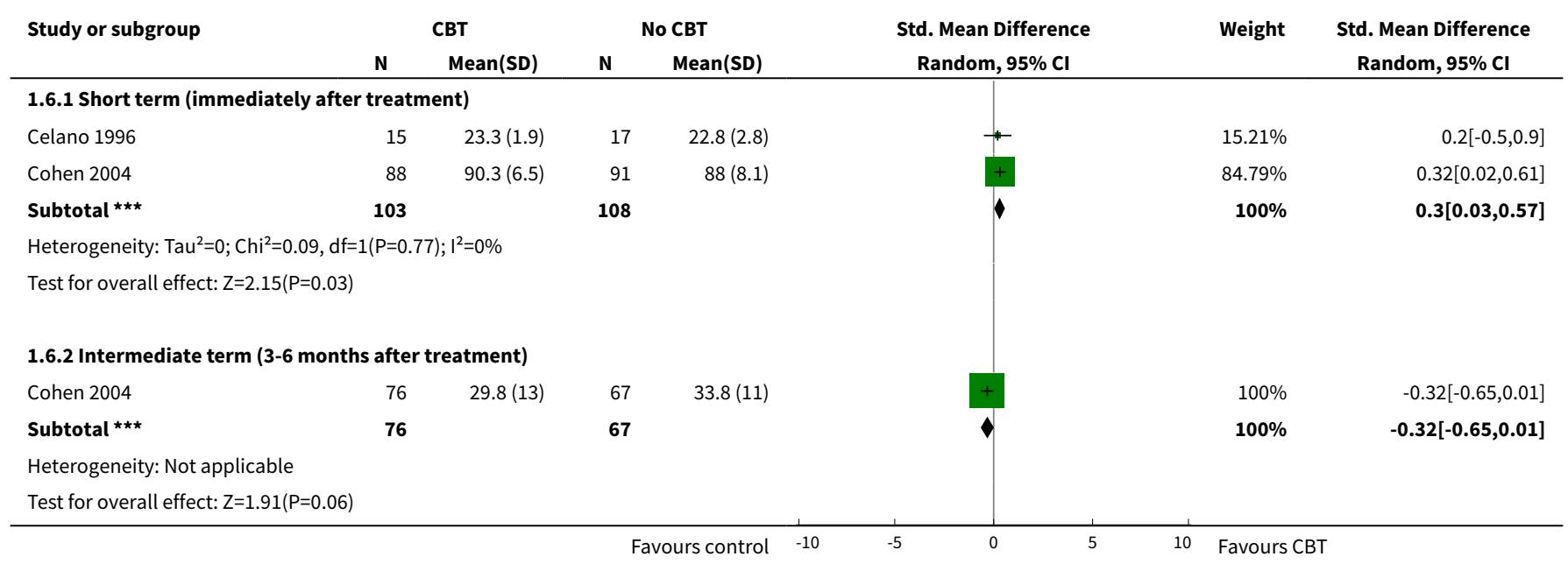




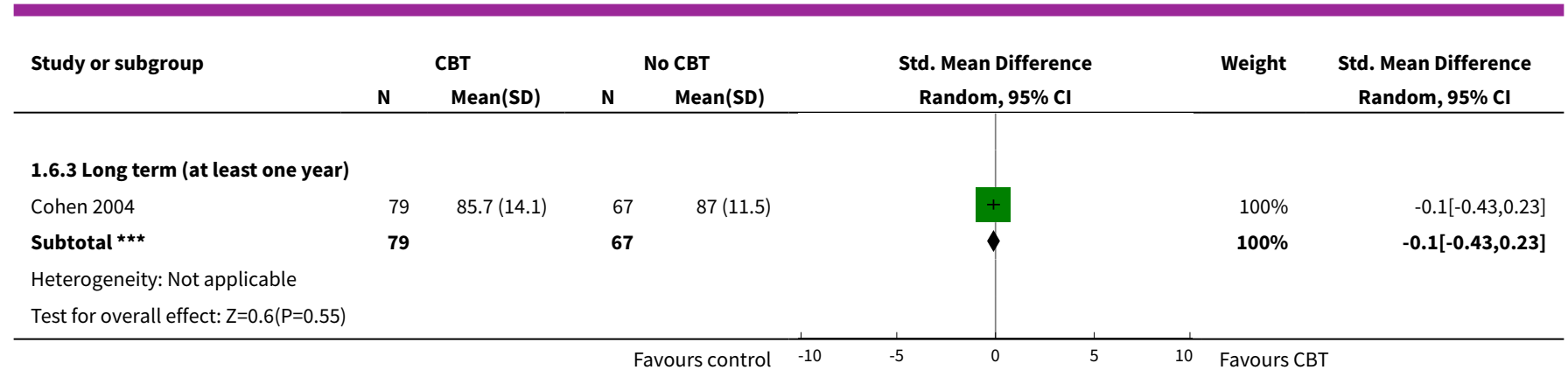

Analysis 1.7. Comparison 1 CBT vs no CBT, Outcome 7 Parental attributions (PAS).

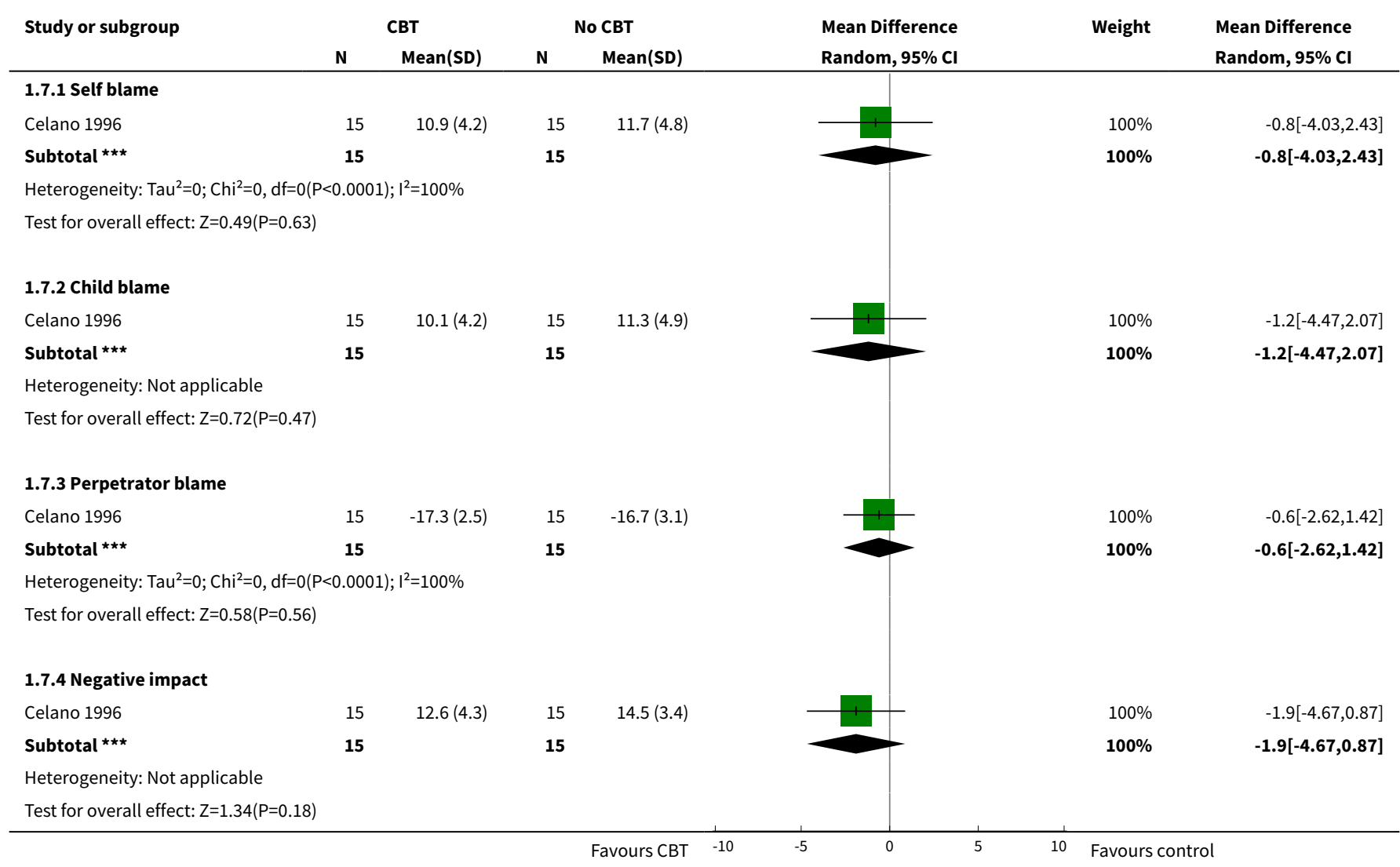

Analysis 1.8. Comparison 1 CBT vs no CBT, Outcome 8 Parenting skills (PPQ).

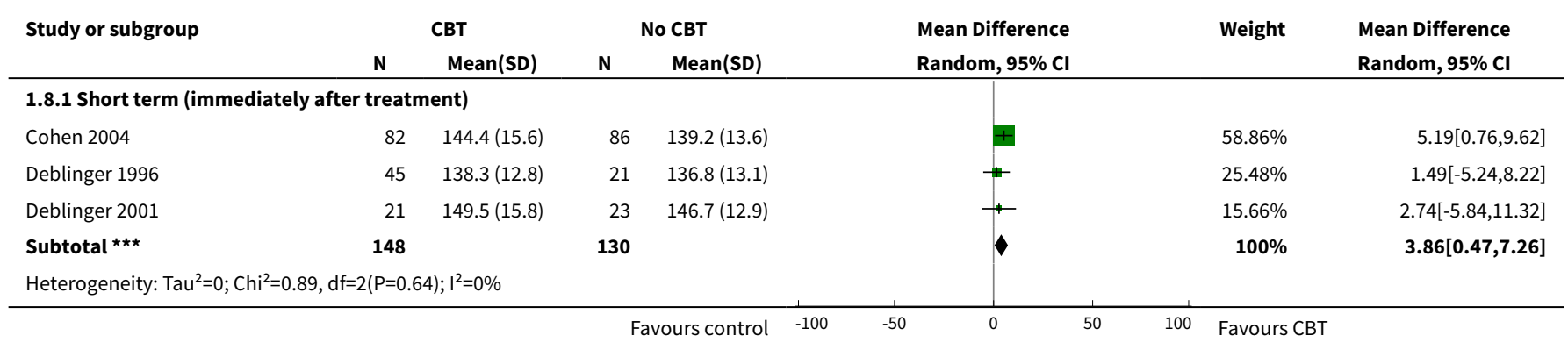




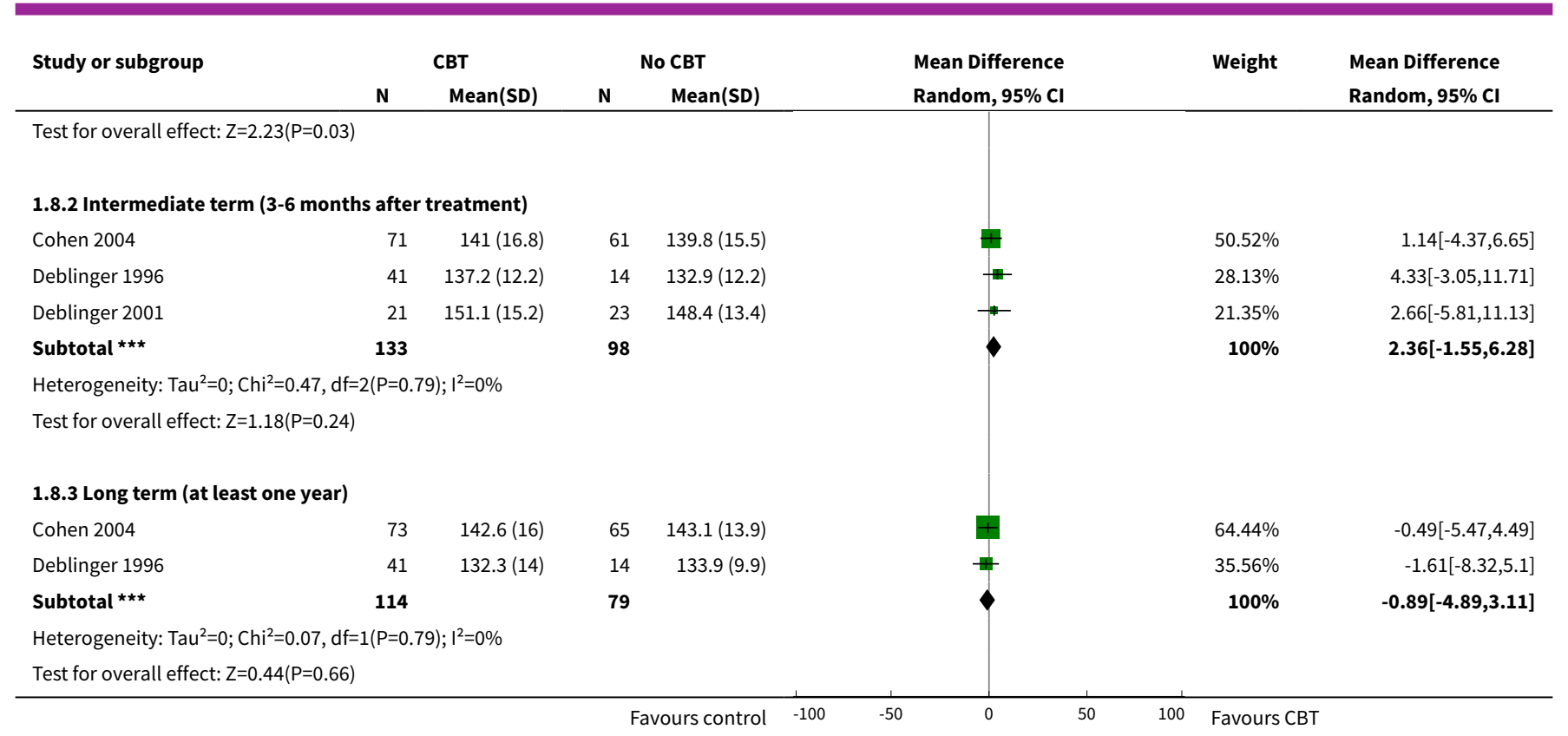

Analysis 1.9. Comparison 1 CBT vs no CBT, Outcome 9 Parents' emotional reaction (PERQ).

\begin{tabular}{|c|c|c|c|c|c|c|c|}
\hline \multirow[t]{2}{*}{ Study or subgroup } & \multicolumn{2}{|c|}{ CBT } & \multicolumn{2}{|c|}{ No CBT } & \multirow{2}{*}{$\begin{array}{c}\text { Mean Difference } \\
\text { Fixed, } 95 \% \mathrm{Cl}\end{array}$} & \multirow[t]{2}{*}{ Weight } & \multirow{2}{*}{$\begin{array}{c}\text { Mean Difference } \\
\text { Fixed, } 95 \% \mathrm{Cl}\end{array}$} \\
\hline & $\mathbf{N}$ & $\operatorname{Mean}(\mathrm{SD})$ & $\mathbf{N}$ & Mean(SD) & & & \\
\hline \multicolumn{8}{|c|}{ 1.9.1 Short term (Immediately after treatment) } \\
\hline Cohen 2004 & 88 & $30.8(11.3)$ & 91 & $38(12.8)$ & & $31.94 \%$ & $-7.22[-10.76,-3.68]$ \\
\hline Deblinger 2001 & 21 & $36.9(13.4)$ & 23 & $42.8(9.8)$ & & $8.2 \%$ & $-5.92[-12.9,1.06]$ \\
\hline Subtotal $\star \star \star ~$ & 109 & & 114 & & & $40.14 \%$ & $-6.95[-10.11,-3.8]$ \\
\hline \multicolumn{8}{|c|}{ Heterogeneity: $\operatorname{Tau}^{2}=0 ; \mathrm{Chi}^{2}=0.11, \mathrm{df}=1(\mathrm{P}=0.74) ; \mathrm{I}^{2}=0 \%$} \\
\hline \multicolumn{8}{|c|}{ 1.9.2 Intermediate term (3-6 months after treatment) } \\
\hline Cohen 2004 & 76 & $29.8(13)$ & 67 & $33.8(11)$ & 1 & $25.69 \%$ & $-3.93[-7.88,0.02]$ \\
\hline Deblinger 2001 & 21 & $37.2(15.4)$ & 23 & $38.9(10.3)$ & & $6.55 \%$ & $-1.63[-9.44,6.18]$ \\
\hline Subtotal $\star \star \star$ & 97 & & 90 & & & $32.24 \%$ & $-3.46[-6.98,0.06]$ \\
\hline \multicolumn{8}{|c|}{ Heterogeneity: Tau $^{2}=0 ; \mathrm{Chi}^{2}=0.27, \mathrm{df}=1(\mathrm{P}=0.61) ; \mathrm{I}^{2}=0 \%$} \\
\hline \multicolumn{8}{|c|}{ Test for overall effect: $Z=1.93(P=0.05)$} \\
\hline \multicolumn{8}{|c|}{ 1.9.3 Long term (at least one year) } \\
\hline Cohen 2004 & 79 & $28.4(11.6)$ & 69 & $33(11.9)$ & $\overline{-}$ & $27.62 \%$ & $-4.56[-8.37,-0.75]$ \\
\hline Subtotal ${ }^{\star \star \star}$ & 79 & & 69 & & & $27.62 \%$ & $-4.56[-8.37,-0.75]$ \\
\hline \multicolumn{8}{|c|}{ Heterogeneity: Not applicable } \\
\hline \multicolumn{8}{|c|}{ Test for overall effect: $Z=2.35(P=0.02)$} \\
\hline Total $\star \star \star ~$ & 285 & & 273 & & & $100 \%$ & $-5.17[-7.17,-3.17]$ \\
\hline \multicolumn{8}{|c|}{ Heterogeneity: $\mathrm{Tau}^{2}=0 ; \mathrm{Chi}^{2}=2.6, \mathrm{df}=4(\mathrm{P}=0.63) ; \mathrm{I}^{2}=0 \%$} \\
\hline \multicolumn{8}{|c|}{ Test for overall effect: $Z=5.06(P<0.0001)$} \\
\hline Test for subgroup dif & $23, \mathrm{df}=$ & $P=0.33), I^{2}=10$ & & & & & \\
\hline
\end{tabular}




\section{ADDITIONAL TABLES}

Table 1. Outcome measures used by studies in the review

\begin{tabular}{|c|c|c|c|}
\hline Outcome & Outcome measures & Studies & Measures used in SR \\
\hline \multirow{7}{*}{$\begin{array}{l}\text { Post-trau- } \\
\text { matic stress }\end{array}$} & CITES-R (child report) & Celano 1996 & Yes \\
\hline & CBCL-PTSD section (parent report) & $\begin{array}{l}\text { Celano } 1996 \\
\text { King } 2000\end{array}$ & No \\
\hline & K-SADS-E & Deblinger 1996 (initial evaluation only) & N/A \\
\hline & PTSD subscale (K-SADS-E) & Deblinger 2001 & Yes \\
\hline & $\begin{array}{l}\text { K-SADS-PL (re-experiencing, avoidance } \\
\text { and hypervigilance) }\end{array}$ & Cohen 2004 & Yes (re-experiencing) \\
\hline & $\begin{array}{l}\text { TSCC (child report) PTSD, anxiety, depres- } \\
\text { sion, sexual problems, dissociation and } \\
\text { anger subscales) }\end{array}$ & Cohen 1998 & Yes (PTSD) \\
\hline & $\begin{array}{l}\text { ADIS-DSM IV PTSD section (child version), } \\
\text { re-experiencing, avoidance, hyperarousal } \\
\text { subscales }\end{array}$ & King 2000 & Yes (re-experiencing) \\
\hline \multirow[t]{3}{*}{ Fear } & $\begin{array}{l}\text { FSCC-Revised (total score, and five sub- } \\
\text { scores) }\end{array}$ & $\begin{array}{l}\text { Burke } 1988 \\
\text { Berliner } 1996\end{array}$ & No \\
\hline & FT-SAC & King 2000 & No \\
\hline & $\begin{array}{l}\text { SAFE (sex-associated fear; interpersonal } \\
\text { discomfort subscales) }\end{array}$ & Berliner 1996 & No \\
\hline \multirow[t]{2}{*}{ Anxiety } & RCMAS (total score plus three subscores) & $\begin{array}{l}\text { Burke } 1988 \\
\text { Berliner } 1996 \\
\text { King } 2000\end{array}$ & $\begin{array}{l}\text { No (no data avail- } \\
\text { able) } \\
\text { Yes (total score) } \\
\text { Yes (total score) }\end{array}$ \\
\hline & STAIC (State and Trait) & $\begin{array}{l}\text { Cohen } 1998 \\
\text { Deblinger } 1996 \\
\text { Cohen } 2004\end{array}$ & $\begin{array}{l}\text { Yes (State) } \\
\text { Yes (State) } \\
\text { Yes (State) }\end{array}$ \\
\hline Behaviour & $\mathrm{CBCL}$ (parent report) & $\begin{array}{l}\text { Burke } 1988 \text { (internalising) } \\
\text { Berliner } 1996 \\
\text { Celano } 1996 \text { (internalising and externalising) } \\
\text { Cohen } 1996 \\
\text { Cohen } 1998 \\
\text { Deblinger } 1996 \\
\text { King } 2000 \\
\text { Deblinger } 2001 \\
\text { Cohen } 2004\end{array}$ & $\begin{array}{l}\text { No data available for } \\
\text { Burke } 1988 \text {. Data on } \\
\text { externalising behav- } \\
\text { iour available and in- } \\
\text { corporated from all } \\
\text { other studies in the } \\
\text { review. }\end{array}$ \\
\hline $\begin{array}{l}\text { Sexual be- } \\
\text { haviour }\end{array}$ & CSBI & $\begin{array}{l}\text { Berliner } 1996 \\
\text { Cohen } 1996 \\
\text { Cohen } 1998 \\
\text { Deblinger } 2001 \\
\text { Cohen } 2004\end{array}$ & Yes \\
\hline
\end{tabular}


Table 1. Outcome measures used by studies in the review (Continued)

\begin{tabular}{|c|c|c|c|}
\hline Child coping & GAF & King 2000 & No \\
\hline & CGAS & Celano 1996 & No \\
\hline & CQ-SAQ & King 2000 & No \\
\hline $\begin{array}{l}\text { Impact of } \\
\text { events }\end{array}$ & IES-R & Dominguez 2001 & No \\
\hline $\begin{array}{l}\text { Children's } \\
\text { attributions }\end{array}$ & CAPS & Cohen 2004 & No \\
\hline $\begin{array}{l}\text { Child de- } \\
\text { pression }\end{array}$ & CDI & $\begin{array}{l}\text { Burke } 1988 \\
\text { Berliner } 1996 \\
\text { Cohen } 1998 \\
\text { Deblinger } 1996 \\
\text { King } 2000 \\
\text { Dominguez } 2001 \\
\text { Cohen } 2004\end{array}$ & Yes \\
\hline $\begin{array}{l}\text { Parental de- } \\
\text { pression }\end{array}$ & $\mathrm{BDI}$ & Cohen 2004 & No \\
\hline $\begin{array}{l}\text { Parental atti- } \\
\text { tudes }\end{array}$ & PAS & Celano 1996 & \\
\hline $\begin{array}{l}\text { Parental be- } \\
\text { lief and sup- } \\
\text { port }\end{array}$ & $\begin{array}{l}\text { PRIDS (emotional support for child, belief } \\
\text { of child) }\end{array}$ & Celano 1996 & No \\
\hline & PSQ revised & Cohen 2004 & Yes \\
\hline $\begin{array}{l}\text { Parents } \\
\text { emotional } \\
\text { reactions }\end{array}$ & PERQ & $\begin{array}{l}\text { Deblinger } 2001 \\
\text { Cohen } 2004\end{array}$ & Yes \\
\hline $\begin{array}{l}\text { Parenting } \\
\text { practices }\end{array}$ & PPQ & $\begin{array}{l}\text { Deblinger } 1996 \\
\text { Deblinger } 2001 \\
\text { Cohen } 2004\end{array}$ & Yes \\
\hline
\end{tabular}

Table 2. Additional methods for future updates

\begin{tabular}{ll}
\hline Issue & Method \\
\hline Dealing with missing data & $\begin{array}{l}\text { In the original protocol for this review, the following sensitivity analyses were planned to deal with } \\
\text { the problem of missing data. }\end{array}$ \\
a) For dichotomous outcomes, such as 'offended' or 'attempted suicide', the authors will assume \\
that those who were lost to follow up (i) had proportionately the same outcomes as those who \\
completed in the control group; (ii) experienced the successful outcome; (iii) all experienced the \\
unsuccessful outcome. \\
b) Where there is evidence of a significant differential drop-out rate between the experimental and \\
control groups, data will be excluded from the analyses to assess their influence on the overall re- \\
sult.
\end{tabular}




\section{Table 2. Additional methods for future updates (Continued)}

Assessment of reporting bias Any disagreements about eligibility will be resolved through discussion and, if necessary, with the involvement of the third author. Where appropriate, further information will be sought from the study authors.

Subgroup analyses and investigation of heterogeneity
If substantial heterogeneity is identified within a meta-analysis, two possible sources will be investigated separately: i) studies that include non-offending parents in the treatment programme and those that do not, and (ii) studies that focus on abuse-specific behaviour and those that do not.
Primary analyses will be based on available data from all included studies relevant to the comparison and outcome of interest. In order to assess the robustness of conclusions to quality of data and approaches to analysis, sensitivity analyses will be performed, as follows:

(a) Intention-to-treat.

For dichotomous outcomes, such as 'offended' or 'attempted suicide', we will assume that those who were lost to follow up (i) had proportionately the same outcomes as those who completed in the control group; (ii) experienced the successful outcome; (iii) all experienced the unsuccessful outcome

(b) Differential dropout.

Studies with severe imbalance in terms of numbers of attrition will be excluded from the analyses to assess their influence on overall results. 


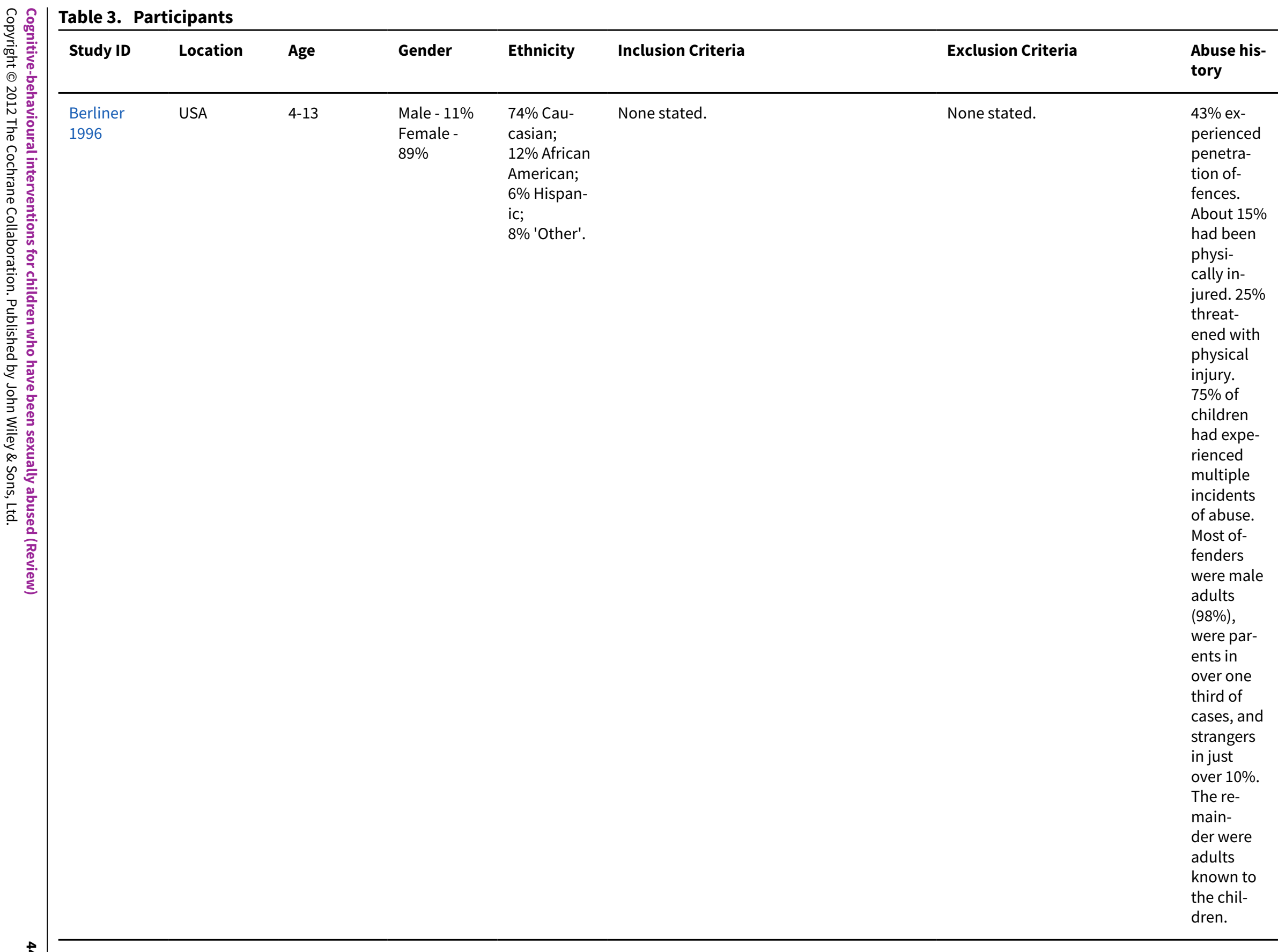




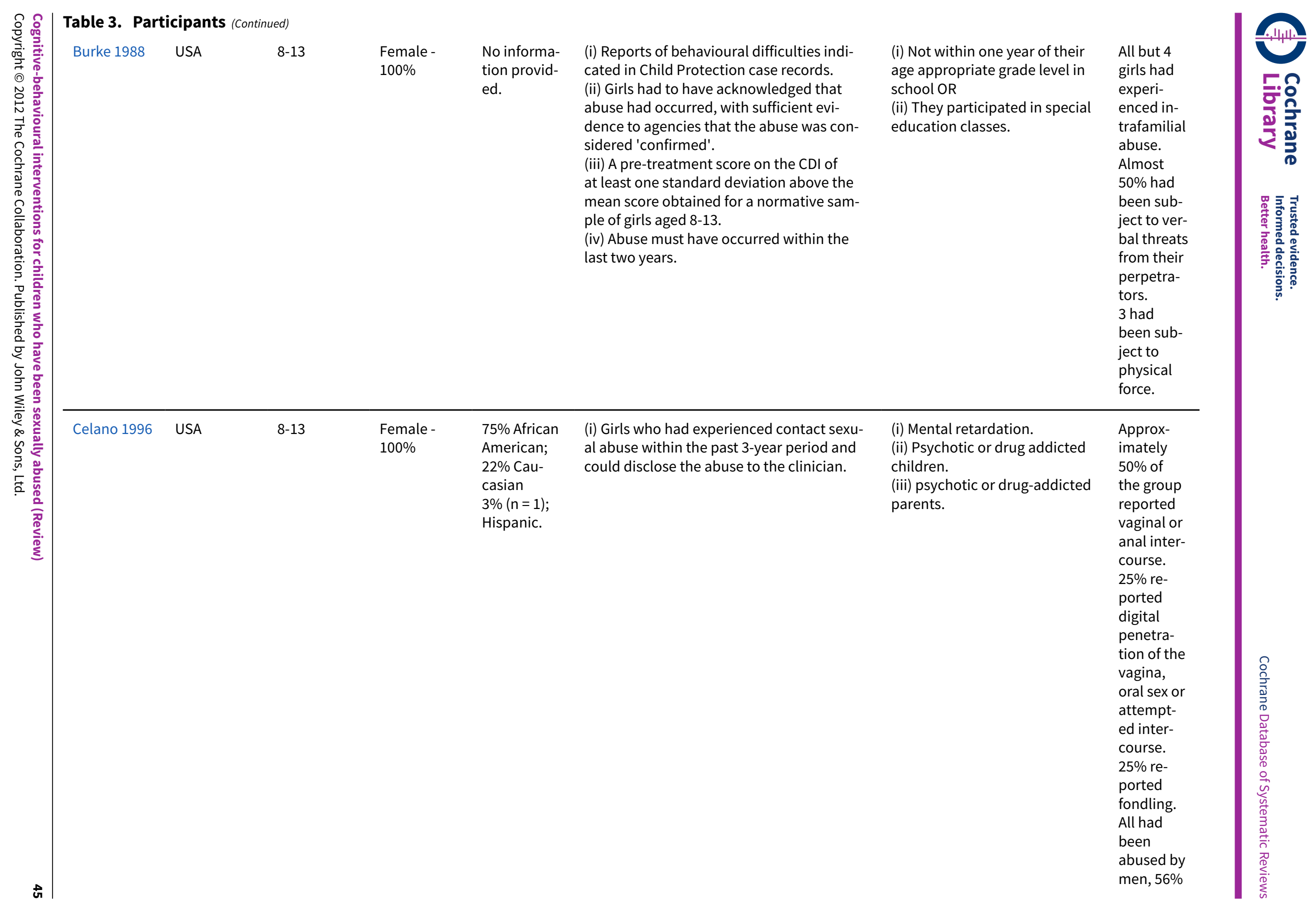




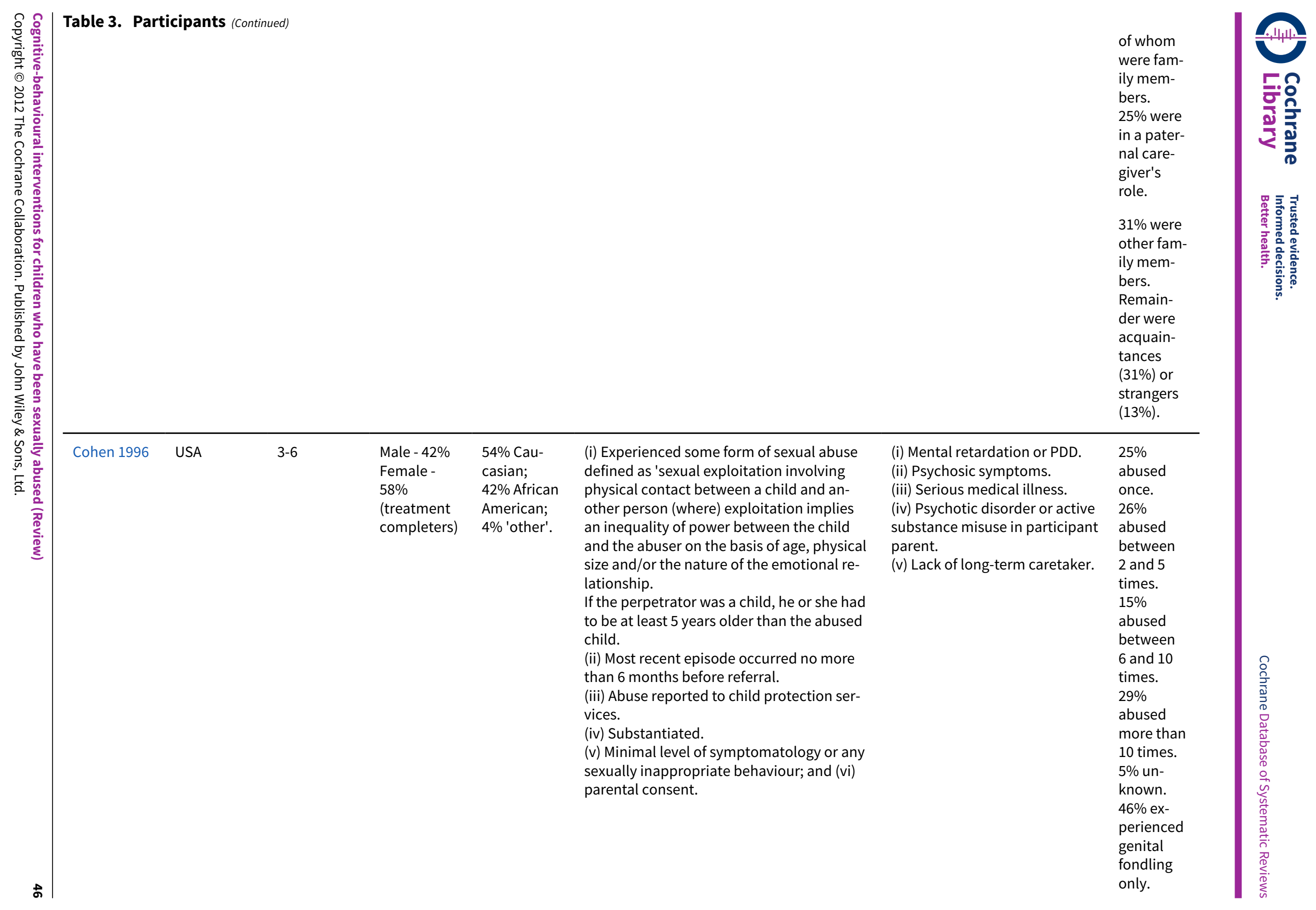




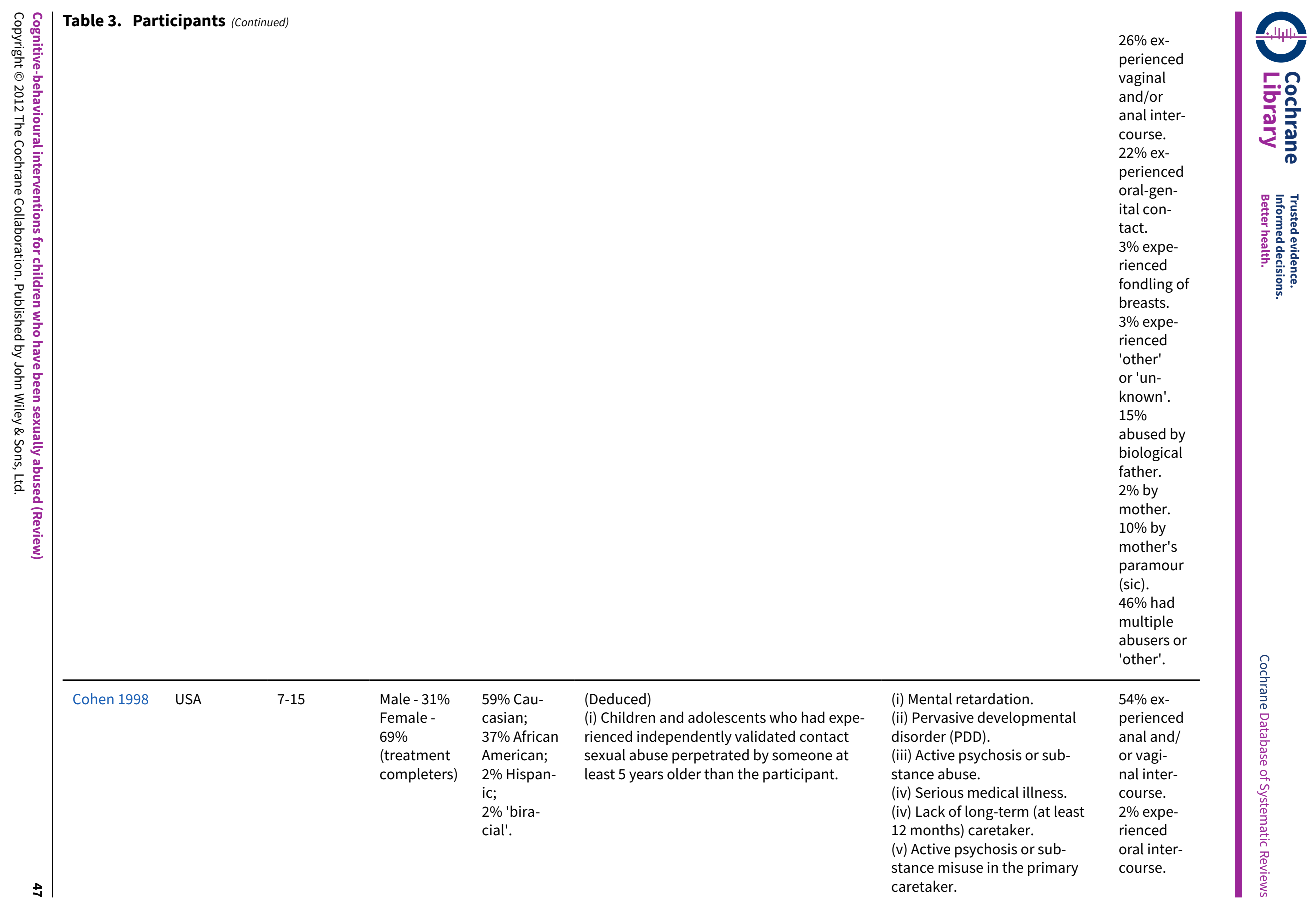




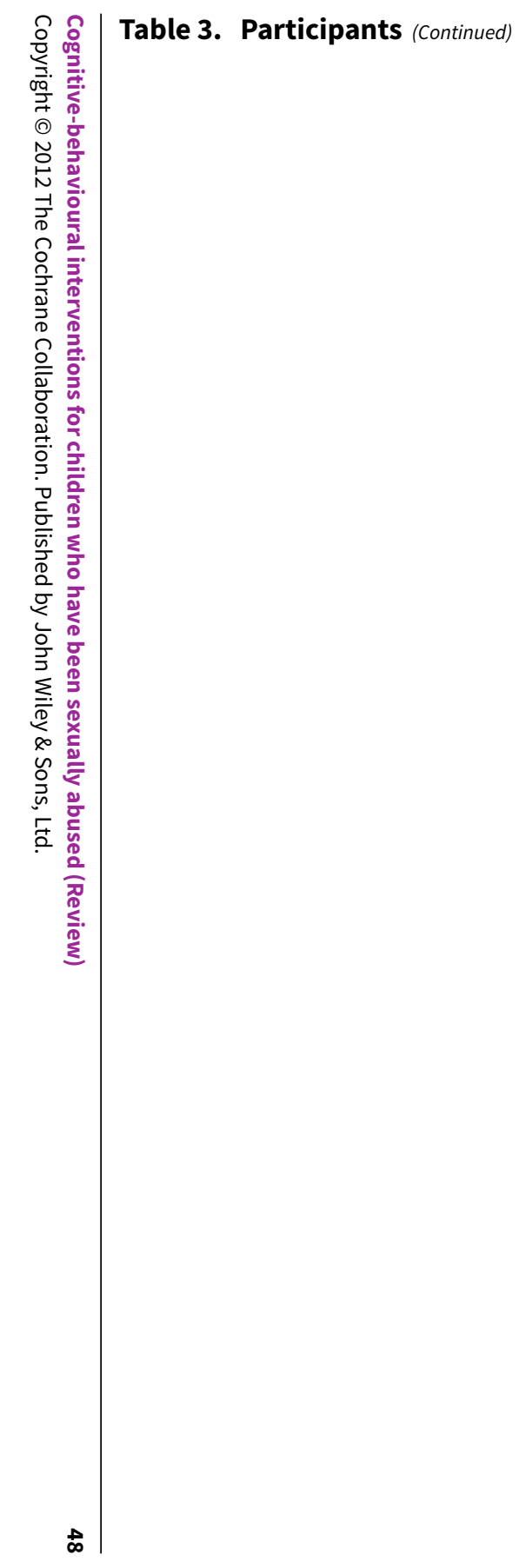

$44 \%$ ex-

perienced

genital

fondling

only.

$36 \%$ re-

ported

having ex-

perienced

a single

episode of

abuse.

$21 \%$ were

abused on

2-5 occa-

sions.

$8 \%$ were

abused

-10 times

and $33 \%$

report-

ed abuse

more tha

1- times.

$2 \%$ did not

report the

number

of abuse

episodes.

In 15\% of

cases the

abuse was

accompa-

nied by

the use

of threat-

ened or

actual

force.

$15 \%$ were

beaten

$28 \%$ were

threat-

ened with

beating,

$26 \%$ were 


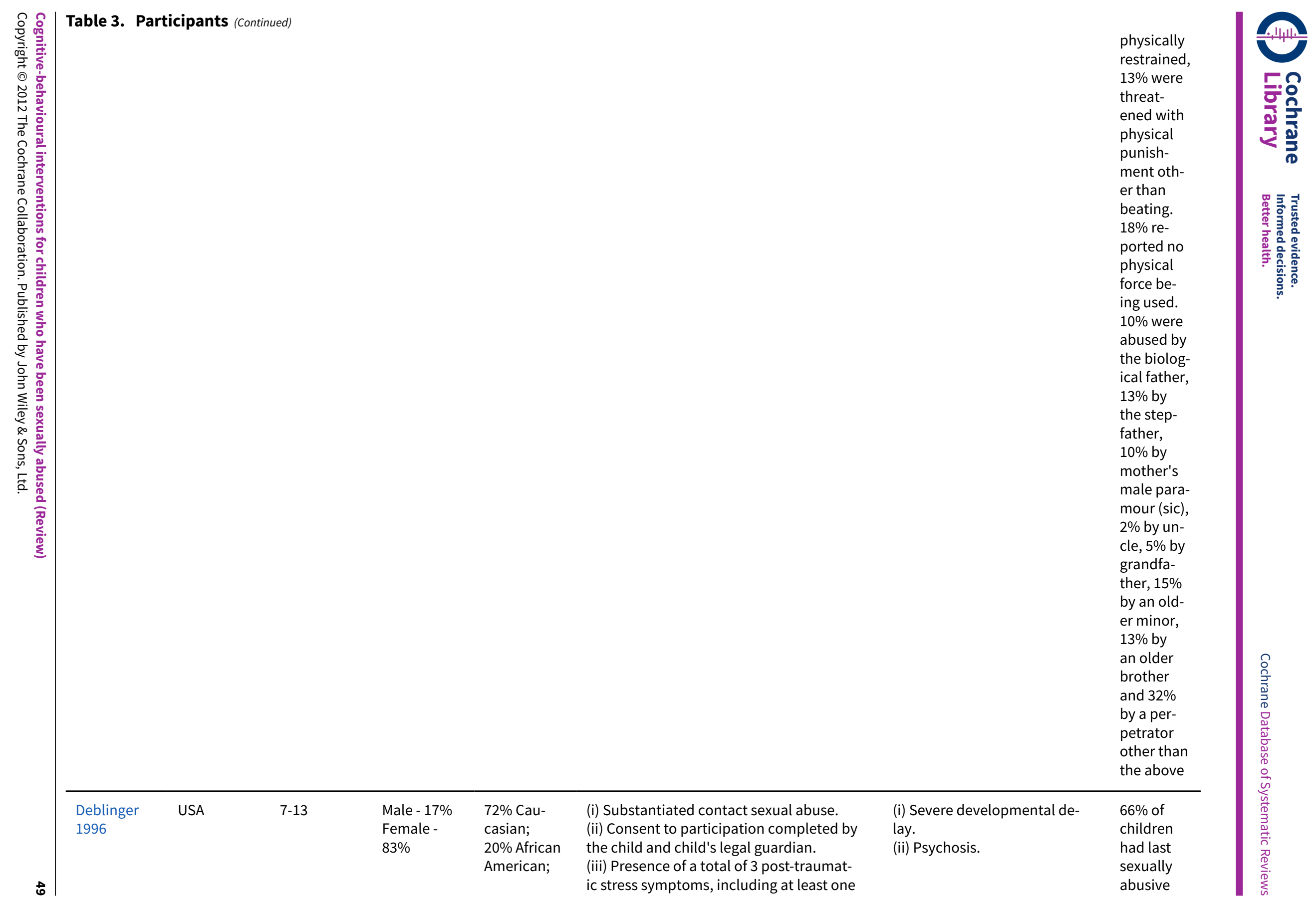


$6 \%$ Hispan- symptom of avoidance or re-experiencing ic; phenomenon. (iii) Ongoing, unsupervised contact with the alleged perpetrator.

(iv) Female caretaker not willing to participate.

(v) Dangerousness to them-

selves (suicidal) or others (for

example, dangerous aggressive

behaviour).

Children in this last group were

referred for crisis intervention

or hospitalisation at any time

during the investigation. They

were excluded only if they were

referred for such treatment

during the initial investigation. incident

in the 6

months

prior to

initial

evalua-

tion.

$16 \%$ had

suffered

sexual

abuse 6

months to

2 years be-

fore, and

$18 \%$ had

experi-

enced the

last abu-

sive inci-

dent over

2 years

previous-

ly.

Duration

of abuse

ranged

from 1 day

to more

than 5

years of

repeated

abuse.

$18 \%$ expe-

rienced 1

sexually

abusive in-

cident.

47\% ex-

perienced

between 2

and 10.

$22 \%$ ex-

perienced

between

11 and 50 . 


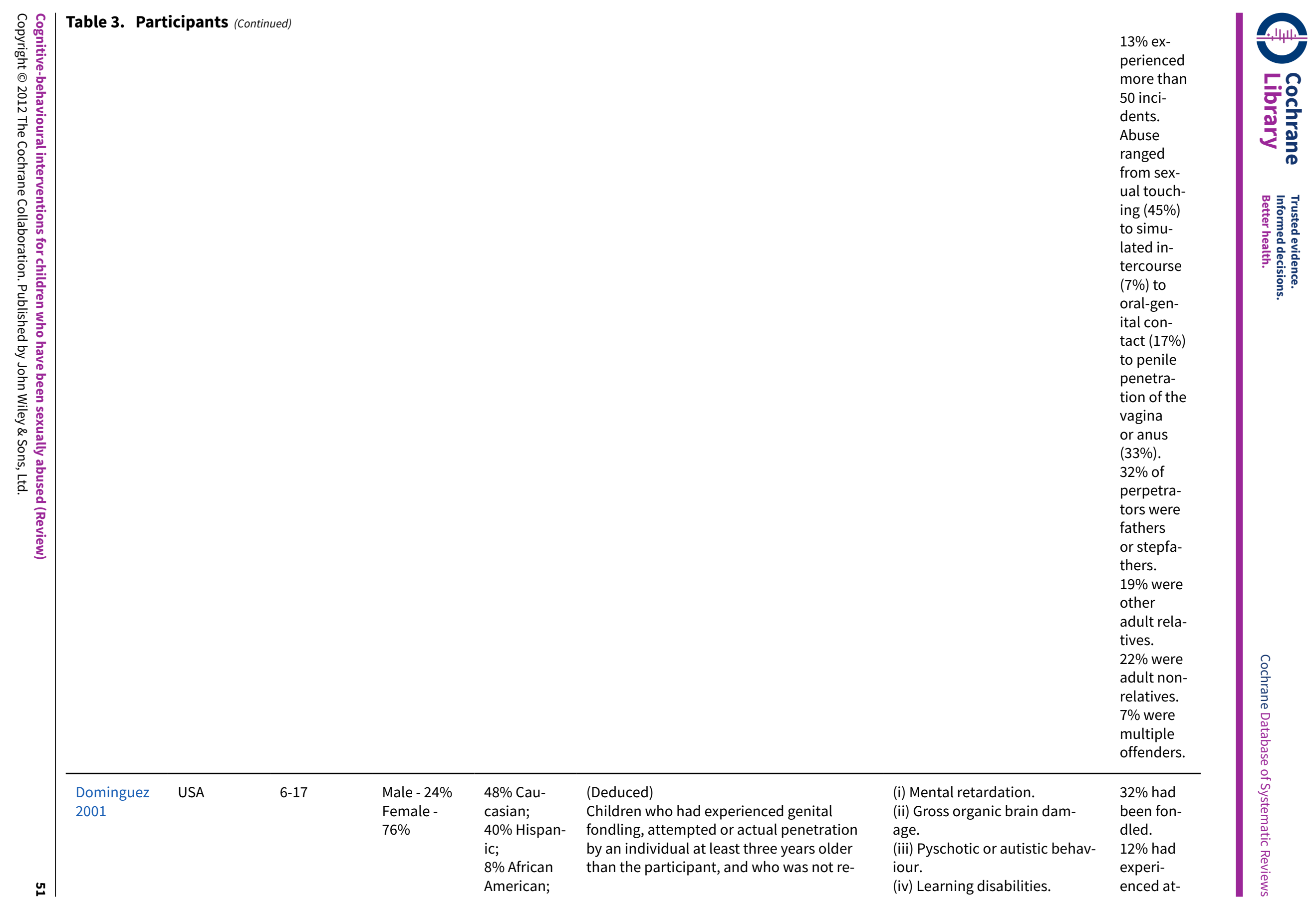


$4 \%$ 'other'. siding in the home at the time of the pretreatment assessment. (v) Perpetrators of violence.

(vi) Substance abusers.

(vii) Gang members.

(viii) Conduct disordered chil-

dren. tempted

penetra-

tion.

$56 \%$ ex-

perienced

penetra-

tion.

$52 \%$ were

abused by

an older

child.

$16 \%$ were

abused by

an adult

stranger.

$8 \%$ were

abused by

an adult

acquain-

tance and

$8 \%$ by a

non-care-

giving

adult well-

known to

the child.

$16 \%$ were

abused by

someone

previously

in a care-

giving role

$58 \%$ did

not expe-

rience life

threat or

injury.

$42 \%$ ex-

perienced

life threat

or injury.

4\% expe-

rienced

both life

threat and 


\begin{tabular}{|c|c|c|c|c|}
\hline King 2000 & Australia & $5-17$ & $\begin{array}{l}\text { Male - } 31 \% \\
\text { Female - }\end{array}$ & $\begin{array}{l}\text { Not report- } \\
\text { ed. }\end{array}$ \\
\hline
\end{tabular}

$69 \%$

(i) English speaking child and parent.

(ii) History of contact sexual abuse where

perpetrator was at least 5 years older than

abused child.

(iii) Independently validated abuse.

(iv) Child's symptoms met diagnostic crite-

ria for PTSD or provided evidence of high

risk of developing the disorder. Children

had to exhibit at least 3 PTSD stress symp-

toms including at least one of avoidance, or

re-experiencing phenomena. (i) Ongoing, unsupervised con-

act with alleged perpetrator.

(ii) Severe intellectual disabili-

ty, psychosis or suicidal behav-

iour.

(iii) Taking anti-depressants or

anti-anxiety medication.

(iv) Child or parents not willing

to participate.

Nearly al

children

had expe-

rienced

multiple

episodes

of sexu-

al abuse,

involv-

ing pen-

etration

offences

and other

forms.

In a major-

ity of cas-

es the of-

fenders

were adult

males

known to

the child:

biological

father ( $\mathrm{n}$

=4), step-

father $(\mathrm{n}=$

3), family

friend $(\mathrm{n}=$

5), neigh-

bour (n

=5), pro-

fession-

al $(n=3)$, 


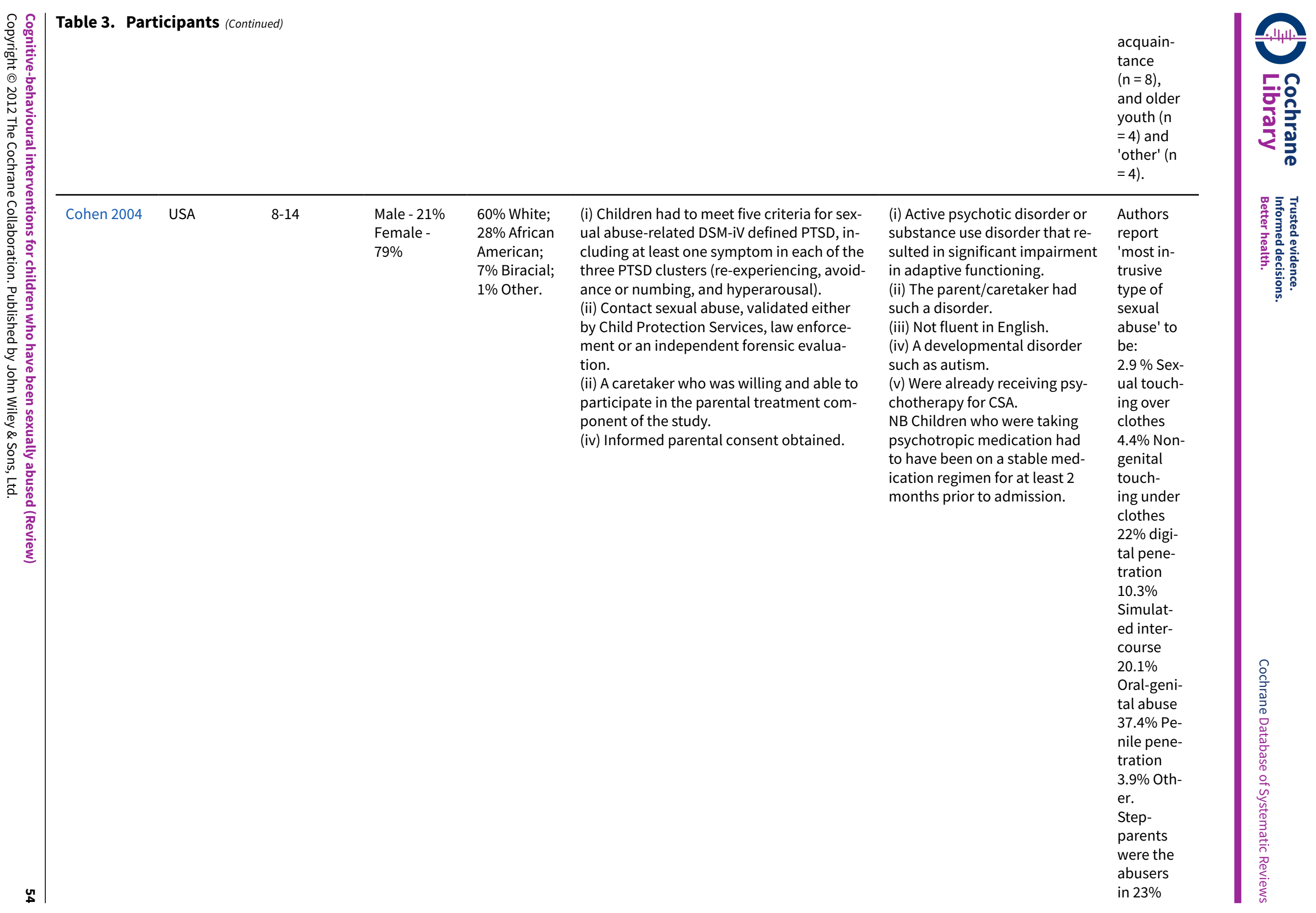




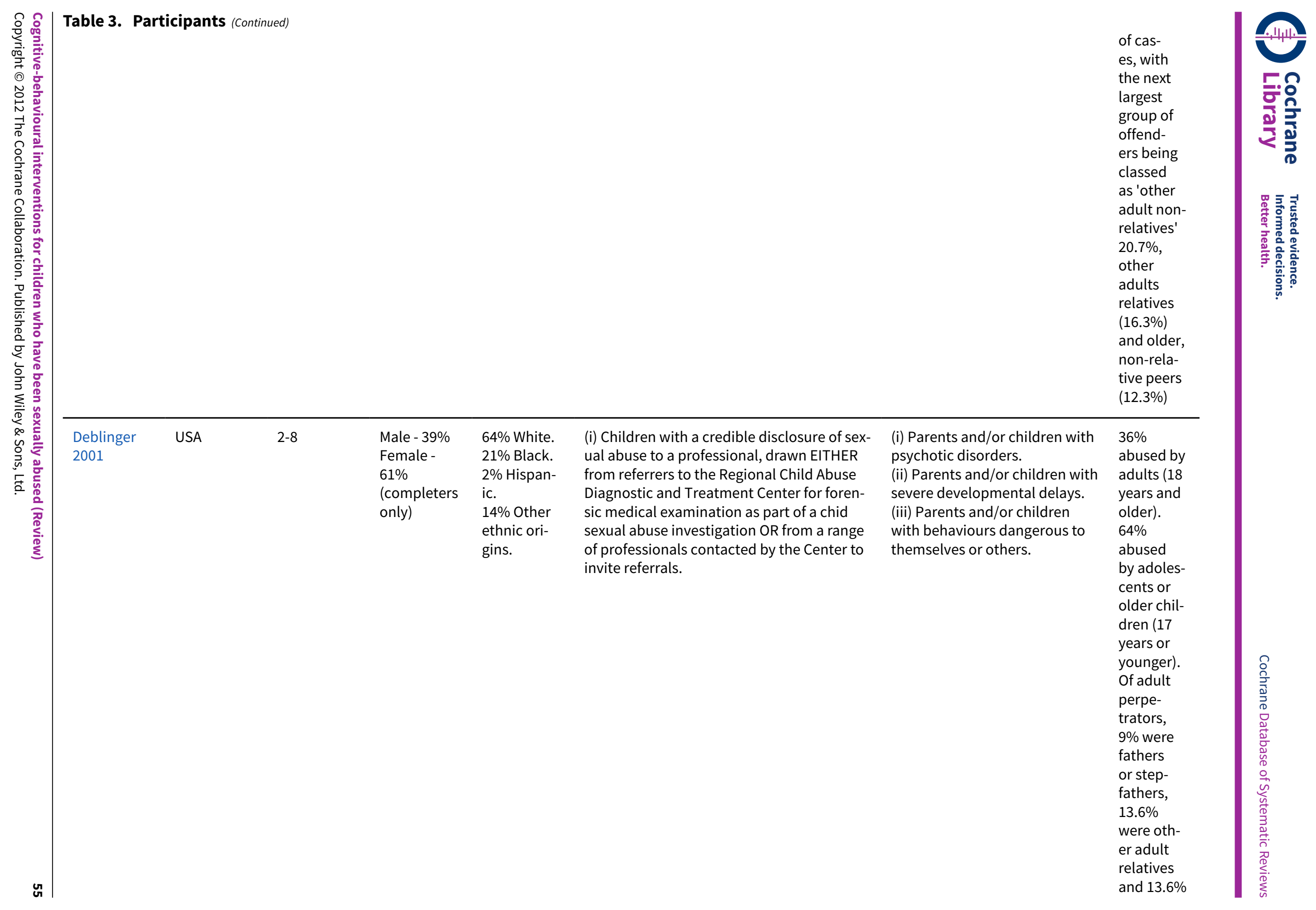




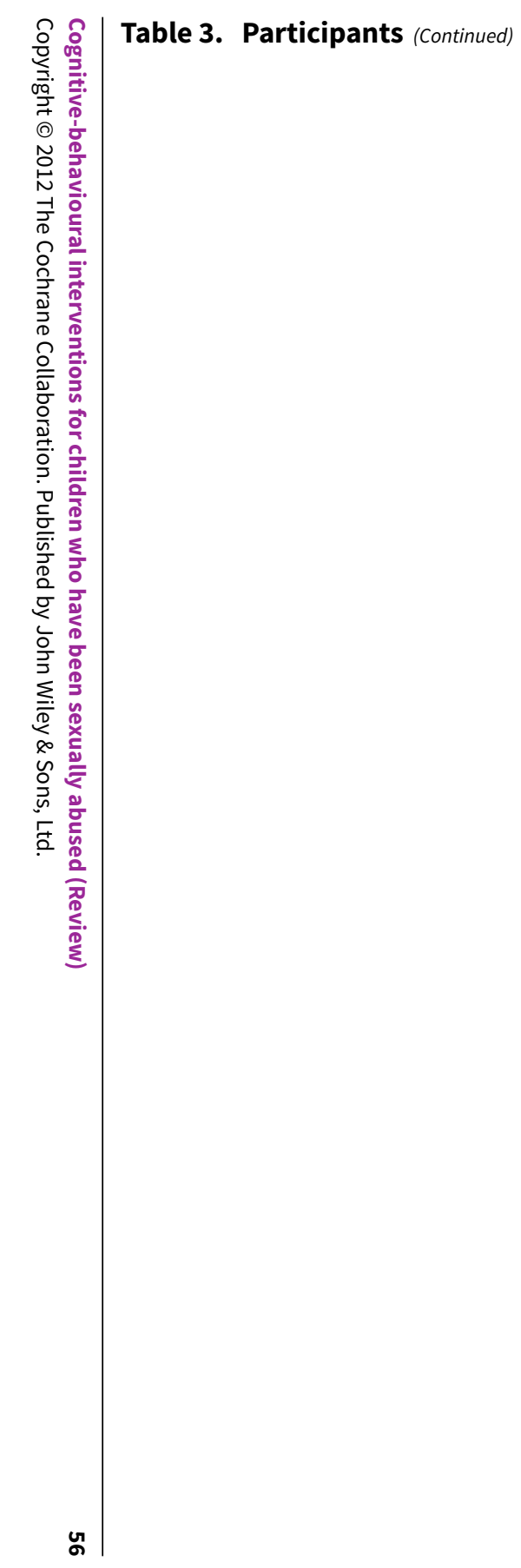

were non-

related.

Of old-

er peer

perpetra-

tors, $4.5 \%$

were sib-

lings, 25\%

were relat-

ed older

peers and

$34 \%$ were

not relat-

ed.

Penile

penetra-

tion had

occurred

with $16 \%$

of the chil-

dren.

Mother's

estimate

of how

old the

children

had been

when sex-

ual abuse

first oc-

curred in-

dicated

a mean

age of 4.50

$(\mathrm{SD}=1.47)$

years.

Mothers

believed

the abuse

had oc-

curred

once for

15 (34\%)

children

and more

than once 


\section{AP PEN DICES}

\section{Appendix 1. Search strategies for original review}

CENTRAL, published on the Cochrane Library, was searched to Issue 3, 2005, using the following terms.

\#1 MeSH descriptor CHILD ABUSE explode trees 1, 2 and 3

\#2(CHILD* in All Text near/6 ABUSE* in All Text)

\#3 (SEX* in All Text near/6 ABUSE* in All Text)

\#4 MeSH descriptor INCEST explode tree 1

\#5 INCEST ${ }^{\star}$ in All Text

\#6 (SEX* in All Text near/6 OFFENC* in All Text)

\#7 (SEX* in All Text near/6 CHILD* in All Text)

\#8 (SEX* in All Text near/6 OFFENS* in All Text)

\#9 ( (\#1 or \#2 or \#3 or \#4 or \#5 or \#6 or \#70r \#8)

\#10 MeSH descriptor CHILD explode tree 1

\#11 CHILD* in All Text

\#12 INFANT* in All Text

\#13 TEENAGE* in All Text

\#14 ADOLESCEN ${ }^{\star}$ in All Text

\#15 PRESCHOOL ${ }^{\star}$ in All Text

\#16 PRE-SCHOOL ${ }^{*}$ in All Text

\#17 BABY in All Text

\#18 BABIES in All Text

$\# 19$ ( ( ( ( ( ( ( $\# 10$ or \#11) or \#12) or \#13) or \#14) or \#15) or \#16) or \#17) or \#18)

$\# 20$ (\#19 and \#9)

\#21 MeSH descriptor PSYCHOTHERAPY explode tree 1

\#22 PSYCHOTHERAP* in All Text

\#23 THERAP* in All Text

\#24 ( (\#21 or \#22 or \#23)

\#25 (\#20 and \#24)

\section{MEDLINE searched via OVID 1966 to November 2005}

1 child abuse/ or child abuse, sexual/

2 (child\$ adj5 abuse\$).tw.

3 (sex\$ adj5 abuse\$).tw.

4 Incest/

5 incest $\$$.tw.

6 (sex\$ adj5 offenc\$).tw.)

7 (sex\$ adj5 child\$).tw.

8 (sex\$ adj5 offens\$).tw.

9 or $1-8$

10 adolescent/ or child/ or child, preschool/ or infant/

11 (child\$ or infant\$ or teenage $\$$ or adolescen $\$$ or preschool\$ or pre-school\$ or baby or babies).tw.

12 or/10-11)

13 Cognitive Therapy/

14 psychotherap\$.tw.

15 therap\$.tw.

16 or $/ 13-15$

179 and 12 and 16

\section{CINAHL searched via OVID 1982 to November 2005}

1 (child\$ adj5 abuse\$).tw.

2 (sex\$ adj5 abuse\$).tw.

3 incest\$.tw.

4 (sex\$ adj5 offenc\$).tw.

5 (sex\$ adj5 child\$).tw.

6 (sex\$ adj5 offens\$).tw.

7 INCEST/

8 child abuse/ or child abuse, sexual/ 
9 or $/ 1-8$

10 adolescence/ or exp child/

11 (child\$ or infant\$ or teenage\$ or adolescen\$ or preschool\$ or pre-school\$ or baby or babies).tw.

12 or/10-11

13 COGNITIVE THERAPY/

14 psychotherap\$.tw.

15 therap\$.tw.

16 or/13-15

179 and 12 and 16

\section{EMBASE searched via OVID 1980 to November 2005}

1 (child\$ adj5 abuse\$).tw.

2 (sex\$ adj5 abuse\$).tw.

3 incest\$.tw.

4 (sex\$ adj5 offenc\$).tw.

5 (sex\$ adj5 child\$).tw.

6 (sex\$ adj5 offens\$).tw.

7 incest/

8 Child Abuse/

9 or $/ 1-8$

10 Child/

11 adolescent/ or infant/

12 (child\$ or infant\$ teenage\$ or adolescen\$ or preschool\$ or pre-school\$ or baby or babies).tw.

13 or/10-12

14 psychotherapy/

15 psychotherap\$.tw.

16 therap\$.tw.

17 or/14-16

189 and 13 and 17

\section{PsycINFO searched via SilverPlatter 1887 to Week 4 November 2005}

$\# 1$ ("Child-Abuse" in MJ,MN)

\#2 (( child $^{\star}$ near abuse $\left.{ }^{\star}\right)$ or ( sex* near abuse* $)$ )

\#3 ("Incest-" in MJ,MN)

\#4 (( incest $\left.^{\star}\right)$ or $\left(\right.$ sex $^{\star}$ near offenc $\left.{ }^{*}\right)$ or $\left(\right.$ sex $^{\star}$ near child $\left.\left.{ }^{\star}\right)\right)$

\#5 (sex* near offens*)

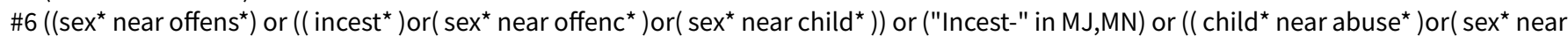
abuse $\left.\left.^{\star}\right)\right)$ or ("Child-Abuse" in MJ,MN))

\#7 (( child $\left.^{\star}\right)$ or ( infant* $)$ or( teenage $\left.\left.{ }^{\star}\right)\right)$

\#8 (( adolescen $\left.^{\star}\right)$ or $($ preschool* $)$ or $\left(\right.$ pre-school $\left.\left.^{\star}\right)\right)$

\#9 (( baby )or( babies ))

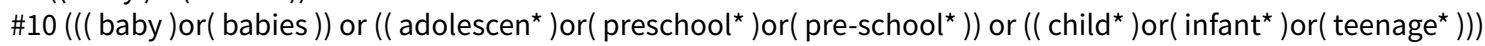

$\# 11$ ("Cognitive-Behavior-Therapy" in MJ,MN)

\#12 psychotherap*

$\# 13$ therap*

\#14 ((therap*) or (psychotherap*) or ("Cognitive-Behavior-Therapy" in MJ,MN))

\#15 ((therap*) or (psychotherap*) or ("Cognitive-Behavior-Therapy" in MJ,MN)) and ((( baby )or( babies )) or

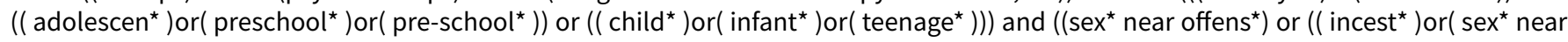
offenc $\left.^{\star}\right)$ or $\left(\right.$ sex $^{\star}$ near child $\left.\left.{ }^{\star}\right)\right)$ or ("Incest-" in MJ,MN) or (( child* near abuse $\left.{ }^{\star}\right)$ or ( sex* near abuse $\left.\left.{ }^{\star}\right)\right)$ or ("Child-Abuse" in MJ,MN))

\section{SIGLE searched via SilverPlatter 1980 to November 2005}

$\# 1$ ( child $^{\star}$ near abuse $\left.{ }^{\star}\right)$ or ( sex near abuse $\left.^{\star}\right)$ or ( incest ${ }^{\star}$ )

$\# 2$ ( sex $^{\star}$ near offenc $\left.{ }^{\star}\right) \operatorname{or}\left(\operatorname{sex}^{\star}\right.$ near child $\left.{ }^{\star}\right) \operatorname{or}\left(\operatorname{sex}^{\star}\right.$ near offens $\left.{ }^{\star}\right)$

\#3 (( sex $^{\star}$ near offenc $\left.{ }^{\star}\right) \operatorname{or}\left(\right.$ sex $^{\star}$ near child* $)$ or $\left(\right.$ sex $^{\star}$ near offens $\left.\left.{ }^{\star}\right)\right)$ or $\left(\left(\right.\right.$ child $^{\star}$ near abuse $\left.{ }^{\star}\right)$ or $\left(\right.$ sex $^{\star}$ near abuse $\left.{ }^{\star}\right)$ or ( incest $\left.\left.{ }^{\star}\right)\right)$

\#4 ( child $\left.^{\star}\right)$ or ( infant $\left.{ }^{\star}\right)$ or ( teenage $\left.{ }^{\star}\right)$

\#5 ( adolescen $\left.^{\star}\right)$ or $\left(\right.$ preschool $\left.^{*}\right)$ or $\left(\right.$ pre-school $\left.^{*}\right)$

\#6 ( baby )or( babies)

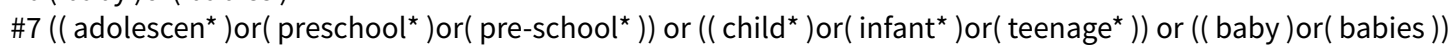

\#8 ( psychotherap $\left.^{\star}\right)$ or ( therap* ${ }^{\star}$ ) 


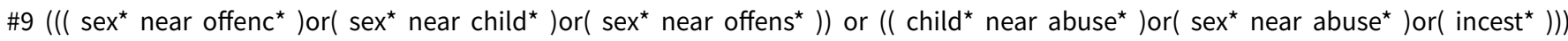

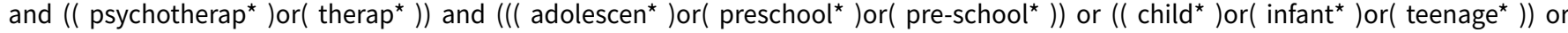
(( baby) $)$ r( babies $))$

\section{LILACS searched via BVS 1982 to November 2005}

((child\$ abuse\$) OR (sex\$ abuse\$) OR (incest\$) or (sex\$ offen\$) OR (sex\$ child\$)) [Words] and ((therap\$) OR (psychotherap\$) OR (cognitiv\$))

\section{Appendix 2. Search strategies for updated review}

\section{Cochrane Central Register of Controlled Trials (CENTRAL) part of The Cochrane Library}

\section{Search strategy for CENTRAL 2009(1), CENTRAL 2009(4), CENTRAL 2010(4) and CENTRAL 2011(4)}

\#1 MeSH descriptor Child Abuse explode all trees

\#2 (child* near/5 abuse*)

\#3 sex $^{\star}$ near/5 abuse*

\#4 MeSH descriptor Incest explode all trees

\#5 sex $^{*}$ near $/ 5$ offenc ${ }^{*}$

\#6 sex* near/5 child*

\#7 sex $^{*}$ near/5 offens ${ }^{*}$

\#8 (\#1 OR \#2 OR \#3 OR \#4 OR \#5 OR \#6 OR \#7)

\#9 (child ${ }^{\star}$ or infant $^{\star}$ or teenage $^{\star}$ or adolescen ${ }^{\star}$ or preschool ${ }^{\star}$ or pre-school* or baby or babies)

\#10 MeSH descriptor Adolescent explode all trees

\#11 (\#9 OR \#10)

\#12 MeSH descriptor Cognitive Therapy explode all trees

\#13 psychotherap*

\#14 therap*

\#15 (\#12 OR \#13 OR \#14)

\#16 (\#8 AND \#11 AND \#15)

\section{MEDLINE Search}

\section{MEDLINE strategy 20 December 2010 (no RCT filter)}

Ovid MEDLINE(R) 1950 to November Week 32010

1 child abuse/ or child abuse, sexual/

2 (child\$ adj5 abuse\$).tw.

3 (sex\$ adj5 abuse\$).tw.

4 Incest/

5 incest\$.tw.

6 (sex\$ adj5 offenc\$).tw.

7 (sex\$ adj5 child\$).tw.

8 (sex\$ adj5 offens\$).tw. 
9 or $/ 1-8$

10 (child\$ or infant\$ or teenage\$ or adolescen\$ or preschool\$ or pre-school\$ or baby or babies).tw.

11 adolescent/ or child/ or child, preschool/ or infant/

12 or/10-11

13 Cognitive Therapy/

14 psychotherap\$.tw.

15 therap\$.tw.

16 or/13-15

179 and 12 and 16

18 limit 17 to ed $=20091201-20101217$

MEDLINE strategy run on 11 February 2009 (limited by publication year $=2005$ to 2009), 8 December 2009 (limited by publication year =2009), 2 December 2011 (limited by date added since 17 December 2010)

1 (child\$ adj5 abuse\$).tw.

2 (sex\$ adj5 abuse\$).tw.

3 incest\$.tw.

4 (sex\$ adj5 offenc\$).tw.

5 (sex\$ adj5 child\$).tw.

6 (sex\$ adj5 offens\$).tw.

7 incest/

8 Child Abuse/ or Child Abuse, Sexual/

9 or $1-8$

10 Child/

11 adolescent/ or infant/

12 (child\$ or infant\$ teenage or adolescen\$ or preschool\$ or pre-school\$ or baby or babies).tw.

13 or/10-12

14 Cognitive Therapy/

15 psychotherap\$.tw.

16 therap\$.tw.

1716 or 15 or 14

$18 \quad 13$ and 9 and 17

19 randomized controlled trial.pt.

20 controlled clinical trial.pt.

21 randomized.ab.

22 placebo.ab.

23 drug therapy.fs. 
24 randomly.ab.

25 trial.ab.

26 groups.ab.

2719 or 20 or 21 or 22 or 23 or 24 or 25 or 26

28 humans.sh.

$29 \quad 27$ and 28

$30 \quad 18$ and 29

\section{EMBASE searches}

EMBASE strategy run on 20th December 2010, 1980 to 2010 Week 50 (no RCT filter)

1 (child\$ adj5 abuse\$).tw.

2 (sex\$ adj5 abuse\$).tw.

3 incest\$়.tw.

4 (sex\$ adj5 offenc\$).tw.

5 (sex\$ adj5 child\$).tw.

6 (sex\$ adj5 offens\$).tw.

7 incest/

8 Child Abuse/

9 or $/ 1-8$

10 Child/

11 adolescent/ or infant/

12 (child\$ or infant\$ teenage\$ or adolescen $\$$ or preschool\$ or pre-school\$ or baby or babies).tw.

13 or/ $10-12$

14 psychotherapy/

15 psychotherap\$.tw.

16 therap\$.tw.

17 or/14-16

189 and 13 and 17

19 limit 18 to em=200947-201049

EMBASE strategy run on 11 February 2009 (limited by publication year = 2005 to 2009), 8 December 2009 (limited by publication year =2009), 2 December 2011 (limited to records added since week 50 2010)

1 (child\$ adj5 abuse\$).tw.

2 (sex\$ adj5 abuse\$).tw.

3 incest\$.tw.

4 (sex\$ adj5 offenc\$).tw.

5 (sex\$ adj5 child\$).tw. 
6 (sex\$ adj5 offens\$).tw.

7 incest/

8 Child Abuse/ or Child Abuse, Sexual/

9 or/1-8

10 Child/

11 adolescent/ or infant/

12 (child\$ or infant\$ teenage or adolescen\$ or preschool\$ or pre-school\$ or baby or babies).tw.

13 or $/ 10-12$

14 Cognitive Therapy/

15 psychotherap\$.tw.

16 therap\$.tw.

1716 or 15 or 14

$18 \quad 13$ and 9 and 17

19 random\$.tw.

20 factorial\$.tw.

21 crossover\$.tw.

22 cross over\$.tw.

23 cross-over\$.tw.

24 placebo\$.tw.

25 (doubl\$ adj blind\$).tw.

26 (singl\$ adj blind\$).tw.

27 assign\$.tw.

28 allocat\$.tw.

29 volunteer\$.tw.

30 Crossover Procedure/

31 double-blind procedure.tw.

32 Randomized Controlled Trial/

33 Single Blind Procedure/

34 or/19-33

3534 and 13 and 9

\title{
CINAHL searches
}

CINAHL Plus strategy run on 20 December 2010 (no RCT filter) (search limited to records added between 1 December 2009 and 20 December 2010)

\author{
S17 S15 and S16 \\ S16 EM 20091201-20101220
}


S15 S6 and S10 and S14

S14 S11 or S12 or S13

S13 therap*

S12 psychotherap*

S11 (MH "Cognitive Therapy")

S10 S7 or S8 or S9

S9 (child* or infant $^{\star}$ or teenage ${ }^{\star}$ or adolescen ${ }^{\star}$ or preschool ${ }^{\star}$ or pre-school ${ }^{*}$ or baby or babies)

S8 (MH "Adolescence") 5

S7 (MH "Child+") 4

$\mathrm{S} 6 \mathrm{~S} 1$ or $\mathrm{S} 2$ or $\mathrm{S} 3$ or $\mathrm{S} 4$ or $\mathrm{S} 5$

S5 incest*

S4 (sex ${ }^{\star}$ N5 offenc $\left.{ }^{\star}\right)$ or (sex ${ }^{\star}$ N5 offens $\left.{ }^{\star}\right)$ or ( $\operatorname{sex}^{\star}$ N5 child $\left.{ }^{\star}\right)$

S3 (child* N5 abuse* ${ }^{\star}$ or (sex* n5 abuse ${ }^{\star}$ )

S2 $\mathrm{MH}$ incest

S1 (MH "Child Abuse") OR (MH "Child Abuse, Sexual")

CINAHL strategy run on 11 February 2009 (limited by publication year = 2005 to 2009), 8 December 2009 (limited by publication year = 2009) and 2 December 2011 (limited to records added since 20 December 2010)

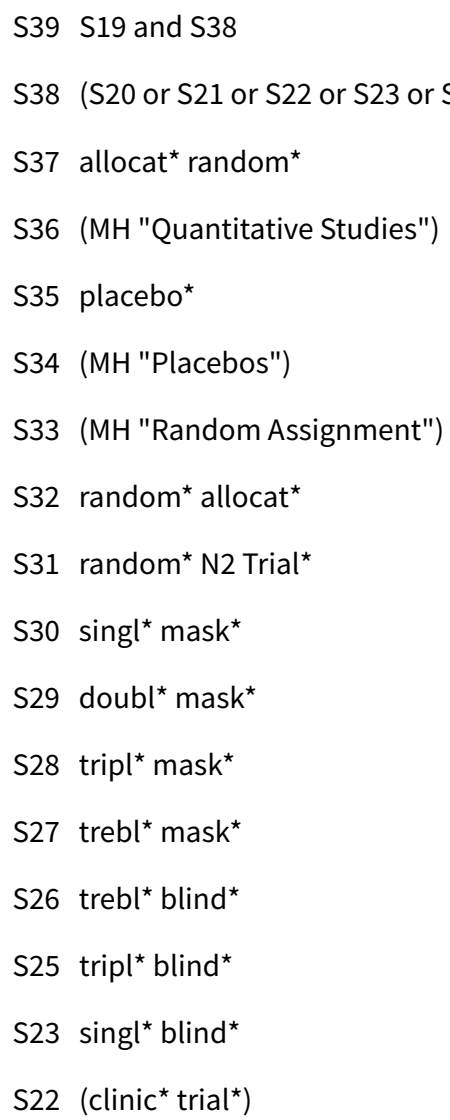


S21 PT clinical trial

S20 (MH "Clinical Trials+")

S19 S9 and S13 and S17

S18 S9 and S13 and S17

S17 S14 or S15 or S16

S16 therap*

S15 psychotherap*

S14 (MH "Cognitive Therapy")

S13 S10 or S11 or S12

S12 (child ${ }^{\star}$ or infant ${ }^{\star}$ or teenage or adolescen $^{\star}$ or preschool ${ }^{\star}$ or pre-school ${ }^{\star}$ or baby or babies)

S11 (MH "Adolescence")

S10 (MH "Child+")

$\mathrm{S} 9 \mathrm{~S} 1$ or $\mathrm{S} 2$ or $\mathrm{S} 3$ or $\mathrm{S} 4$ or $\mathrm{S} 5$ or $\mathrm{S} 6$ or $\mathrm{S} 7$ or $\mathrm{S} 8$

S8 sex $^{*}$ N5 offens*

S7 sex* N5 child*

S6 sex* N5 offenc* $^{*}$

S5 incest*

S4 sex* N5 abuse*

S3 child* N5 abuse*

S2 (MH "Incest")

S1 (MH "Child Abuse+")

\section{PsycINFO searches}

PsycINFO strategy run on 20 December 2010 (no RCT filter) (search limited to records added between 1 December 2009 and 20 December 2010)

S12 S10 and S11

S11 ED 20091201-20101220

S10 S5 and S6 and S9

S9 $\quad \mathrm{S} 7$ or $\mathrm{S} 8$

S8 therap* or psychotherap*

S7 DE "Cognitive Behavior Therapy" OR DE "Cognitive Therapy"

S6 child $^{\star}$ or infant ${ }^{\star}$ or teenage or adolescen $^{\star}$ or preschool ${ }^{\star}$ or pre-school* or baby or babies

S5 S1 or S2 or S3 or S4

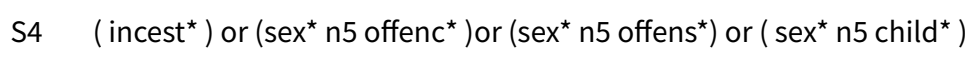

S3 DE "Sex Offenses"

S2 ( child $^{\star}$ n5 abuse ${ }^{\star}$ ) or (sex ${ }^{\star}$ 5 abuse $\left.{ }^{\star}\right)$ 
S1 (DE "Child Abuse") OR (DE "Sexual Abuse" OR DE "Incest" OR DE "Rape")

PsycINFO strategy run on 11 February 2009 (limited by publication year = 2005 to 2009), 8 December 2009 (limited by publication year =2009) and 2 Decemberr 2011 (limited to records added since 20 December 2010)

1 (child\$ adj5 abuse\$).tw.

2 (sex\$ adj5 abuse\$).tw.

3 incest\$.tw.

4 (sex\$ adj5 offenc\$).tw.

5 (sex\$ adj5 child\$).tw.

6 (sex\$ adj5 offens\$).tw.

7 incest/

8 Child Abuse/ or Child Abuse, Sexual/

9 or $1-8$

10 (child\$ or infant\$ teenage\$ or adolescen\$ or preschool\$ or pre-school\$ or baby or babies).tw.

11 Cognitive Therapy/

12 psychotherap\$.tw.

13 therap\$.tw.

1413 or 12 or 11

15 Treatment Effectiveness Evaluation/

16 exp Treatment Outcomes/

17 Psychotherapeutic Outcomes/

18 PLACEBO/

19 exp Followup Studies/

20 placebo\$.tw.

21 random\$.tw.

22 comparative stud\$.tw.

23 randomi\#ed controlled trial\$.tw.

24 (clinical adj3 trial\$).tw.

25 (research adj3 design).tw.

26 (evaluat\$ adj3 stud\$).tw.

27 (prospectiv\$ adj3 stud\$).tw.

28 ((singl\$ or doubl\$ or trebl\$ or tripl\$) adj3 (blind\$ or mask\$)).tw.

29 control\$.tw.

3029 or 21 or 19 or 27 or 26 or 22 or 15 or 20 or 16 or 28 or 24 or 18 or 17 or 25 or 23

3130 and 10 and 9 and 14

\section{OpenSIGLE search strategy}


(("child abuse" or incest or "sex abuse" or "sexually abused") AND (therap* or psychotherap* or cognitiv*))

\section{OpenGrey search strategy}

child abuse and therap*

child abuse and cognit*

sex* abuse and therapy*

sex $^{\star}$ abuse and cognit*

child abuse and psychotherap*

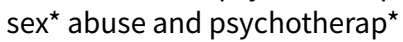

\section{LILACS search strategy run on 2 December 2011, 20 December 2010, 8 December 2009 and 11 February 2009}

child abuse or sex abuse or sexual abuse or incest or sexual offence $\$$ or sexual offense\$ [Palavras] and therap\$ or psychotherap\$ cognitiv $\$[$ Palavras] and trial\$ or blind\$ or placebo $\$$ or random\$

\section{ClinicalTrials.gov search strategy run for all years on 2 December 2011}

[CONDITION =sex abuse] AND [Intervention = cognitive behavioral therapy] AND [ Age Group= Child ]

\section{ICTRP search strategy}

[CONDITION = sex abuse] AND [ Intervention = CBT OR cognitive OR behavioural OR behavioral $]$

AND [Search for clinical trials in children selected]

\section{WHAT'S NEW}

\begin{tabular}{lll}
\hline Date & Event & Description \\
\hline 7 February 2012 & $\begin{array}{l}\text { New citation required but conclusions } \\
\text { have not changed }\end{array}$ & $\begin{array}{l}\text { No new trial included but one study added to 'awaiting assess- } \\
\text { ment'. New data added and new 'Risk of bias' tables added. No } \\
\text { change to substantive conclusions. }\end{array}$ \\
\hline 13 December 2011 & New search has been performed & Literature search updated. New authors added. \\
\hline
\end{tabular}

\section{H I S T O RY}

Protocol first published: Issue 1, 2000

Review first published: Issue 4, 2006

\begin{tabular}{lll}
\hline Date & Event & Description \\
\hline 16 June 2008 & Amended & Converted to new review format. \\
\hline 16 August 2006 & $\begin{array}{l}\text { New citation required and conclusions } \\
\text { have changed }\end{array}$ & Substantive amendment \\
\hline 20 February 2006 & Amended & Searches added; author details updated \\
\hline
\end{tabular}

\section{CONTRIBUTIONSOF AUTHORS}

Geraldine Macdonald, Paul Ramchandani and Julian Higgins each contributed to all aspects of the review. For the original review, GM and PR selected studies for inclusion in the review and extracted data from the included studies. JH, GM and PR entered data in Review Manager. GM and JH took primary responsibility for assessing the risk of bias in the studies, for describing them and analysing the data. GM and PR took responsibility for drafting the discussion and identifying issues for research and practice. 
For the update, Jeff Valentine contributed to all aspects of the review. Latricia Bronger, Paul Klein, Roland O'Daniel, Mark Pickering, Ben Rademaker, George Richardson, Matthew Taylor and Jennifer Wolf selected studies for inclusion in the review and extracted data from the new follow-up. GM, JV, JH and PR all contributed to the drafting of this version of the review.

\section{DECLARATIONS OF INTEREST}

Geraldine Macdonald - none known

Julian PT Higgins - received a payment from the Nordic Campbell Centre for his work on the first version of this review in 2006.

Paul Ramchandani - none known

Jeffrey C Valentine - none known

Bronger Latricia - none known

Paul Klein - none known

Roland O'Daniel - none known

Mark Pickering - none known

Ben Rademaker - none known

George Richardson - none known

Matthew Taylor - none known

\section{SOURCES OF SUPPORT}

\section{Internal sources}

- No sources of support supplied

\section{External sources}

- Northern Ireland Research \& Developmen, UK.

- Nordic Campbell Center, Denmark.

\section{DIFFERENCES BETWEEN PROTOCOL AND REVIEW}

Inclusion criteria for participants: the original protocol said the abuse should have occurred in the 12 months before referral. The review authors subsequently removed this restriction as lacking a sufficiently clear rationale.

'Parents' emotional reactions' added as an outcome due to its connection to the other parental outcomes already specified.

\section{NOTES}

This review is co-registered within the Campbell Collaboration.

\section{INDEX TERMS}

\section{Medical Subject Headings (MeSH)}

Child Abuse, Sexual [psychology] [ ${ }^{\star}$ therapy]; Cognitive Behavioral Therapy [ ${ }^{\star}$ methods]; Randomized Controlled Trials as Topic

\section{MeSH check words}

Adolescent; Child; Child, Preschool; Female; Humans; Infant; Male 